\title{
Monitoring of Childhood Asthma
}

Sandra Voorend-van Bergen 
The BATMAN study was financially supported by Lung Foundation Netherlands, the Netherlands Organisation for Health Research and Development (ZonMW), and Fund Nuts Ohra.

Publication of this thesis was financially supported by Stichting Astma Bestrijding, Boehringer Ingelheim, Chiesi pharmaceuticals BV, Chipsoft BV, Glaxosmithkline, Novartis pharma BV, Abbvie BV, and Teva pharma.

Cover: "Happy Lungs" by Xandra Zijlmans (Atelier La Lupa Hellevoetsluis), based on the hands of my son Ruben

Lay-out by: Nikki Vermeulen, Ridderprint BV, Ridderkerk, the Netherlands

Printed by: $\quad$ Ridderprint BV, Ridderkerk, the Netherlands

ISBN: $\quad 978-90-5335-953-2$ 


\title{
Monitoring of Childhood Asthma
}

\author{
Monitoren van kinderen met astma
}

\author{
Proefschrift \\ ter verkrijging van de graad van doctor aan de \\ Erasmus Universiteit Rotterdam \\ op gezag van de \\ rector magnificus
}

Prof.dr. H.A.P. Pols

en volgens besluit van het College voor Promoties.

De openbare verdediging zal plaatsvinden op woensdag 26 november 2014 om 13:30 uur

door

Teunie Antonia Suzanna Voorend- van Bergen

geboren te Oostflakkee

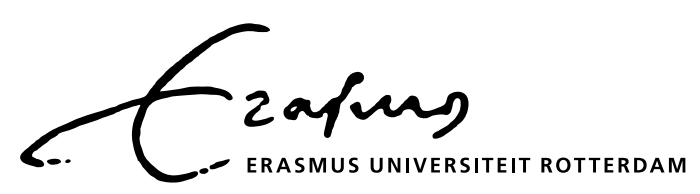




\section{Promotiecommissie}

Promotor: $\quad$ Prof.dr. J.C. de Jongste

Overige leden: Prof.dr. J.H. Raat

Prof.dr. G.H. Koppelman

Prof.dr. M.P.M.H. Rutten

Copromotor: Dr. M.W.H. Pijnenburg 


\section{Contents}

Chapter 1 General introduction and aims of the thesis

Chapter 2 Asthma control questionnaires in the management of asthma in children: a review.

Chapter 3 Assessment of asthma control by children and parents.

Chapter 4 Monitoring childhood asthma: web-based diaries and the asthma control test.

Chapter 5 Novel monitoring strategies in children with asthma: a randomised controlled trial.

Chapter 6 Cost-effectiveness of FeNO- and web-based monitoring in pediatric asthma management: a randomized controlled trial.

Chapter 7 FeNO monitoring in concordant and discordant asthma phenotypes in children.

Chapter 8 General discussion and conclusions

Chapter 9 Summary

Nederlandse samenvatting

Chapter 10 List of abbreviations

List of publications

PhD portfolio

About the author

Dankwoord 



\section{Chapter}

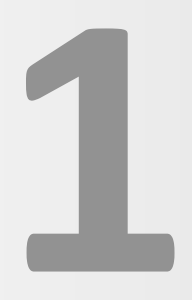

General introduction and aims of the thesis 



\section{Introduction}

Asthma is a chronic inflammatory disease of the airways, which is characterized by episodes of wheezing, shortness of breath, chest tightness, and coughing, with reversible airway obstruction and airway hyperresponsiveness. Worldwide asthma affects $5-10 \%$ of all schoolchildren and in most countries the prevalence is still increasing ${ }^{1}$. Antiinflammatory drugs, with inhaled corticosteroids (ICS) as first choice, are the mainstay of asthma treatment and guidelines recommend a step up-step down scheme when adjusting asthma treatment ${ }^{2,3}$. The goals of asthma treatment are to reduce symptoms, to allow for a normal and active life, and to reduce future risks to the patient. In this respect 'asthma control' has become a central concept in asthma management.

\section{Asthma control}

All asthma guidelines place a strong emphasis on monitoring asthma control. The Global Initiative For Asthma (GINA) proposes to define levels of asthma control based on clinical manifestations, Forced Expiratory Volume in $1 \mathrm{sec}$ (FEV1) and expected future risk and classifies patients as well-controlled, partly controlled or uncontrolled ${ }^{2}$ (Table 1). GINA states that monitoring is essential to maintain control and establish the lowest step in treatment that produces good asthma control. Similarly, the British Thoracic Society (BTS) guidelines aim at asthma control based on clinical manifestations and FEV1 ${ }^{3}$. The BTS recommends the assessment of asthma control by means of questionnaires in combination with spirometry, check of inhaler technique, and assessment of adherence to treatment in the monitoring of asthma. The American National Asthma Education and Prevention Program (NAEPP) defines control as the degree to which the manifestations of asthma are minimized by therapeutic interventions and the goals of therapy are met ${ }^{4}$.

Table 1 GINA assessment of asthma control in adults, adolescents and children 6-11 years

\begin{tabular}{|c|c|c|c|c|}
\hline \multicolumn{5}{|l|}{ Asthma symptom control } \\
\hline In the past 4 weeks, has the patient had: & & $\begin{array}{l}\text { Well } \\
\text { controlled }\end{array}$ & $\begin{array}{l}\text { Partly } \\
\text { controlled }\end{array}$ & Uncontrolled \\
\hline Daytime asthma symptoms more than twice/week? & Yes/No & \multirow{4}{*}{$\begin{array}{l}\text { None of } \\
\text { these }\end{array}$} & \multirow{4}{*}{$1-2$ of these } & \multirow{4}{*}{$3-4$ of these } \\
\hline Any night waking due to asthma? & Yes/No & & & \\
\hline $\begin{array}{l}\text { Reliever needed for symptoms more than twice/ } \\
\text { week? }\end{array}$ & Yes/No & & & \\
\hline Any activity limitation due to asthma? & Yes/No & & & \\
\hline
\end{tabular}

From the Global Strategy for Asthma Management and Prevention 2014, @ Global Initiative for Asthma (GINA) all rights reserved. Available from http://www.ginasthma.org. 
To achieve and maintain control, all guidelines, including Dutch guidelines, propose a step up-step down scheme to adjust therapy (Figure 1).

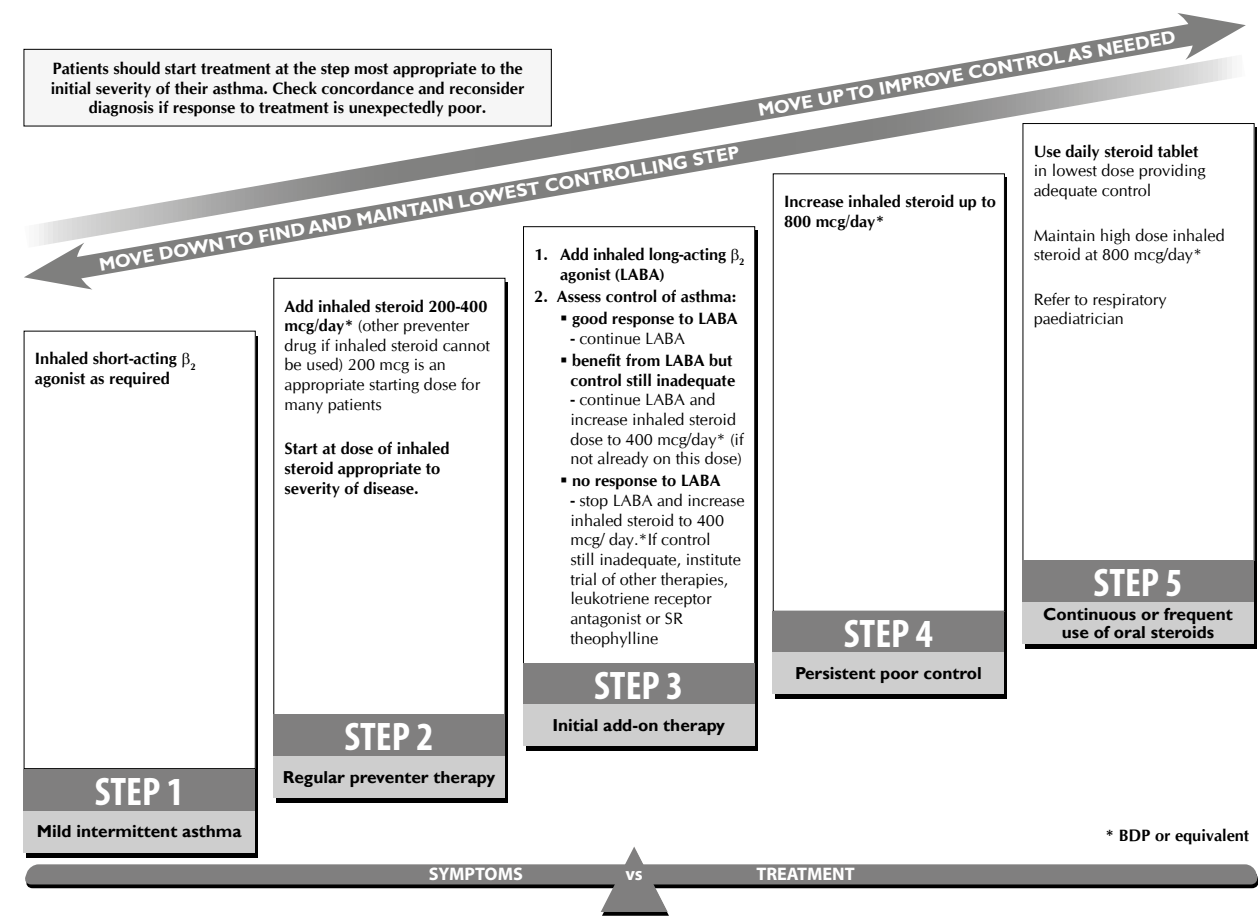

Figure 1 Management of asthma in children 5-12 yrs

From the BTS/SIGN Guideline on the management of asthma, (c) British Thoracic Society (BTS) all rights reserved. Available from http://www.brit-thoracic.org.uk.

Future risks for the patients are impaired lung function development or accelerated lung function decline, exacerbations, hospital admissions, and fatal or near-fatal asthma attacks.

\section{Monitoring asthma}

Despite the strong emphasis on optimal control and the wide availability of safe and effective asthma medication, good asthma control is not achieved in a substantial proportion of asthmatic children (up to $90 \%)^{2,4-7}$. Several studies report high frequencies of sleep disturbances, school absenteeism and limitations of physical activity due to asthma ${ }^{6,7}$. Also, asthma is the third ranking course of hospitalization in children and the first chronic disease that causes school absenteeism among children in the US'. In Europe unscheduled health care visits accounted for $45 \%$ of total asthma costs in children; $7 \%$ of 
all children reported at least 1 hospitalization ${ }^{9}$. Therefore, monitoring of asthma control is essential in order to know if asthma control is achieved. There are several tools available to measure and monitor asthma control; subjective parameters like daily and nocturnal symptoms, and more objective measures such as spirometry, bronchoprovocation tests and markers of inflammation.

\section{Clinical tools}

Symptoms and rescue medication use are easy to quantify, and can be assessed at all ages. Symptoms form a distinct domain in the clinical expression of asthma, independent from exacerbations, lung function, and inflammation. Most physicians agree that assessment of a patient's symptoms history should include daytime asthma symptoms, nocturnal awakenings as a result of asthma symptoms, frequency of use of short acting beta-2-agonists (SABA) for relief of symptoms and inability or difficulty performing normal activities, including exercise, because of asthma symptoms ${ }^{2-4}$. However, it should be noted that the use of SABA reflects the subjective perception of asthma complains by asthmatic children or observation by their parents. Several self-administered questionnaires have been developed to assess asthma control in a standardized way. Contrary to the concept of GINA, these questionnaires use numeric scores, which supposed to be easy for patients and caregivers to understand, to record and to interpret. Examples of such questionnaires are the Asthma Control Test $(\mathrm{ACT})^{10}$, and the Childhood Asthma Control Test (C-ACT $)^{11}$. Although simple and easy to use, the added value of these questionnaires over usual care with casual history taking remains to be shown.

\section{Telemonitoring of symptoms}

Mobile phones or web-based applications offer new possibilities for monitoring of asthma and guided self-management. The widespread use of user-friendly electronic devices like tablets and smart phones will increasingly facilitate the use of web-based monitoring in asthma research and clinical practice. Children, and adolescents in particular, are an attractive population for web-based monitoring as they are very active on the Internet with $75 \%$ of all European children of 6-17 years using the Internet, and even $86 \%$ of the 15 17 year olds, while in some countries like the Netherlands even $100 \%$ of all children of 15 17 years use the Internet ${ }^{12}$. Studies with Internet-based home monitoring and education have shown to improve adherence and asthma control ${ }^{13-16}$. Also a recent review showed that text reminder systems increase patient medication adherence, but did not improve clinical outcomes ${ }^{17}$. Internet-based programs may increase the awareness of patients and their parents, and this may lead to improved adherence to treatment. However, a recent meta-analysis on 21 randomized controlled trials on telemonitoring interventions 
in both children and adults with asthma concluded that telemonitoring was comparable to standardized care regarding the effect on quality of life, emergency room visits and hospitalizations for asthma ${ }^{18}$. Frequent monitoring of asthma control by using the ACT or C-ACT via an Internet based program has the potential to standardize the assessment of asthma control, increase awareness of asthma and improve adherence, which may contribute to better asthma control.

\section{Lung function}

Children's lung function increases with growth, and maximal lung function is achieved for most individuals by 20 years of age. Children who have asthma may have a reduced lung growth compared to children who do not have asthma ${ }^{19,20}$. As reduced lung function is associated with poor short and long-term asthma outcome ${ }^{21}$, lung function is an important measure of asthma control and future risk and can be used as a monitoring tool in children from the age of 5 to 6 . Regular monitoring of lung function is particularly important for asthma patients who do not perceive their symptoms until airflow obstruction is severe. Unfortunately there is no valid method to detect poor perceivers. The post-bronchodilator FEV1 can be used to follow lung growth patterns over time ${ }^{22}$. Observations of reduced lung function may reflect a progressive worsening of asthma control that should be treated accordingly. FEV1 has been shown as a predictor of future exacerbations ${ }^{21}$, but as a diagnostic tool, FEV1 is too insensitive, because children with asthma might have normal FEV1 values ${ }^{23}$. The use of regular measurements of FEV1 as a monitoring tool in childhood asthma has not been shown to be of additional value ${ }^{24}$.

\section{Peak Expiratory Flow measurements}

Peak Expiratory Flow (PEF) measurements provide a means to obtain simple, quantitative and reproducible assessment of the presence and severity of airways obstruction. PEF can easily be measured at home and may detect changes in disease control or responses to changes in therapy. However, the measurements of PEF strongly depend on the effort and technique of the patients. Also, it is known that the accuracy of peak flow monitoring devices may decrease over time ${ }^{25}$. There is also a large variation in PEF values between healthy children. Studies in children have shown that routine serial measurements of peak expiratory flow did not provide additional benefit when added to a symptom-based management strategy ${ }^{26,27}$.

\section{Airway hyperresponsiveness}

Airway hyperresponsiveness is one of the hallmarks of asthma. The response to a direct or indirect stimulus is usually measured by repeated FEV1 measurements, and expressed as 
the dose $\left(\mathrm{PD}_{20}\right)$ or concentration $\left(\mathrm{PC}_{20}\right)$ of the stimulus required to decrease $\mathrm{FEV} 1$ by $20 \%$. However, the measurement is time-consuming and not routinely applicable in children under the age of six. Measurements of airway hyperreponsiveness (AHR) were not useful in asthma monitoring, with the exception of children with low symptom perception in whom benefit from monitoring AHR has been shown in terms of improved FEV1 ${ }^{28}$.

\section{Inflammatory markers}

As asthma is a chronic inflammatory disease with anti-inflammatory drugs as the treatment of choice, much attention has been drawn to markers of inflammation in the monitoring of asthma. Fractional exhaled Nitric Oxide (FeNO) has been extensively studied as a non-invasive biomarker of eosinophilic airway inflammation ${ }^{29}$. FeNO can be measured in breath and is increased when eosinophilic airway inflammation is present. $\mathrm{FeNO}$ is elevated in untreated atopic patients and increases in FeNO are thought to reflect the intensity of eosinophilic inflammation of the bronchial mucosa ${ }^{30-33}$. Measurements of FeNO distinguish patients with allergic asthma, although with considerable overlap. FeNO is repeatable, associated with other markers of severity and predicts the response to ICS ${ }^{34-37}$. The correlation with other measurements of asthma control like spirometry or questionnaires is poor, which might be explained by the fact that inflammation reflects a different domain of asthma ${ }^{38-42}$.

FeNO is a suitable biomarker for the diagnosis and follow-up of asthma, and as a guide to therapy, and is increasingly used in the management of pediatric asthma ${ }^{43}$. Several randomized controlled trials addressed the question if adjustment of ICS therapy on repeated FeNO measurements could improve asthma outcomes ${ }^{34,44-48}$. However, results are conflicting. A study by Pijnenburg et al. showed that one year of ICS titrated with repeated FeNO measurements did not affect the primary outcome, cumulative corticosteroid dose, in children with asthma, but improved $\mathrm{AHR}^{34}$. Two other pediatric studies showed no benefit of FeNO dose titration (and higher ICS doses) and a minimal improvement in lung function without change in asthma contro|45, 47. De Jongste et al assessed daily FeNO telemonitoring in the management of childhood asthma and found no added value of daily FeNO monitoring compared to daily symptom monitoring ${ }^{44}$. A Cochrane metaanalysis concluded that the benefits of FeNO monitoring were not yet clear, partly due to a large variation in study design ${ }^{49}$. A more recent randomized controlled trial showed that FeNO monitoring led to less exacerbations at the cost of higher ICS doses ${ }^{46}$. On the other hand, Pike et al. recently showed that FeNO-guided ICS titration did not appear to reduce corticosteroid usage or exacerbation frequency in pediatric outpatients with moderate to severe asthma ${ }^{48}$.

Eosinophils in sputum are also considered as a biomarker of eosinophilic airway inflammation. Sputum eosinophils predict the response to ICS, predict exacerbations and 
successful steroid reduction in adults and children ${ }^{50-53}$. Only a single study has assessed the usefulness of 3-monthly measurement of sputum eosinophils in children with severe asthma and concluded that this strategy did not reduce exacerbations or improve asthma control $^{54}$. Limitations of the use of sputum analysis in clinical practice are the problematic feasibility for repeated sputum induction procedures, the risk of bronchoconstriction and the high technical demands and costs.

\section{Aims of the studies in this thesis}

This thesis focuses on monitoring of childhood asthma, including the definition of asthma control, the assessment of asthma control, and achieving asthma control.

The BATMAN study (Better Asthma Treatment; Monitoring with ACT and Nitric Oxide), on which this thesis is based, evaluated the possible benefits of two asthma monitoring strategies. We investigated if an Internet-based monitoring program with monthly ACT or C-ACT measurements improves asthma control and if asthma management guided by FeNO with a new algorithm improves asthma control. The BATMAN study was a multicenter, prospective, partly blinded, parallel-group, randomized controlled trial in the Netherlands, with a follow up of one year. Two-hundred-eighty children with atopic asthma participated in 5 general hospitals and 2 tertiary referral centers.

The major aims of this thesis are:

1. To review available asthma control questionnaires for their usefulness in pediatric asthma management

2. To study the validity of the Asthma Control Test (ACT) and Childhood Asthma Control Test (C-ACT) in a Dutch population and define the cut off levels for well controlled asthma and minimal clinically relevant differences

3. To investigate if web-based monthly monitoring using the ACT or C-ACT improves asthma control

4. To investigate if asthma management guided by Fractional exhaled Nitric Oxide (FeNO) improves asthma control

5. To investigate if these monitoring strategies are cost-effective

\section{Outline of this thesis}

Chapter 2 provides an overview of commonly used asthma control questionnaires and explores their usefulness in asthma management in children.

Chapter 3 compares the assessment of asthma control by children and parents using the 
Childhood Asthma Control Test. Subscores of children and their parents were compared. In chapter 4, we investigated the validity of a web-based diary in assessing asthma control in children, and we calculated the cut-off levels for 'well-controlled' asthma and the minimal important differences of the Asthma Control Test and the Childhood Asthma Control Test.

In chapter 5, we present the main results of the BATMAN study. This study compares two novel monitoring strategies with standard care: monthly web-based assessment of asthma control by means of the ACT, and 4-monthly measurements of FeNO.

In chapter 6, the cost-effectiveness of web-based monitoring and FeNO monitoring is described.

In chapter 7, the effect of web-based monitoring and FeNO monitoring in different pediatric asthma phenotypes is presented.

The main findings and implications described in this thesis are discussed in the general discussion in chapter 8 , followed by a summary in chapter 9 . 


\section{References}

1. Asher MI, Montefort S, Bjorksten B, et al. Worldwide time trends in the prevalence of symptoms of asthma, allergic rhinoconjunctivitis, and eczema in childhood: ISAAC Phases One and Three repeat multicountry cross-sectional surveys. Lancet 2006; 368(9537): 733-43.

2. GINA. Global Strategy for Asthma Management and Prevention: Global Initiative for Asthma (GINA), 2011.

3. BTS. BTS/SIGN Guideline on the management of asthma: British Thoracic Society, 2012.

4. National Asthma E, Prevention P. Expert Panel Report 3 (EPR-3): Guidelines for the Diagnosis and Management of Asthma-Summary Report 2007. J Allergy Clin Immunol 2007; 120(5 Suppl): S94-138.

5. Bacharier LB, Boner A, Carlsen $\mathrm{KH}$, et al. Diagnosis and treatment of asthma in childhood: a PRACTALL consensus report. Allergy 2008; 63(1): 5-34.

6. Gustafsson PM, Watson L, Davis KJ, Rabe KF. Poor asthma control in children: evidence from epidemiological surveys and implications for clinical practice. Int J Clin Pract 2006; 60(3): 321-34.

7. Rabe KF, Vermeire PA, Soriano JB, Maier WC. Clinical management of asthma in 1999: the Asthma Insights and Reality in Europe (AIRE) study. Eur Respir J 2000; 16(5): 802-7.

8. AAFA. Asthma and Allergy Foundation of America: Asthma and Allergy Foundation of America.

9. Williams AE, Lloyd AC, Watson L, Rabe KF. Cost of scheduled and unscheduled asthma management in seven European Union countries. Eur Respir Rev 2006; 15(89): 4-9.

10. Nathan RA, Sorkness CA, Kosinski M, et al. Development of the asthma control test: a survey for assessing asthma control. J Allergy Clin Immunol 2004; 113(1): 59-65.

11. Liu AH, Zeiger R, Sorkness C, et al. Development and cross-sectional validation of the Childhood Asthma Control Test. J Allergy Clin Immunol 2007; 119(4): 817-25.

12. European children's use, risk and safety online.

13. Chan DS, Callahan CW, Hatch-Pigott VB, et al. Internet-based home monitoring and education of children with asthma is comparable to ideal office-based care: results of a 1-year asthma in-home monitoring trial. Pediatrics 2007; 119(3): 569-78.

14. Jan RL, Wang JY, Huang MC, Tseng SM, Su HJ, Liu LF. An internet-based interactive telemonitoring system for improving childhood asthma outcomes in Taiwan. Telemed J E Health 2007; 13(3): 257-68.

15. van der Meer V, van Stel HF, Bakker MJ, et al. Weekly self-monitoring and treatment adjustment benefit patients with partly controlled and uncontrolled asthma: an analysis of the SMASHING study. Respir Res 2010; 11: 74.

16. van der Meer V, van Stel HF, Detmar SB, Otten W, Sterk PJ, Sont JK. Internet-based self-management offers an opportunity to achieve better asthma control in adolescents. Chest 2007; 132(1): 112-9.

17. Tran N, Coffman JM, Sumino K, Cabana MD. Patient reminder systems and asthma medication adherence: a systematic review. The Journal of asthma : official journal of the Association for the Care of Asthma 2014 51(5): 536-43.

18. McLean S, Chandler D, Nurmatov U, et al. Telehealthcare for asthma: a Cochrane review. CMAJ : Canadian Medical Association journal = journal de l'Association medicale canadienne 2011; 183(11): E733-42.

19. Al-Muhsen S, Johnson JR, Hamid Q. Remodeling in asthma. J Allergy Clin Immunol 2011; 128(3): 451-62; quiz 63-4.

20. Bisgaard $\mathrm{H}$, Jensen $\mathrm{SM}$, Bonnelykke $\mathrm{K}$. Interaction between asthma and lung function growth in early life. American journal of respiratory and critical care medicine 2012; 185(11): 1183-9.

21. Fuhlbrigge $A L$, Kitch $B T$, Paltiel $A D$, et al. $F E V(1)$ is associated with risk of asthma attacks in a pediatric population. J Allergy Clin Immunol 2001; 107(1): 61-7.

22. Covar RA, Spahn JD, Murphy JR, Szefler SJ, Childhood Asthma Management Program Research G. Progression of asthma measured by lung function in the childhood asthma management program. American journal of respiratory and critical care medicine $2004 ; 170(3): 234-41$.

23. Bacharier LB, Strunk RC, Mauger D, White D, Lemanske RF, Jr., Sorkness CA. Classifying asthma severity in children: mismatch between symptoms, medication use, and lung function. American journal of respiratory and critical care medicine $2004 ; 170(4): 426-32$. 
24. Brand PL, Roorda RJ. Usefulness of monitoring lung function in asthma. Archives of disease in childhood 2003; 88(11): 1021-5.

25. Irvin CG, Martin RJ, Chinchilli VM, Kunselman SJ, Cherniack RM. Quality control of peak flow meters for multicenter clinical trials. The Asthma Clinical Research Network (ACRN). American journal of respiratory and critical care medicine 1997; 156(2 Pt 1): 396-402.

26. Burkhart PV, Rayens MK, Revelette WR, OhImann A. Improved health outcomes with peak flow monitoring for children with asthma. The Journal of asthma : official journal of the Association for the Care of Asthma 2007; 44(2): 137-42.

27. Wensley D, Silverman M. Peak flow monitoring for guided self-management in childhood asthma: a randomized controlled trial. American journal of respiratory and critical care medicine 2004; 170(6): 606-12.

28. Nuijsink M, Hop WC, Sterk PJ, Duiverman EJ, de Jongste JC. Long-term asthma treatment guided by airway hyperresponsiveness in children: a randomised controlled trial. Eur Respir J 2007; 30(3): 457-66.

29. Pijnenburg MW, De Jongste JC. Exhaled nitric oxide in childhood asthma: a review. Clin Exp Allergy 2008; 38(2): 246-59.

30. Brussee JE, Smit HA, Kerkhof M, et al. Exhaled nitric oxide in 4-year-old children: relationship with asthma and atopy. Eur Respir J 2005; 25(3): 455-61.

31. Frank TL, Adisesh A, Pickering AC, et al. Relationship between exhaled nitric oxide and childhood asthma. American journal of respiratory and critical care medicine 1998; 158(4): 1032-6.

32. Franklin PJ, Turner SW, Le Souef PN, Stick SM. Exhaled nitric oxide and asthma: complex interactions between atopy, airway responsiveness, and symptoms in a community population of children. Thorax 2003; 58(12): 1048-52.

33. Jouaville LF, Annesi-Maesano I, Nguyen LT, Bocage AS, Bedu M, Caillaud D. Interrelationships among asthma, atopy, rhinitis and exhaled nitric oxide in a population-based sample of children. Clin Exp Allergy 2003; 33(11): 1506-11.

34. Pijnenburg MW, Bakker EM, Hop WC, De Jongste JC. Titrating steroids on exhaled nitric oxide in children with asthma: a randomized controlled trial. American journal of respiratory and critical care medicine 2005; 172(7): 831-6.

35. Zacharasiewicz A. Fractional exhaled nitric oxide and induced sputum. Paediatric respiratory reviews 2007; 8(1): 94-6.

36. American Thoracic S, European Respiratory S. ATS/ERS recommendations for standardized procedures for the online and offline measurement of exhaled lower respiratory nitric oxide and nasal nitric oxide, 2005. American journal of respiratory and critical care medicine 2005; 171(8): 912-30.

37. Kharitonov S, Alving K, Barnes PJ. Exhaled and nasal nitric oxide measurements: recommendations. The European Respiratory Society Task Force. Eur Respir J 1997; 10(7): 1683-93.

38. Green RJ, Klein M, Becker $\mathrm{P}$, et al. Disagreement among common measures of asthma control in children. Chest 2013; 143(1): 117-22.

39. Khalili B, Boggs PB, Shi R, Bahna SL. Discrepancy between clinical asthma control assessment tools and fractional exhaled nitric oxide. Annals of allergy, asthma \& immunology : official publication of the American College of Allergy, Asthma, \& Immunology 2008; 101(2): 124-9.

40. Shirai T, Furuhashi K, Suda T, Chida K. Relationship of the asthma control test with pulmonary function and exhaled nitric oxide. Annals of allergy, asthma \& immunology : official publication of the American College of Allergy, Asthma, \& Immunology 2008; 101(6): 608-13.

41. Tibosch M, de Ridder J, Landstra A, et al. Four of a kind: asthma control, FEV1, FeNO, and psychosocial problems in adolescents. Pediatric pulmonology 2012; 47(10): 933-40.

42. Waibel V, Ulmer H, Horak E. Assessing asthma control: symptom scores, GINA levels of asthma control, lung function, and exhaled nitric oxide. Pediatric pulmonology 2012; 47(2): 113-8.

43. NICE. Quality standard for asthma: National Institute for Health and Care Excellence, 2013.

44. de Jongste JC, Carraro S, Hop WC, Group CS, Baraldi E. Daily telemonitoring of exhaled nitric oxide and symptoms in the treatment of childhood asthma. American journal of respiratory and critical care medicine 2009; 179(2): 93-7. 
45. Fritsch M, Uxa S, Horak F, Jr., et al. Exhaled nitric oxide in the management of childhood asthma: a prospective 6-months study. Pediatric pulmonology 2006; 41(9): 855-62.

46. Peirsman EJ, Carvelli TJ, Hage PY, et al. Exhaled nitric oxide in childhood allergic asthma management a randomised controlled trial. Pediatric pulmonology 2013.

47. Szefler SJ, Mitchell H, Sorkness CA, et al. Management of asthma based on exhaled nitric oxide in addition to guideline-based treatment for inner-city adolescents and young adults: a randomised controlled trial. Lancet 2008; 372(9643): 1065-72.

48. Pike K, Selby A, Price S, et al. Exhaled nitric oxide monitoring does not reduce exacerbation frequency or inhaled corticosteroid dose in paediatric asthma: a randomised controlled trial. The clinical respiratory journal 2012.

49. Petsky HL, Cates CJ, Li A, Kynaston JA, Turner C, Chang AB. Tailored interventions based on exhaled nitric oxide versus clinical symptoms for asthma in children and adults. Cochrane Database Syst Rev 2009; (4): CD006340.

50. Duong $M$, Subbarao $P$, Adelroth $E$, et al. Sputum eosinophils and the response of exercise-induced bronchoconstriction to corticosteroid in asthma. Chest 2008; 133(2): 404-11.

51. Green RH, Brightling CE, McKenna $\mathrm{S}$, et al. Asthma exacerbations and sputum eosinophil counts: a randomised controlled trial. Lancet 2002; 360(9347): 1715-21.

52. Jayaram L, Pizzichini MM, Cook RJ, et al. Determining asthma treatment by monitoring sputum cell counts: effect on exacerbations. Eur Respir J 2006; 27(3): 483-94.

53. Zacharasiewicz $\mathrm{A}$, Wilson $\mathrm{N}$, Lex $\mathrm{C}$, et al. Clinical use of noninvasive measurements of airway inflammation in steroid reduction in children. American journal of respiratory and critical care medicine 2005; 171(10): 1077-82.

54. Fleming L, Wilson N, Regamey N, Bush A. Use of sputum eosinophil counts to guide management in children with severe asthma. Thorax 2012; 67(3): 193-8. 


\section{Chapter}

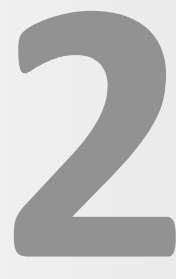

\section{Asthma control questionnaires in the management of asthma in children: a review}

S. Voorend-van Bergen ${ }^{1}$, A.A. Vaessen-Verberne ${ }^{2}$, J.C. de Jongste ${ }^{1}$, M.W. Pijnenburg ${ }^{1}$

${ }^{1}$ Erasmus University Medical Center-Sophia Children's Hospital, Rotterdam, the Netherlands

${ }^{2}$ Amphia Hospital, Breda, the Netherlands 


\section{Summary}

Several self-administered questionnaires have been developed to assess childhood asthma control in a simple and standardized way. This review discusses the most commonly used questionnaires and explores their usefulness in asthma management in children. We conclude that the use of asthma control questionnaires in daily practice and in research contributes to the standardized evaluation of children with asthma and helps to track asthma symptoms, but validation studies in a wider range of settings are needed. 


\section{Introduction}

In a substantial proportion of asthmatic children (up to 90\%) the goals of asthma management are not reached, which means that despite current treatment guidelines numerous children still suffer from sleep disturbances and exercise intolerance ${ }^{1,2}$. Asthma is the third ranking course of hospitalization in children and the most important chronic disease that causes school absenteeism among children in the US ${ }^{3}$. In Europe unscheduled health care visits accounted for $45 \%$ of total asthma costs in children; $7 \%$ of all children reported at least 1 hospitalization for asthma in the past year ${ }^{4}$. Hence, there is an urgent need for validated instruments to assess asthma control in a simple, noninvasive, cheap and standardized way.

Asthma control is a central concept in all asthma guidelines and is defined as the extent to which the various asthma manifestations, including symptoms, the use of reliever medication, and the ability to carry out daily activities and exercise, have been reduced by treatment ${ }^{5,6}$. Asthma management also aims to reduce future risks to the patient including exacerbations, accelerated decline in lung function and side effects of treatment ${ }^{5}$. As current poor control predicts future poor control ${ }^{7}$, assessment of asthma control has become a key element in asthma management ${ }^{6}$.

The assessment of asthma control by patients will depend on their perception of airway obstruction $^{8}$, as well as their personal interpretation of optimal control. This may differ markedly from that of the clinician ${ }^{9}$. In general, both patients and physicians tend to overestimate asthma control ${ }^{10-12}$. Similarly, in asthmatic children, parents tend to underreport asthma symptoms of their child ${ }^{12-14}$, which might be explained by adaptation of the activity level of children to their asthma symptoms ${ }^{15,16}$. The Global Initiative For Asthma (GINA) proposed levels of asthma control based on clinical manifestations, forced expiratory volume in 1 second (FEV1) and expected future risk and proposed to classify patients as well-controlled, partly controlled or uncontrolled ${ }^{5}$. Complementary, several self-administered questionnaires have been developed to assess asthma control in a standardized way. Contrary to the concept of GINA, these questionnaires use numeric scores. Examples of such questionnaires are the Asthma Control Questionnaire (ACQ), the Asthma Control Test (ACT) and Childhood Asthma Control Test (C-ACT), the Asthma Treatment Assessment Questionnaire (ATAQ) and Test for Respiratory and Asthma Control in Kids (TRACK) (Table 1). In this review we summarize questionnaires that have been used to assess asthma control in children and discuss their value for asthma management. 
Table 1 Questionnaires for measuring asthma control in children

\begin{tabular}{|c|c|c|c|c|c|}
\hline Name of test & Age & Number of items & Scoring & Recall period & $\mathrm{MID}^{\mathrm{a}}$ \\
\hline $\begin{array}{l}\text { Asthma Control Test } \\
\text { (ACT) }\end{array}$ & $\begin{array}{l}\text { - adults } \\
\text { - child } \geq 12 \text { yrs }\end{array}$ & 5 items & $\begin{array}{l}\text { S19: uncontrolled } \\
\text { asthma } \\
\text { Range: } 5-25\end{array}$ & 4 weeks & $\begin{array}{l}3 \text { (adults) } \\
2 \text { (children) }\end{array}$ \\
\hline $\begin{array}{l}\text { Childhood Asthma } \\
\text { Control Test (C-ACT) }\end{array}$ & - child 4-12 yrs & $\begin{array}{l}7 \text { items: } \\
-4 \text { child } \\
-3 \text { parent }\end{array}$ & $\begin{array}{l}\text { S19: uncontrolled } \\
\text { asthma } \\
\text { Range: } 5-27\end{array}$ & 4 weeks & 2 \\
\hline $\begin{array}{l}\text { Asthma Control } \\
\text { Questionnaire (ACQ) }\end{array}$ & $\begin{array}{l}\text { - adults } \\
\text { - child 6-16 yrs }\end{array}$ & $\begin{array}{l}7 \text { items, including } \\
\text { FEV1 }\end{array}$ & $\begin{array}{l}\leq 0.75 \text { controlled } \\
\text { asthma } \\
\geq 1.5 \text { uncontrolled } \\
\text { asthma } \\
\text { Range: } 0-6\end{array}$ & 1 week & 0.5 \\
\hline $\begin{array}{l}\text { Asthma Therapy } \\
\text { Assessment } \\
\text { Questionnaire (ATAQ) }\end{array}$ & $\begin{array}{l}\text { - adults } \\
\text { - child 5-17 yrs }\end{array}$ & 4 items & $\begin{array}{l}0 \text { : controlled } \\
\text { asthma } \\
\geq 1 \text { : uncontrolled } \\
\text { asthma } \\
\text { (1-2: not well } \\
\text { controlled; } 3-4 \text { very } \\
\text { poorly controlled) } \\
\text { Range: } 0-4\end{array}$ & 4 weeks & No MID \\
\hline $\begin{array}{l}\text { Test for Respiratory } \\
\text { and Asthma Control } \\
\text { in Kids (TRACK) }\end{array}$ & - child $<5$ yrs & 5 items & $\begin{array}{l}<80 \text { : uncontrolled } \\
\text { asthma } \\
\geq 80 \text { : controlled } \\
\text { asthma }\end{array}$ & $\begin{array}{l}4 \text { weeks } \\
\text { (oral steroid } \\
\text { courses } 12 \\
\text { months) }\end{array}$ & 10 \\
\hline
\end{tabular}

a) MID: minimal important difference.

\section{Asthma Control Questionnaire}

The ACQ was developed by Juniper et al. and was the first validated questionnaire for assessing asthma control in clinical trials and clinical practice ${ }^{17,18}$. The questionnaire has a recall period of 1 week and consists of 7 questions, asking for breathlessness, nocturnal awakenings, symptoms when waking up, activity limitation, wheeze, frequency of rescue medication, and pre-bronchodilator FEV1 \%predicted. The items are scored from 0 (optimal) to 6 (worst), and are equally weighted. The ACQ score is the mean of the seven items and therefore ranges from 0 (well controlled) to 6 (extremely poorly controlled) ${ }^{17}$, ${ }^{18}$. The ACQ has been validated against quality of life and physician assessment of asthma control $^{17,19-22}$, and the minimal clinically important difference is $0.5^{19}$. The ACQ has only recently been validated for use in children aged 6-16 years, with a trained interviewer administering the questionnaire to children aged 6-10 years ${ }^{18}$. A score less than or equal to 0.75 indicated well-controlled asthma with a negative predictive value of $85 \%$, and a value of greater than or equal to 1.50 had a positive predictive value of $88 \%$ for detecting uncontrolled asthma ${ }^{19}$. However, recently these cut-offs have been debated and $<0.5$ for 
controlled asthma and $\geq 1$ or $\geq 1.25$ for uncontrolled asthma have been proposed as better cut-off points ${ }^{23,24}$. Shortened versions of the ACQ, with omission of the items on shortacting beta agonists (SABA) use and/or FEV1, perform as well as the complete version ${ }^{19,21}$ and may be suitable for self-completion at home or in primary care ${ }^{25}$.

\section{Asthma Control Test}

The ACT is a patient-completed questionnaire for patients 12 years and older with a recall time of 4 weeks. It consists of 5 questions on shortness of breath, awakenings at night, limitation of activity, rescue SABA use, and patient rating of asthma control. Each item is scored using a 1-5 scale and the scores are added, to a total score of 5-25. The ACT has been validated against specialist's rating of asthma control and spirometry ${ }^{26-28}$, GINA criteria of asthma control ${ }^{29-31}$, and quality of life $^{32}$. The test is easy to use, and can be completed on the Internet ${ }^{33,34}$ or by telephone ${ }^{35,36}$. A score of less than 20 corresponds to uncontrolled asthma (sensitivity $69-71 \%$, specificity $71-76 \%$ ) and less than or equal to 15 to very poorly controlled asthma (sensitivity $61 \%$, specificity $74 \%)^{26,28,32}$. An ACT $\geq$ 23 indicates well controlled asthma ${ }^{37}$. The minimal important difference (MID) has been shown to be 3 ACT points in adults ${ }^{38}$ and 2 in children ${ }^{37}$.

In children aged 4 to 11 years, the Childhood Asthma Control Test may be used (C-ACT) ${ }^{39}$. The C-ACT is a 7-item questionnaire that addresses the previous 4 weeks and is divided into 2 parts. The first part is filled in by the child with the aid of a visual scale and consists of 4 questions on perception of asthma control, limitations of activities, coughing and nocturnal awakenings. Response levels vary from 0 to 3 . The second part is filled in by a parent or caregiver and its 3 questions ask for daytime symptoms, daytime wheezing and awakenings at night, with response levels between 0 and 5. The C-ACT score is the sum of all scores, ranging from 0 (poorest asthma control) to 27 (optimal asthma control). Again, a cut-off of $\leq 19$ indicates uncontrolled asthma ${ }^{39}$ and $\geq 22$ indicated well controlled asthma ${ }^{37}$. The minimal important difference is 2 C-ACT points ${ }^{37}$.

\section{Asthma Therapy Assessment Questionnaire}

The ATAQ is a validated, self-administered questionnaire that asks about self-perception, limitation of activity, night-time symptoms, and the use of reliever medication in the previous 4 weeks ${ }^{40}$. Each item is scored as either having (1) or not having a problem (0). The number of positive control items provides a total score ranging from 0 to 4 . Zero indicates controlled asthma, $\geq 1$ indicates uncontrolled asthma, whereas score 3-4 indicates very poorly controlled asthma ${ }^{40,41}$. For children and adolescents aged 5-17 years a child 
version has been developed ${ }^{42}$. This is a 20 -item parent-completed questionnaire, intended to identify children with uncontrolled asthma ${ }^{42}$. The ATAQ for children and adolescents covers questions in 4 dimensions: asthma control ( 7 questions), attitude and behavior ( 2 questions), self-efficacy (3 questions) and patient-provider communication (5 questions). Each question is dichotomized and the sum of scores pertaining to a dimension represents problems in that dimension ${ }^{42}$. The asthma control domain is scored from 0 to 7 , with 0 indicating no asthma problems, and higher scores indicating increasing asthma problems. Children with a score of 4-7 are at increased risk for exacerbations ${ }^{43}$.

\section{Test for Respiratory and Asthma Control in Kids}

TRACK is a validated parent-completed asthma control questionnaire designed for children under the age of $5^{44}$. It consists of 5 questions, asking for perception, limitations of activities, awakenings at night, the use of reliever medication in the previous 4 weeks and the need of oral corticosteroids in the last 12 months. A score less than 80 indicates uncontrolled asthma ${ }^{44,45}$. Changes in TRACK scores of 10 or more points represent clinically meaningful changes ${ }^{46}$.

\section{Gold standard of asthma control}

There is no gold standard for the assessment of asthma control, although levels of asthma control according to GINA guidelines are frequently used as such ${ }^{6}$. However, the proposed definition by GINA of controlled, partly controlled and uncontrolled asthma was primarily developed as an arbitrary working scheme for adults and has not been validated for children ${ }^{5}$. It might be argued that criteria for well-controlled asthma in children may differ from those in adults. In children, in particular limitation of activities and nocturnal symptoms may impact the quality of life of the children and their caregivers ${ }^{47}$. Based on GINA criteria, the diagnostic performances of the ACT or ACQ in assessing levels of asthma control have been evaluated in several studies. Most of these studies have shown a high level of agreement between both tests and GINA criteria ${ }^{23,29-31,48-51}$. Only one study found a significant discrepancy between C-ACT and GINA levels of control ${ }^{52}$. It was hypothesized that this discrepancy was due to the fact that GINA levels are based on frequency of symptoms and on pulmonary function tests, whereas the C-ACT score is determined by the severity of symptoms only. The area under the receiver operating characteristics curves (AUC) of C-ACT and ACT score for predicting uncontrolled asthma according to GINA varied from 0.84 to 0.92 29-31, 50,51,53. The AUC for the ACQ score to predict GINA uncontrolled asthma varied from 0.85 to $0.87^{23}$. 


\section{Asthma control questionnaires, lung function and airway inflammation}

As asthma is a chronic inflammatory disorder with reversible airway obstruction as one of the prominent features, measurements of airway obstruction (FEV1) and airway inflammation (like fractional exhaled nitric oxide (FeNO) as a biomarker of eosinophilic airway inflammation) are frequently used in addition to clinical tools to assess asthma control. Several studies have examined the relation between asthma control questionnaires and these objective features. Most studies have shown an association between FEV1 or quality of life and the ACT, C-ACT or ACQ scores ${ }^{18,21,54-57}$. However, other studies found a weak or absent correlation between lung function measurements and asthma control scores $^{57-61}$. Ko et al. showed that adding FEV1 to the ACT did not significantly improve the predictive value for the adjustment of asthma therapy compared to the ACT alone ${ }^{62}$. Also, evidence is lacking that the use of FEV1 in assessing asthma control improves asthma outcomes in children ${ }^{63}$. The relationship between questionnaires and FeNO was significant in newly diagnosed steroid-naïve asthma patients ${ }^{55,60}$ but weak or absent in those children using inhaled corticosteroids ${ }^{57,58,64,65}$. Green et al. found a poor agreement among FeNO, spirometry, C-ACT and clinical assessment to assess asthma control ${ }^{66}$.

It is obvious that lung function and airways inflammation represent different domains of the asthma phenotype and reflect different aspects of asthma control. It is unclear how these different tools may be used in the assessment of asthma control and if the addition of lung function and/or inflammatory markers in the monitoring of children with asthma leads to improved outcomes. In a systematic review, Petsky et al. concluded that tailoring of asthma treatment based on FeNO levels did not show effectiveness in improving asthma outcomes in children ${ }^{67}$. There are no studies comparing symptom based treatment with treatment based on symptoms and FEV1, however a benefit of peak flow guided treatment over management based on symptoms alone could not be shown ${ }^{68,69}$. Therefore, it is unclear if considering lung function and inflammatory markers adds up to a more reliable assessment of asthma control and if so, in which children.

\section{The added value of questionnaires in asthma management}

Questionnaires to assess asthma control may be useful in asthma management as they enable for a standardized assessment, and give a quick overview of a patients' asthma control. They may be filled in in the waiting room or at home before medical evaluation in the clinic. They offer the possibility to adjust asthma treatment based on pre-specified cutoff points. This can be used as part of self-management strategies. Asthma questionnaires 
can be administered by mail ${ }^{32}$, by the Internet ${ }^{33,34}$, and by telephone ${ }^{36}$, which facilitates their use in self-management ${ }^{6}$. However, a limitation may be that asthma control may be overestimated by poor symptom perception. Both the ACT and the ACQ have a short recall time of 4 weeks and 1 week respectively, which may give a 'snapshot' of asthma control but possibly an insufficient overview of asthma control between clinic visits. Therefore, daily diaries may be a more sensitive tool than questionnaires for assessing differential treatment responses in clinical trials ${ }^{70}$. Still, asthma questionnaires have been shown useful in evaluating the efficacy of various therapeutic interventions $\mathrm{s}^{71-73}$.

If questionnaires are to be used in daily practice, the preference for a particular questionnaire may depend on its recall window, the age of the child and the availability of spirometry. In a meta-analysis Jia et al. showed that the ACT and ACQ performed equally well when used to assess asthma control ${ }^{74}$. They concluded that the ACQ required further cross-validation and therefore they recommended the ACT for children in clinical practice $^{74}$. As the ACT does not include spirometry, this test may be more feasible in clinics with a high volume of patients and limited resources ${ }^{74}$. TRACK is the only asthma questionnaire for use in preschool children, however, only limited data are available on TRACK, and validation studies in different populations are missing ${ }^{44}$. The C-ACT ${ }^{39}$ might be the preferred test in children from the age of 4 years, because of the visual scale and because it has been validated in different settings ${ }^{32,34}$. In addition, assessment of asthma control with the C-ACT is not only parent reported, but also based on the child's own report. As parents tend to underestimate asthma control ${ }^{13}$, assessment by the child itself is valuable. The ACQ is validated from the age of 6 years, but the complete version of 20 questions is time consuming. Few data are available on the use of the ATAQ in children ${ }^{42,43}$. Most questionnaires have been developed to detect uncontrolled asthma and only few studies proposed a cut-off for well-controlled asthma ${ }^{19,54,75}$. The magnitude of a clinically relevant change in C-ACT and ACT scores has only recently been published by our group ${ }^{37}$. Little is known about the potential of asthma control questionnaires to predict future risks, and in particular exacerbations, and studies are limited to adults ${ }^{6,76-78}$. The TRACK is the only questionnaire including exacerbations (oral steroid courses) in the assessment of asthma control. As children may have unexpected exacerbations after long periods of control and exacerbations may occur in children with good and poor short-term asthma control, this is a serious drawback of most asthma control questionnaires ${ }^{79-81}$. New studies should focus on the clinical value of asthma control questionnaires which include exacerbations in their assessment and on the potential of these questionnaires to predict lung function decline. Also, further research is required to establish whether the use of composite measures of asthma control improves asthma outcomes.

It is unknown if the use of monitoring of asthma control with asthma control questionnaires, with or without FEV1 or FeNO, has added value in specific asthma phenotypes ${ }^{6}$. Finally, 
it should be realized that questionnaire scores could be influenced and consequently misinterpreted by obesity and allergic rhinitis, because of discrepancy between symptoms and asthmatic inflammation.

In conclusion, the use of asthma questionnaires in daily practice and research potentially contributes to the standardized evaluation of children with asthma and helps to track asthma symptoms. However, there remains a need for validation of methodological aspects of the different questionnaires, including repeatability, cutoffs for well-controlled and uncontrolled asthma and validation in a wide range of settings $\mathrm{s}^{82}$. Controlled trials are needed to establish the added value of asthma questionnaires for asthma management and to answer the question if final outcomes will be different by using asthma questionnaires in clinical practice in children with asthma. 


\section{References}

1. Gustafsson PM, Watson L, Davis KJ, Rabe KF. Poor asthma control in children: evidence from epidemiological surveys and implications for clinical practice. Int J Clin Pract 2006; 60(3): 321-34.

2. Rabe KF, Adachi M, Lai CK, et al. Worldwide severity and control of asthma in children and adults: the global asthma insights and reality surveys. J Allergy Clin Immunol 2004; 114(1): 40-7.

3. Asthma and Allergy Foundation of America. http://www.aafa.org.

4. Williams AE, Lloyd AC, Watson L, Rabe KF. Cost of scheduled and unscheduled asthma management in seven European Union countries. Eur Respir Rev 2006; 15(98): 4-9.

5. GINA report Global Strategy for Asthma Management and Prevention, updated December 2011, 2011.

6. Reddel HK, Taylor DR, Bateman ED, et al. An official American Thoracic Society/European Respiratory Society statement: asthma control and exacerbations: standardizing endpoints for clinical asthma trials and clinical practice. Am J Respir Crit Care Med 2009; 180(1): 59-99.

7. Sullivan SD, Wenzel SE, Bresnahan BW, et al. Association of control and risk of severe asthma-related events in severe or difficult-to-treat asthma patients. Allergy 2007; 62(6): 655-60.

8. Rubinfeld AR, Pain MC. Perception of asthma. Lancet 1976; 1(7965): 882-4.

9. Taylor DR, Bateman ED, Boulet LP, et al. A new perspective on concepts of asthma severity and control. Eur Respir J 2008; 32(3): 545-54.

10. Chapman KR, Boulet LP, Rea RM, Franssen E. Suboptimal asthma control: prevalence, detection and consequences in general practice. Eur Respir J 2008; 31(2): 320-5.

11. Boulet LP, Phillips R, O'Byrne P, Becker A. Evaluation of asthma control by physicians and patients: comparison with current guidelines. Can Respir J 2002; 9(6): 417-23.

12. Carroll WD, Wildhaber J, Brand PL. Parent misperception of control in childhood/adolescent asthma: the Room to Breathe survey. Eur Respir J 2012; 39(1): 90-6.

13. Voorend-van Bergen S, Brackel H, Caudri D, de Jongste J, Pijnenburg M. Assessment of asthma control by children and parents. Eur Respir J 2013; 41(1): 233-4.

14. Halterman JS, McConnochie KM, Conn KM, et al. A potential pitfall in provider assessments of the quality of asthma control. Ambul Pediatr 2003; 3(2): 102-5.

15. Davis KJ, Disantostefano R, Peden DB. Is Johnny wheezing? Parent-child agreement in the Childhood Asthma in America survey. Pediatr Allergy Immunol 2011; 22(1 Pt 1): 31-5.

16. Lara M, Duan N, Sherbourne C, et al. Differences between child and parent reports of symptoms among Latino children with asthma. Pediatrics 1998; 102(6): E68.

17. Juniper EF, O’Byrne PM, Guyatt GH, Ferrie PJ, King DR. Development and validation of a questionnaire to measure asthma control. Eur Respir J 1999; 14(4): 902-7.

18. Juniper EF, Gruffydd-Jones K, Ward S, Svensson K. Asthma Control Questionnaire in children: validation, measurement properties, interpretation. Eur Respir J 2010; 36(6): 1410-6.

19. Juniper EF, Bousquet J, Abetz L, Bateman ED, Committee G. Identifying 'well-controlled' and 'not wellcontrolled' asthma using the Asthma Control Questionnaire. Respir Med 2006; 100(4): 616-21.

20. Juniper EF, O’Byrne PM, Ferrie PJ, King DR, Roberts JN. Measuring asthma control. Clinic questionnaire or daily diary? Am J Respir Crit Care Med 2000; 162(4 Pt 1): 1330-4.

21. Juniper EF, Svensson K, Mork AC, Stahl E. Measurement properties and interpretation of three shortened versions of the asthma control questionnaire. Respir Med 2005; 99(5): 553-8.

22. Juniper EF, O’Byrne PM, Roberts JN. Measuring asthma control in group studies: do we need airway calibre and rescue beta2-agonist use? Respir Med 2001; 95(5): 319-23.

23. Olaguibel JM, Quirce S, Julia B, et al. Measurement of asthma control according to Global Initiative for Asthma guidelines: a comparison with the Asthma Control Questionnaire. Respir Res 2012; 13: 50.

24. Nguyen JM, Holbrook JT, Wei CY, et al. Validation and psychometric properties of the Asthma Control Questionnaire among children. J Allergy Clin Immunol 2013.

25. Ehrs PO, Nokela M, Stallberg B, Hjemdahl P, Wikstrom Jonsson E. Brief questionnaires for patient-reported outcomes in asthma: validation and usefulness in a primary care setting. Chest 2006; 129(4): 925-32. 
26. Nathan RA, Sorkness CA, Kosinski M, et al. Development of the asthma control test: a survey for assessing asthma control. J Allergy Clin Immunol 2004; 113(1): 59-65.

27. Lenoir M, Williamson A, Stanford RH, Stempel DA. Assessment of asthma control in a general population of asthmatics. Curr Med Res Opin 2006; 22(1): 17-22.

28. Schatz M, Sorkness CA, Li JT, et al. Asthma Control Test: reliability, validity, and responsiveness in patients not previously followed by asthma specialists. J Allergy Clin Immunol 2006; 117(3): 549-56.

29. Koolen BB, Pijnenburg MW, Brackel HJ, et al. Comparing Global Initiative for Asthma (GINA) criteria with the Childhood Asthma Control Test (C-ACT) and Asthma Control Test (ACT). Eur Respir J 2011; 38(3): 561-6.

30. Thomas M, Kay S, Pike J, et al. The Asthma Control Test (ACT) as a predictor of GINA guideline-defined asthma control: analysis of a multinational cross-sectional survey. Prim Care Respir J 2009; 18(1): 41-9.

31. Yu HR, Niu CK, Kuo HC, et al. Comparison of the Global Initiative for Asthma guideline-based Asthma Control Measure and the Childhood Asthma Control Test in evaluating asthma control in children. Pediatr Neonatol 2010; 51(5): 273-8.

32. Schatz M, Mosen DM, Kosinski M, et al. Validity of the Asthma Control Test completed at home. Am J Manag Care 2007; 13(12): 661-7.

33. Peters SP, Jones CA, Haselkorn T, Mink DR, Valacer DJ, Weiss ST. Real-world Evaluation of Asthma Control and Treatment (REACT): findings from a national Web-based survey. J Allergy Clin Immunol 2007; 119(6): 1454-61.

34. Koolen BB, Pijnenburg MW, Brackel HJ, et al. Validation of a web-based version of the asthma control test and childhood asthma control test. Pediatr Pulmonol 2011; 46(10): 941-8.

35. Kosinski M, Kite A, Yang M, Rosenzweig JC, Williams A. Comparability of the Asthma Control Test telephone interview administration format with self-administered mail-out mail-back format. Curr Med Res Opin 2009; 25(3): 717-27.

36. Schatz M, Zeiger RS, Drane A, et al. Reliability and predictive validity of the Asthma Control Test administered by telephone calls using speech recognition technology. J Allergy Clin Immunol 2007; 119(2): 336-43.

37. Voorend-van Bergen S, Vaessen-Verberne AA, Landstra AM, et al. Monitoring childhood asthma: Web-based diaries and the asthma control test. J Allergy Clin Immunol 2013.

38. Schatz M, Kosinski M, Yarlas AS, Hanlon J, Watson ME, Jhingran P. The minimally important difference of the Asthma Control Test. J Allergy Clin Immunol 2009; 124(4): 719-23 e1.

39. Liu AH, Zeiger R, Sorkness C, et al. Development and cross-sectional validation of the Childhood Asthma Control Test. J Allergy Clin Immunol 2007; 119(4): 817-25.

40. Vollmer WM, Markson LE, O'Connor E, et al. Association of asthma control with health care utilization and quality of life. Am J Respir Crit Care Med 1999; 160(5 Pt 1): 1647-52.

41. Cloutier MM, Schatz M, Castro M, et al. Asthma outcomes: composite scores of asthma control. J Allergy Clin Immunol 2012; 129(3 Suppl): S24-33.

42. Skinner EA, Diette GB, Algatt-Bergstrom PJ, et al. The Asthma Therapy Assessment Questionnaire (ATAQ) for children and adolescents. Dis Manag 2004; 7(4): 305-13.

43. Diette GB, Sajjan SG, Skinner EA, Weiss TW, Wu AW, Markson LE. Using the pediatric asthma therapy assessment questionnaire to measure asthma control and healthcare utilization in children. Patient 2009; 2(4): 233-41.

44. Murphy KR, Zeiger RS, Kosinski M, et al. Test for respiratory and asthma control in kids (TRACK): a caregivercompleted questionnaire for preschool-aged children. J Allergy Clin Immunol 2009; 123(4): 833-9 e9.

45. Chipps B, Zeiger RS, Murphy K, et al. Longitudinal validation of the Test for Respiratory and Asthma Control in Kids in pediatric practices. Pediatrics 2011; 127(3): e737-47.

46. Zeiger RS, Mellon M, Chipps B, et al. Test for Respiratory and Asthma Control in Kids (TRACK): clinically meaningful changes in score. J Allergy Clin Immunol 2011; 128(5): 983-8.

47. Horner CC, Mauger D, Strunk RC, et al. Most nocturnal asthma symptoms occur outside of exacerbations and associate with morbidity. J Allergy Clin Immunol 2011; 128(5): 977-82 e1-2. 
48. van den Nieuwenhof L, Schermer T, Eysink P, et al. Can the Asthma Control Questionnaire be used to differentiate between patients with controlled and uncontrolled asthma symptoms? A pilot study. Fam Pract 2006; 23(6): 674-81.

49. O’Byrne PM, Reddel HK, Eriksson G, et al. Measuring asthma control: a comparison of three classification systems. Eur Respir J 2010; 36(2): 269-76.

50. Korn S, Both J, Jung M, Hubner M, Taube C, Buhl R. Prospective evaluation of current asthma control using ACQ and ACT compared with GINA criteria. Ann Allergy Asthma Immunol 2011; 107(6): 474-9.

51. Nguyen VN, Chavannes N, Le LT, Price D. The Asthma Control Test (ACT) as an alternative tool to Global Initiative for Asthma (GINA) guideline criteria for assessing asthma control in Vietnamese outpatients. Prim Care Respir J 2012; 21(1): 85-9.

52. Erkocoglu M, Akan A, Civelek E, Kan R, Azkur D, Kocabas CN. Consistency of GINA criteria and childhood asthma control test on the determination of asthma control. Pediatr Allergy Immunol 2012; 23(1): 34-9.

53. Zhou X, Ding FM, Lin JT, Yin KS. Validity of asthma control test for asthma control assessment in Chinese primary care settings. Chest 2009; 135(4): 904-10.

54. Ito $\mathrm{Y}$, Adachi $\mathrm{Y}$, Itazawa $\mathrm{T}$, et al. Association between the results of the childhood asthma control test and objective parameters in asthmatic children. J Asthma 2011; 48(10): 1076-80.

55. Piacentini GL, Peroni DG, Bodini A, et al. Childhood Asthma Control Test and airway inflammation evaluation in asthmatic children. Allergy 2009; 64(12): 1753-7.

56. Leung TF, Ko FW, Sy HY, et al. Identifying uncontrolled asthma in young children: clinical scores or objective variables? J Asthma 2009; 46(2): 130-5.

57. Waibel V, Ulmer H, Horak E. Assessing asthma control: symptom scores, GINA levels of asthma control, lung function, and exhaled nitric oxide. Pediatr Pulmonol 2012; 47(2): 113-8.

58. Tibosch M, de Ridder J, Landstra A, et al. Four of a kind: asthma control, FEV1, FeNO, and psychosocial problems in adolescents. Pediatr Pulmonol 2012; 47(10): 933-40.

59. Rosias PP, Dompeling E, Dentener MA, et al. Childhood asthma: exhaled markers of airway inflammation, asthma control score, and lung function tests. Pediatr Pulmonol 2004; 38(2): 107-14.

60. Senna G, Passalacqua G, Schiappoli M, Lombardi C, Wilcock L. Correlation among FEV, nitric oxide and asthma control test in newly diagnosed asthma. Allergy 2007; 62(2): 207-8.

61. Lee MS, Kao JK, Lee $\mathrm{CH}$, et al. Correlations between Pulmonary Function and Childhood Asthma Control Test Results in 5-11-Year-Old Children with Asthma. Pediatr Neonatol 2013.

62. Ko FW, Leung TF, Hui DS, et al. Asthma Control Test correlates well with the treatment decisions made by asthma specialists. Respirology 2009; 14(4): 559-66.

63. Brand PL, Roorda RJ. Usefulness of monitoring lung function in asthma. Arch Dis Child 2003; 88(11): $1021-5$.

64. Shirai T, Furuhashi K, Suda T, Chida K. Relationship of the asthma control test with pulmonary function and exhaled nitric oxide. Ann Allergy Asthma Immunol 2008; 101(6): 608-13.

65. Khalili B, Boggs PB, Shi R, Bahna SL. Discrepancy between clinical asthma control assessment tools and fractional exhaled nitric oxide. Ann Allergy Asthma Immunol 2008; 101(2): 124-9.

66. Green RJ, Klein M, Becker $\mathrm{P}$, et al. Disagreement among common measures of asthma control in children. Chest 2013; 143(1): 117-22.

67. Petsky HL, Cates CJ, Lasserson TJ, et al. A systematic review and meta-analysis: tailoring asthma treatment on eosinophilic markers (exhaled nitric oxide or sputum eosinophils). Thorax 2012; 67(3): 199-208.

68. Tantisira KG, Fuhlbrigge AL, Tonascia J, et al. Bronchodilation and bronchoconstriction: predictors of future lung function in childhood asthma. J Allergy Clin Immunol 2006; 117(6): 1264-71.

69. Wensley D, Silverman M. Peak flow monitoring for guided self-management in childhood asthma: a randomized controlled trial. Am J Respir Crit Care Med 2004; 170(6): 606-12.

70. Okupa AY, Sorkness CA, Mauger DT, Jackson DJ, Lemanske RF. Daily Diaries vs Retrospective Questionnaires to Assess Asthma Control and Therapeutic Responses in Asthma Clinical Trials: Is Participant Burden Worth the Effort? Chest 2013; 143(4): 993-9.

71. Ma J, Strub P, Camargo CA, Jr., et al. The Breathe Easier through Weight Loss Lifestyle (BE WELL) Intervention: a randomized controlled trial. BMC Pulm Med 2010; 10: 16. 
72. Mehuys E, Van Bortel L, De Bolle L, et al. Effectiveness of pharmacist intervention for asthma control improvement. Eur Respir J 2008; 31(4): 790-9.

73. Writing Committee for the American Lung Association Asthma Clinical Research C, Holbrook JT, Wise RA, et al. Lansoprazole for children with poorly controlled asthma: a randomized controlled trial. JAMA 2012; 307(4): 373-81.

74. Jia CE, Zhang HP, Lv Y, et al. The Asthma Control Test and Asthma Control Questionnaire for assessing asthma control: Systematic review and meta-analysis. J Allergy Clin Immunol 2012.

75. Alvarez-Gutierrez FJ, Medina-Gallardo JF, Perez-Navarro P, et al. [Comparison of the Asthma Control Test (ACT) with lung function, levels of exhaled nitric oxide and control according to the Global Initiative for Asthma (GINA)] Relacion del test de control del asma (ACT) con la funcion pulmonar, niveles de oxido nitrico exhalado y grados de control segun la Iniciativa Global para el Asma (GINA). Arch Bronconeumol 2010; 46(7): 370-7.

76. Ko FW, Hui DS, Leung TF, et al. Evaluation of the asthma control test: a reliable determinant of disease stability and a predictor of future exacerbations. Respirology 2012; 17(2): 370-8.

77. Meltzer EO, Busse WW, Wenzel SE, et al. Use of the Asthma Control Questionnaire to predict future risk of asthma exacerbation. J Allergy Clin Immunol 2011; 127(1): 167-72.

78. Sato R, Tomita K, Sano H, et al. The strategy for predicting future exacerbation of asthma using a combination of the Asthma Control Test and lung function test. J Asthma 2009; 46(7): 677-82.

79. Covar RA, Szefler SJ, Zeiger RS, et al. Factors associated with asthma exacerbations during a long-term clinical trial of controller medications in children. J Allergy Clin Immunol 2008; 122(4): 741-7 e4.

80. Forno E, Fuhlbrigge A, Soto-Quiros ME, et al. Risk factors and predictive clinical scores for asthma exacerbations in childhood. Chest 2010; 138(5): 1156-65.

81. Wu AC, Tantisira K, Li L, et al. Predictors of symptoms are different from predictors of severe exacerbations from asthma in children. Chest 2011; 140(1): 100-7.

82. Krishnan JA, Lemanske RF, Jr., Canino GJ, et al. Asthma outcomes: symptoms. J Allergy Clin Immunol 2012; 129(3 Suppl): S124-35. 



\section{Chapter}

\section{Assessment of asthma control by children and parents}

Sandra Voorend-van Bergen ${ }^{1}$, Hein Brackel ${ }^{2}$, Daan Caudri ${ }^{1}$, Johan de Jongste ${ }^{1}$, Mariëlle Pijnenburg ${ }^{1}$

${ }^{1}$ Dept of Pediatric Pulmonology, Erasmus University Medical Center Sophia Children's Hospital, Rotterdam, the Netherlands

${ }^{2}$ Dept of Pediatrics, Catharina Hospital, Eindhoven, the Netherlands

Based on 'Assessment of asthma control by children and parents (letter to the editor)' 


\section{Abstract}

\section{Background}

The Childhood Asthma Control Test (C-ACT) is a validated patient-completed questionnaire to assess asthma control in children 4-11 years. It consists of seven items, addresses the previous 4 weeks and is divided into two parts. One part is filled in by the child with aid of a visual analogue scale and has a maximal score of 12; the second part is filled in by the parent with a maximal score of 15 .

\section{Objectives}

To compare asthma control scores between children and their parents.

\section{Methods}

Asthmatic children 4-11 years and their parents visiting KinderHaven, an outpatient asthma clinic, between January and December 2011 completed the C-ACT as part of routine patient care. Spearmans correlation and Intraclass Correlation Coefficient (ICC) between C-ACT by child and parent were calculated. Both scores were expressed as percentage of the maximum and pair wise compared using the Wilcoxon Signed Ranks Test and a Bland-Altman plot.

\section{Results}

283 children (aged 7.7 yrs, $66.8 \%$ male) and their parents participated; 272 C-ACT's were filled in correctly. Correlation between C-ACT-score between children and parents was $r=0.724(p<0.001)$, the ICC was reasonable $(0.77, p<0.001)$. Children scored median $75 \%(0-100)$ of the maximal score, whereas parents scored median $87 \%(0-100)$. On average children scored $8.3 \%$ lower than parents $(p<0.001)$. The difference between children and parents was independent of the child's age $(p=0.8)$.

\section{Conclusions}

Asthmatic children report significantly lower asthma control than their parents using the C-ACT, irrespective of the child's age. This may indicate that parents underestimate the complaints of their children. 


\section{Introduction}

Recent guidelines place a strong emphasis on monitoring asthma control and adjusting treatment accordingly ${ }^{1}$. Several tools are available to assess asthma control, including the asthma control test (ACT) and childhood asthma control test (C-ACT). These tests were developed to detect uncontrolled asthma and are widely used in research and patient care $^{2,3}$.

The C-ACT is a seven-item questionnaire, which was designed and validated for children from age 4 to 11, and addresses the previous 4 weeks. The C-ACT is divided into two parts. The first is filled in by the child and consists of 4 questions on perception of asthma control, limitations of activities, coughing and nocturnal awakenings. Response levels vary from 0 to 3 . The second part is filled in by a parent or caregiver and consists of 3 questions on daytime complaints, daytime wheezing and awakenings at night, with response levels between 0 and 5 . The C-ACT score is the sum of all scores, ranging from 0 (poorest asthma control) to 27 (optimal asthma control). A cut-off of $\leq 19$ indicates uncontrolled asthma ${ }^{4}$. Because the C-ACT consists of questions answered by the child and by the parent, this instrument offers the possibility to compare patient's and parents perception on asthma control measured at the same time.

Earlier studies have shown that parents tend to underreport asthma symptoms of their child and that children may adapt their activity level to their asthma symptoms ${ }^{5,6}$. We hypothesized that parents would underestimate their children's asthma control, and compared C-ACT subscores of children and parents.

\section{Methods}

We included children between 4 and 11 years of age with a doctor's diagnosis of asthma, who visited KinderHaven, our outpatient asthma clinic (Rotterdam, the Netherlands) between January and December 2011. All children and parents completed the C-ACT as part of routine patient care. The child completed the first 4 questions under supervision of the parent, and then one of the parents completed the remaining questions and calculated the total score before visiting the doctor or nurse. For this study formal medical ethical permission was not required according to the Medical Ethical Committee of Erasmus Medical Center, Rotterdam, The Netherlands.

To compare asthma control scores between children and parents, Spearman's correlations and the Intraclass Correlation Coefficient (ICC) were calculated. Scores of the children and the parents were expressed as percentage of the maximum, and pairwise compared 
using the Wilcoxon Signed Ranks Test. To test the effect of age, mean differences per age category were compared using ANOVA. Data were analyzed using SPSS (version 17.0; SPSS Inc., Chicago, IL, USA) and a p-value $<5 \%$ was considered statistically significant.

\section{Results}

283 children (mean age 7.7 years (range 4-12), 66.8\% boys) and their parents completed a C-ACT; 272 C-ACT's were filled in correctly by both child and parent. The median C-ACT score was 22 (interquartile range (IQR) 18-25).

Children scored median $75 \%$ of the maximal score (IQR $58-83 \%$ ), versus $87 \%$ for the parents (IQR 73-100\%). On average, children scored 8.3\% lower than their parents (95\% $\mathrm{Cl} 6.4-10.2, \mathrm{p}<0.001)$. The upper and lower $95 \%$ limits of agreement were $-40 \%$ and $+23 \%$, respectively. The differences between scores of the child and parent tended to be higher at lower mean scores. One question of the C-ACT is identical for child and parents, the question on nocturnal complaints. For this question children had a median score of $67 \%$ (IQR 67-100\%), compared to $100 \%$ for parents (IQR $80-100 \%, p<0.001$ ).

Spearman's correlation between C-ACT-scores of children and parents was $0.72(p<0.001)$ and the ICC was $0.77(p<0.001)$. The difference in scores between children and parents was independent of the child's age $(p=0.8)$.

\section{Discussion}

We showed that children reported significantly lower asthma control than their parents using the C-ACT. This confirms our hypothesis that parents underestimate the asthma symptoms of their children ${ }^{6-8}$. We speculate that the systematic difference between parents and children might be one of the factors responsible for under treatment of asthma in children ${ }^{7}$. Alternatively, it might also be possible that children overestimate their complaints, and the interpretation of the parent is more accurate. In the absence of any objective gold standard test of asthma control it is impossible to draw conclusions. In favour of a more accurate perception by the parents is that perception of children may be limited to a shorter recall time, as the common recall period for a child below the age of 8 years is only a few days ${ }^{9}$, whereas the C-ACT asks about the previous 4 weeks. Parents might be better able to recall symptoms for a longer period of time. However, we found that the difference between children and parents was independent of the child's age, and this argues against this mechanism.

Another reason for the discrepancy between children and parents might be that the questions to be answered by the parents were more quantitative (number of days with 
complaints) while the child questions were qualitative (how do you feel). In younger children, this may lead to more extreme scores as they will have more trouble in interpreting a neutral state ${ }^{4}$. Comparison between scores is hampered by the fact that most questions to the children and the parents were different. For the single identical question on nocturnal complaints we found children scoring significantly lower than their parents.

We conclude that there was a systematic difference in C-ACT scores by parents and children, with parents tending to under report or children to over report. We recommend considering the scores by parents and children separately when assessing asthma control. 


\section{References}

1. Global Initiative for Asthma. Global Strategy for Asthma Management and Prevention. Updated 2011. www. ginasthma.org.

2. Juniper EF, O'Byrne PM, Guyatt GH, Ferrie PJ, King DR. Development and validation of a questionnaire to measure asthma control. Eur Respir J 1999; 14(4): 902-7.

3. Schatz M, Sorkness CA, Li JT, et al. Asthma Control Test: reliability, validity, and responsiveness in patients not previously followed by asthma specialists. J Allergy Clin Immunol 2006; 117(3): 549-56.

4. Liu AH, Zeiger R, Sorkness $\mathrm{C}$, et al. Development and cross-sectional validation of the Childhood Asthma Control Test. J Allergy Clin Immunol 2007; 119(4): 817-25.

5. Lara M, Duan N, Sherbourne C, et al. Differences between child and parent reports of symptoms among Latino children with asthma. Pediatrics 1998; 102(6): E68.

6. Davis KJ, Disantostefano R, Peden DB. Is Johnny wheezing? Parent-child agreement in the Childhood Asthma in America survey. Pediatr Allergy Immunol 2011; 22(1 Pt 1): 31-5.

7. Carroll WD, Wildhaber J, Brand PL. Parent misperception of control in childhood/adolescent asthma: the Room to Breathe survey. Eur Respir J 2012; 39(1): 90-6.

8. Kieckhefer GM, Lentz MJ, Tsai SY, Ward TM. Parent-child agreement in report of nighttime respiratory symptoms and sleep disruptions and quality. J Pediatr Health Care 2009; 23(5): 315-26.

9. Eiser C, Morse R. A review of measures of quality of life for children with chronic illness. Arch Dis Child 2001; 84(3): 205-11. 


\title{
Chapter

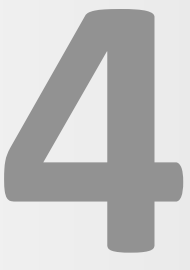

\section{Monitoring childhood asthma: web-based diaries and the asthma control test}

\begin{abstract}
Sandra Voorend-van Bergen MD ${ }^{1}$, Anja A. Vaessen-Verberne MD PhD², Anneke M. Landstra MD PhD ${ }^{3}$, Hein J. Brackel ${ }^{4}$, Norbert J. van den Berg MD", Daan Caudri MD PhD ${ }^{1}$, Johan C. de Jongste MD PhD ${ }^{1}$, Peter J Merkus MD PhD ${ }^{6}$, Mariëlle W Pijnenburg MD PhD ${ }^{1}$
\end{abstract}

${ }^{1}$ Dept of Pediatric Pulmonology, Erasmus University Medical Center Sophia Children's Hospital, Rotterdam, the Netherlands ${ }^{2}$ Dept of Pediatrics, Amphia Hospital, Breda, the Netherlands ${ }^{3}$ Dept of Pediatrics, Rijnstate Hospital, Arnhem, the Netherlands

${ }^{4}$ Dept of Pediatrics, Catharina Hospital, Eindhoven, the Netherlands ${ }^{5}$ Dept of Pediatrics, Flevo Hospital - De Kinderkliniek, Almere, the Netherlands ${ }^{6}$ Dept of Pediatric Pulmonology, Radboud University Nijmegen Medical Centre, Nijmegen, the Netherlands 


\section{Abstract}

\section{Background}

Data from asthma diaries are frequently used as an endpoint in asthma studies, however, data on the validity of web-based diaries are scarce.

\section{Objectives}

First, we examined the validity of a web-based diary in assessing asthma control. Second, we determined the cut-off points for well-controlled asthma of the Childhood Asthma Control Test (C-ACT) and the Asthma Control Test (ACT), and calculated the minimal important difference for both tests.

\section{Methods}

Asthmatic children 4-18 years $(n=228)$ completed a 4-week web-based diary, (C-)ACT and an asthma-related quality-of-life questionnaire at baseline and after 1 year follow up.

\section{Results}

Completion rate of the web-based diaries was $89 \%$. The diary scores correlated strongly with C-ACT and ACT scores ( $r=-0.73, p<0.01 ; r=-0.64, p<0.01$ respectively) and the changes in diary scores correlated well with changes in (C-)ACT scores. The best cut-off points for well-controlled asthma were C-ACT $\geq 22$ and ACT $\geq 23$. The minimal important differences were $1.9(95 \% \mathrm{Cl} 1.3-2.5)$ for $\mathrm{ACT}$ and $1.6(95 \% \mathrm{Cl} 1.1$ 2.1) for C-ACT and -0.7 points/ day $(95 \% \mathrm{Cl}-1.1-0.4)$ for the web-based diary.

\section{Conclusions}

Our web-based diary was valid for recording asthma symptoms. Cut-off points of $\geq 22$ (C-ACT) and $\geq 23$ (ACT) define well-controlled asthma. We recommend a 2 (C-)ACT points difference as minimally important. 


\section{Introduction}

Asthma affects approximately $5-8 \%$ of all school-aged children in the Western world ${ }^{1}$. The ultimate goal of asthma treatment is to achieve and maintain clinical control and reduce future risk; hence, measures of asthma control are important outcomes in clinical asthma trials ${ }^{2}$. Symptoms and symptom-free days as recorded in diaries are frequently used as endpoints that reflect control ${ }^{3,4}$. Symptom diaries are easy to use, cheap and symptoms are important for the patients and parents. However, recall bias is a problem with paperbased diaries, especially if these are not filled in on a daily basis ${ }^{5}$. This problem might be minimised by web-based diaries, which are easily accessible at any time. However, data on their feasibility and reliability are scarce. Other tools available for measuring asthma control are the asthma control test (ACT) and childhood asthma control test (C-ACT). Both these questionnaires were developed and validated for detection of uncontrolled asthma and are available for children from the ages of 12 (ACT) and 4 to 11 years (C-ACT) ${ }^{6-8}$. They are frequently used by patients and physicians, and although a cut-off of $<20$ has good sensitivity and enough specificity to detect uncontrolled asthma, only few studies have proposed a cut-off point for well-controlled asthma ${ }^{9-11}$. Also the minimal important difference in score for C-ACT and ACT, defined as the scores that reflect a clinically meaningful change for the patient, is currently lacking. We therefore studied the validity of a web-based diary in assessing asthma control in children, using C-ACT and ACT as gold standard. Second, we determined C-ACT and ACT cut-off points for 'well-controlled' asthma and calculated the minimal important difference (MID) in C-ACT, ACT and the diary scores with the Paediatric Asthma Quality of Life score as a gold standard.

\section{Materials and Methods}

This study is part of the multi-centre study 'Better Asthma Treatment: Monitoring with ACT and Nitric oxide' ('BATMAN'), a prospective, randomized controlled trial on new monitoring strategies in asthmatic children in the Netherlands with a follow up of 1 year (trial number NTR 1995). At baseline ( $\mathrm{t}=0$ ), parents and children completed a C-ACT or an ACT (if $\geq 12$ years) and fractional exhaled nitric oxide (FeNO) was measured (Figure 1).

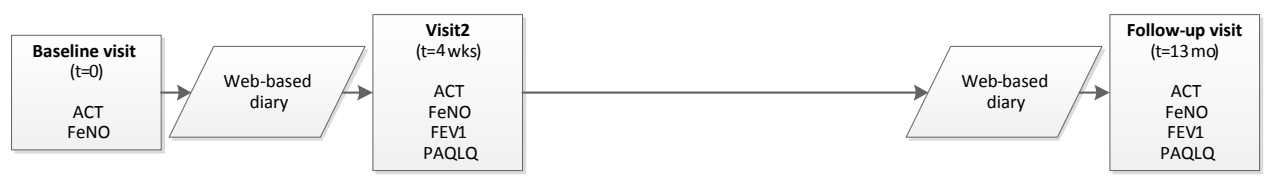

Figure 1 Study design. ACT: asthma control test; FeNO: fraction of exhaled nitric oxide; FEV1: forced expiratory volume in 1 second; PAQLQ: paediatric asthma quality of life questionnaire. 
Subsequently, patients and/or their parents filled in a daily web-based diary for 4 weeks (baseline diary). Participants who completed less than $50 \%$ of the diaries dropped out of the study, as we felt we did not have enough information on the primary endpoint (symptom free days). At visit 2 ( $t=4$ weeks), asthma control was assessed with the C-ACT or $A C T$; FeNO and forced expiratory volume in 1 second (FEV1) were measured and asthmarelated quality of life was assessed with the Paediatric Asthma Caregivers Quality of Life Questionnaire (PACQLQ) or Paediatric Asthma Quality of Life Questionnaire (PAQLQ, if $\geq 12$ years $)^{12,13}$. After one year follow up, all children filled in a second daily web-based diary for 4 weeks (follow up diary), and C-ACT/ACT, PACQLQ/PAQLQ, FEV1 and FeNO were repeated at the end of this 4-weeks period ( $\mathrm{t}=13$ months).

\section{Study population}

Children 4 to 18 years of age, with a doctor's diagnosis of atopic asthma based on clinical symptoms, and FEV1 bronchodilator response of $>9 \%$ of predicted and/or airway hyperresponsiveness and/or FeNO $>25 \mathrm{ppb}$, were recruited from 3 tertiary referral centers and 4 general hospitals. Patients had been using inhaled corticosteroids for at least 3 months before inclusion and had Internet access at home. Exclusion criteria were active smoking, pulmonary diseases other than asthma, recent ( $<1$ year) admission to an intensive care unit for asthma, inability to perform FeNO measurements, and the use of omalizumab. The Medical Ethics Committee of the Erasmus University Medical Center, Rotterdam, approved the study. All patients (if 12 years or older) and their parents gave written informed consent before entering the study.

\section{Web-based diaries}

The web-based diary recorded daytime and night-time symptoms (coughing, wheezing, shortness of breath), limitation in activity and use of reliever medication (Figure 2). The diary score for either night-time as well as daytime symptoms ranged from 0 (no symptoms) to 21 (severe symptoms), plus the number of occasions when reliever medication was used. Diaries were sent out twice daily (5:00 am and 3:30 pm), were automatically date and time stamped, and participants received a reminder by email once daily. Data entry was possible at the latest 5 days later. The web-based diary is a web-version of an existing paper diary based on GINA criteria4.

To correct for different completion rates, the diary scores were divided by the number of completed days ('corrected diary score'). For assessing the validity of the web-based diaries and determination of the GINA levels that were used for the calculation of cut-off values, only patients who completed at least $75 \%$ of the diaries were selected. 


\begin{tabular}{|c|c|c|c|c|}
\hline \\
\hline Coughing: & $\begin{array}{l}\text { None } \\
\text { (0) }\end{array}$ & $\begin{array}{l}\text { One episode } \\
\text { (1) }\end{array}$ & $\begin{array}{l}\text { Two or more episodes } \\
\text { (2) }\end{array}$ & $\begin{array}{l}\text { Coughing during the } \\
\text { whole night } \\
\text { (3) }\end{array}$ \\
\hline Wheezing: & $\begin{array}{l}\text { None } \\
\text { (0) }\end{array}$ & $\begin{array}{l}\text { One episode } \\
\text { (1) }\end{array}$ & $\begin{array}{l}\text { Two or more wheezing } \\
\text { episodes } \\
\text { (2) }\end{array}$ & $\begin{array}{l}\text { Wheezing during the } \\
\text { whole night } \\
\text { (3) }\end{array}$ \\
\hline Shortness of breath: & $\begin{array}{l}\text { None } \\
\text { (0) }\end{array}$ & $\begin{array}{l}\text { One episode } \\
\text { (1) }\end{array}$ & $\begin{array}{l}\text { Two or more episodes } \\
\text { (2) }\end{array}$ & $\begin{array}{l}\text { Shortness of breath } \\
\text { during the whole night } \\
\text { (3) }\end{array}$ \\
\hline \multicolumn{2}{|c|}{ Use of reliever medication: } & \multicolumn{3}{|c|}{........ times } \\
\hline \multicolumn{5}{|l|}{ b } \\
\hline Coughing: & $\begin{array}{l}\text { None } \\
\text { (0) }\end{array}$ & $\begin{array}{l}\text { One episode } \\
\text { (1) }\end{array}$ & $\begin{array}{l}\text { Two or more episodes } \\
\text { (2) }\end{array}$ & $\begin{array}{l}\text { Coughing during the } \\
\text { whole day } \\
\text { (3) }\end{array}$ \\
\hline Wheezing: & $\begin{array}{l}\text { None } \\
\text { (0) }\end{array}$ & $\begin{array}{l}\text { One episode } \\
\text { (1) }\end{array}$ & $\begin{array}{l}\text { Two or more wheezing } \\
\text { episodes } \\
\text { (2) }\end{array}$ & $\begin{array}{l}\text { Wheezing during the } \\
\text { whole day } \\
\text { (3) }\end{array}$ \\
\hline Shortness of breath: & $\begin{array}{l}\text { None } \\
\text { (0) }\end{array}$ & $\begin{array}{l}\text { One episode } \\
\text { (1) }\end{array}$ & $\begin{array}{l}\text { Two or more episodes } \\
\text { (2) }\end{array}$ & $\begin{array}{l}\text { Shortness of breath } \\
\text { during the whole day } \\
\text { (3) }\end{array}$ \\
\hline Limitation of activity: & $\begin{array}{l}\text { No limitation } \\
\text { (0) }\end{array}$ & $\begin{array}{l}\text { Little complains, } \\
\text { no limitation of } \\
\text { activities } \\
\text { (1) }\end{array}$ & $\begin{array}{l}\text { Some limitation of } \\
\text { activities } \\
\text { (2) }\end{array}$ & $\begin{array}{l}\text { Much limitation of } \\
\text { activities } \\
\text { (3) }\end{array}$ \\
\hline \multicolumn{5}{|c|}{ Use of reliever medication: $\quad$........ times } \\
\hline
\end{tabular}

Figure 2 Web-based diaries. a) Morning diaries to register night-time symptoms; b) Evening diaries to register daytime symptoms.

\section{(Childhood) Asthma Control}

The Asthma Control Test (ACT) was used to assess asthma control in children from the age of $12^{8}$. This patient-completed questionnaire consists of 5 questions on shortness of breath, awakenings at night, limitation of activity, rescue use of inhaled bronchodilators, and patient rating of asthma control, over the past 4 weeks. Total score ranges between 5 and 25 with a score of less than 20 corresponding to uncontrolled asthma ${ }^{8,14,15}$. In this study we used the Dutch, validated version of the ACT. In children aged 4 to 11 years, the translated Childhood Asthma Control Test was used (C-ACT) ${ }^{7}$. The C-ACT is a sevenitem questionnaire that also addresses the previous 4 weeks and is divided into two parts. The first part is filled in by the child with the aid of a visual scale and consists of 4 questions on perception of asthma control, limitations of activities, coughing and nocturnal awakenings. The second part is filled in by a parent or caregiver and consists of 3 questions on daytime complaints, daytime wheezing and awakenings at night. The C-ACT score may range from 0 (poorest asthma control) to 27 (optimal asthma control). A score of $\leq 19$ indicates uncontrolled asthma ${ }^{7}$. 


\section{Lung function and FeNO}

FeNO was measured online (NIOX NO-analyzer or NIOX MINO, Aerocrine, Stockholm, Sweden) with an expiratory flow of $50 \mathrm{~mL} / \mathrm{s}^{16}$. Spirometry was performed using a MasterScreen electronic spirometer (Jaeger/Carefusion, Würzburg, Germany). FEV1 was recorded and expressed as percentage predicted.

\section{Pediatric Asthma Quality of Life}

In children 12 years and older, asthma-related quality of life was measured with the 23-item self-reported Dutch validated version of the PAQLQ for children ${ }^{13,17}$. This questionnaire consists of domains related to emotions, activity, and symptoms, which are all equally weighted. Results were expressed as overall asthma-related quality of life. In children under the age of 12 years, asthma-related quality of life was measured using the PACQLQ, which measures how caregivers are limited in their own quality of life by their child's asthma ${ }^{12,17}$. In both tests the maximal score is 7 , which indicates optimal quality of life.

\section{Defining asthma control}

Based on the diary data, patients were categorized as having either well-controlled, partly controlled or uncontrolled asthma, according to GINA guidelines including FEV $1^{1}$. In this survey, the definition of partly controlled was adapted from 'any measure present in any week' to 'any measure present per week' in the previous 4 weeks. The features 'daytime symptoms' and 'need for rescue treatment' were scored as present if patients recorded these for more than 2 days a week ${ }^{11}$. After 4 weeks, an overall GINA asthma control level was determined, being the mean score of control status of all weeks. Three completed weeks were considered the minimum in the final assessment of GINA asthma control level ( $75 \%$ of the diaries).

\section{Statistical Analysis}

To validate the web-based diary, symptom scores from diaries were correlated with C-ACT or ACT scores. Both cross-sectional and longitudinal construct validity were evaluated by comparing associations (Pearson correlation coefficient) between C-ACT or ACT and the web-based diary data. Responsiveness (sensitivity of change) of the web-based diary was evaluated by comparing changes in the score between baseline and after one year follow-up with changes in the C-ACT and ACT score over the same period. Sensitivity, specificity, positive and negative predictive values for well-controlled asthma as defined by GINA criteria were calculated for different cut-off points of C-ACT and ACT. The highest Youden index (sensitivity-[1-specificity]) was considered the optimal cut-off ${ }^{18}$. The MID for the C-ACT, ACT and symptom scores from the diary were calculated using the PAQCLQ 
or PAQLQ score. In a linear regression model, we calculated the change in C-ACT, ACT and symptom scores that corresponded to a change in PACQLQ or PAQLQ score of 0.5 , which has been considered as a clinically significant and relevant change ${ }^{19,20}$. Data were analyzed using SPSS version 20.0. All statistical tests used were two-tailed. The level of significance was set at $5 \%$.

\section{Results}

Two hundred twenty-eight patients (67\% male) participated; their mean age was 10.5 years (SD 3.0). Baseline characteristics are shown in Table 1. Seven patients dropped out, because they did not complete $50 \%$ of all diaries or they did not show up at their second visit.

Table 1 Baseline characteristics of the patients

\begin{tabular}{|c|c|c|}
\hline & $\begin{array}{l}\text { Age group 4-11 yrs } \\
(n=151)\end{array}$ & $\begin{array}{l}\text { Age group } 12-18 \text { yrs } \\
(n=77)\end{array}$ \\
\hline Age $(y r s)^{a}$ & $8.7(1.8)$ & $13.8(1.6)$ \\
\hline Gender (male) ${ }^{b}$ & $106(70 \%)$ & $43(56 \%)$ \\
\hline Duration of asthma (yrs) ${ }^{a}$ & $4.5(2.8)$ & $8.3(3.9)$ \\
\hline $\begin{array}{l}\text { Daily dose of inhaled corticosteroids }{ }^{b} \\
\leq 400 \text { ug budesonide or equivalent } \\
>400 \text { ug budesonide or equivalent }\end{array}$ & $\begin{array}{l}116(77 \%) \\
35(23 \%)\end{array}$ & $\begin{array}{l}42(55 \%) \\
34(45 \%)\end{array}$ \\
\hline Use of long-acting beta-2-agonists ${ }^{b}$ & $57(38 \%)$ & $54(70 \%)$ \\
\hline Use of leukotriene receptor antagonist ${ }^{\text {b }}$ & $12(8 \%)$ & $15(20 \%)$ \\
\hline Self-reported medication adherence ${ }^{c, *}$ & $7.0(6.0-7.0)$ & $7.0(6.0-7.0)$ \\
\hline C-ACT or ACT score ${ }^{c}$ & $22.0(19.0-24.0)$ & $22.0(20.0-23.0)$ \\
\hline FeNO $(p p b)^{d}$ & $15.9(2.2)$ & $19.9(2.2)$ \\
\hline FEV1 (\%predicted) $)^{\mathrm{a}, \#}$ & $97(14)$ & $96(15)$ \\
\hline
\end{tabular}

Data are shown as a) mean (standard deviation); b) absolute numbers (\%); c) median (interquartile range); d) geometric mean (standard deviation). * Range: 1-7 days/wk; \# measured after baseline diary.

\section{Validation of web diaries}

Patients reported more symptoms in the baseline diary than in the follow up diary 1 year later; median (IQR) corrected diary scores were $1.1(0.3-3.1)(<12$ years, $n=127)$ and $1.4(0.5-2.7)(\geq 12$ years, $n=67)$ versus $1.0(0.3-3.0)(<12$ years, $n=93)$ and $0.8(0.3-3.3)$ ( $\geq 12$ years, $n=53$ ) in the follow-up period. The median (IQR) C-ACT and ACT scores at the end of the baseline period were $22(19-25 ; n=146)$ and $22(19-23 ; n=75)$, respectively. After completion of the follow up diary, the median (IQR) C-ACT score was 23 (20-25; 
$\mathrm{n}=114)$ and the median C-ACT score was $23(20-24, \mathrm{n}=66)$. There was a strong correlation between ACT and C-ACT scores and the diary scores of both baseline diary and follow up diary (Table 2). One hundred thirty four children completed both ACTs and at least 21 diary days in both periods. There was a good correlation between the change in diary score and the change in C-ACT $(r=-0.48, p<0.01)$ and ACT score $(r=-0.69, P<0.01)$ (Table 2).

Table 2 Diary scores, C-ACT and ACT-scores, and correlations

\begin{tabular}{|c|c|c|c|c|c|c|c|c|}
\hline & $\begin{array}{c}\text { Diary score, } \\
<12 \text { yrs } \\
\text { (median, } \\
\text { IQR) }\end{array}$ & $\begin{array}{c}\text { C-ACT } \\
\text { (median, } \\
\text { IQR) }\end{array}$ & $\begin{array}{c}\text { Correlation } \\
\text { diary- } \\
\text { C-ACT, r* }\end{array}$ & $p$-value & $\begin{array}{c}\text { Diary score, } \\
\geq 12 \text { yrs } \\
\text { (median, } \\
\text { IQR) }\end{array}$ & $\begin{array}{c}\text { ACT } \\
\text { (median, } \\
\text { IQR) }\end{array}$ & $\begin{array}{c}\text { Correlation } \\
\text { diary-ACT, } \\
r^{*}\end{array}$ & $p$-value \\
\hline \multicolumn{9}{|c|}{ Cross-sectional } \\
\hline Baseline & $\begin{array}{c}1.1 \\
(0.3-3.1)\end{array}$ & $\begin{array}{c}22 \\
(19-25)\end{array}$ & $-0.64^{a}$ & $<0.001$ & $\begin{array}{c}1.4 \\
(0.5-2.7)\end{array}$ & $\begin{array}{c}22 \\
(19-23)\end{array}$ & $-0.72^{c}$ & $<0.001$ \\
\hline Follow up & $\begin{array}{c}1.0 \\
(0.3-3.0)\end{array}$ & $\begin{array}{c}23 \\
(20-25)\end{array}$ & $-0.70^{b}$ & $<0.001$ & $\begin{array}{c}0.8 \\
(0.3-3.3)\end{array}$ & $\begin{array}{c}23 \\
(20-24)\end{array}$ & $-0.58^{d}$ & $<0.001$ \\
\hline \multicolumn{9}{|c|}{ Longitudinal (baseline-follow up) } \\
\hline Change\# & $-0.2(2.2)$ & $0.5(4.0)$ & $-0.48^{e}$ & $<0.001$ & $-0.3(2.0)$ & $0.6(3.8)$ & $-0.69^{f}$ & $<0.001$ \\
\hline
\end{tabular}

C-ACT=Childhood Asthma Control test; ACT=Asthma Control Test; $a: n=131 ; b: n=124 ; c: n=67 ; d: n=68 ; e: n=117$; $\mathrm{f}: \mathrm{n}=60$; * Pearson correlation coefficient. \# mean (standard deviation).

\section{C-ACT and ACT cut-off point for well-controlled asthma}

According to the GINA criteria, after the baseline period $20 \%(n=39)$ of patients were classified as well-controlled, $40 \%(n=78)$ as partly controlled and $40 \%(n=77)$ as uncontrolled $^{1}$. Children with well-controlled asthma had a median C-ACT of 25.0 (23.026.0) and a median ACT score of 24.0 (23.0-25.0)(Table 3). GINA levels of control were used to determine a cut-off point for well-controlled asthma. The best C-ACT cut-off score for well-controlled asthma was $\geq 22$ (AUC 0.81). When using the ACT, the best cut-off score for well-controlled asthma was $\geq 23$ (AUC 0.91). ROC curves are shown in Figure 3.

\section{FeNO and lung function}

At baseline, geometric mean FeNO was $18.0 \mathrm{ppb}$ in children with controlled asthma, $19.7 \mathrm{ppb}$ in children with partly controlled asthma and $17.8 \mathrm{ppb}$ in uncontrolled children $(p=0.61)$. There was no significant correlation between FeNO and C-ACT $(p=0.78)$ or ACT $(p=0.37)$. FEV1 values per GINA level were $97 \%$ for controlled asthma, $96 \%$ for partly controlled asthma and $98 \%$ for uncontrolled asthma $(p=0.71)$. Again, there was no significant correlation with C-ACT $(p=0.72)$ or ACT $(p=0.43)$ and FEV1.

After one year follow up, geometric mean FeNO was significant higher for all GINA levels (all p<0.02); $27.3 \mathrm{ppb}$ for controlled asthma, $26.9 \mathrm{ppb}$ for partly controlled asthma and $23.0 \mathrm{ppb}$ for uncontrolled asthma. There was no significant difference between the GINA 
levels ( $p=0.42$ ). FEV1 values at follow up were $99 \%$ for controlled asthma, $97 \%$ for partly controlled asthma and $95 \%$ for uncontrolled asthma $(p=0.40)$.

We also assessed the predictive value of FeNO to predict well-controlled asthma, which was poor (AUC 0.55; data not shown).

Table 3 ACT-, C-ACT- and PAQL-scores in well-controlled, partly controlled and uncontrolled asthmatic children according to GINA criteria, based on the baseline diary data.

\begin{tabular}{|c|c|c|c|c|}
\hline & $\begin{array}{l}\text { Well-controlled a } \\
n=40(20 \%)\end{array}$ & $\begin{array}{l}\text { Partly controlled } \\
n=81(41 \%)\end{array}$ & $\begin{array}{l}\text { Uncontrolled }^{c} \\
n=76(39 \%)\end{array}$ & p-value ${ }^{d}$ \\
\hline C-ACT & $25.0(23.0-26.0)$ & $24.0(20.0-25.0)$ & $19.0(17.0-21.0)$ & $<0.001$ \\
\hline ACT & $24.0(23.0-25.0)$ & $22.0(21.0-23.0)$ & $19.0(16.5-21.5)$ & $<0.001$ \\
\hline FeNO\# & $18.0(2.0)$ & $19.7(2.4)$ & 17.8 (1.9) & 0.61 \\
\hline FEV1\%pred* & $97(10)$ & $96(14)$ & $98(17)$ & 0.71 \\
\hline SFD (\%)* & $92(9)$ & $69(23)$ & 23 (19) & $<0.001$ \\
\hline Symptom score* & $0.12(0.15)$ & $0.60(0.57)$ & $2.39(1.14)$ & $<0.001$ \\
\hline PACQLQ & $6.8(6.5-7.0)$ & $6.7(6.1-7.0)$ & $6.0(5.6-6.5)$ & $<0.001$ \\
\hline PAQLQ & $6.8(6.6-7.0)$ & $6.5(6.0-6.7)$ & $5.9(5.4-6.1)$ & $<0.001$ \\
\hline
\end{tabular}

Data are expressed as median (interquartile range); \# geometric mean (standard deviation); ${ }^{*}$ mean (standard deviation). C-ACT: childhood asthma control test; ACT= asthma control test; $\mathrm{FeNO}=$ fraction of exhaled nitric oxide; $\mathrm{SFD}=$ symptom free days; $\mathrm{PACQLQ}=$ paediatric asthma-related caregivers quality of life questionnaire; PAQLQ = paediatric asthma-related quality of life questionnaire. a: age $<12$ yrs $n=31$; age $\geq 12$ yrs $n=9$; $b$ : age $<12$ yrs $n=52$; age $\geq 12$ yrs $n=29$; c: age $<12$ yrs $n=47$; age $\geq 12$ yrs $n=29$; $d$ : Kruskal-Wallis Test.

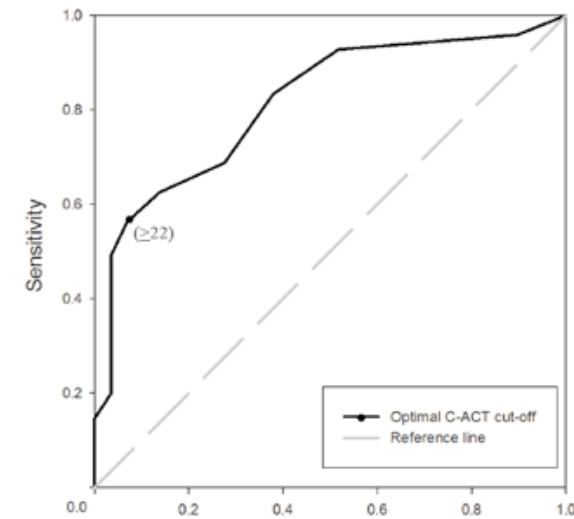

a.

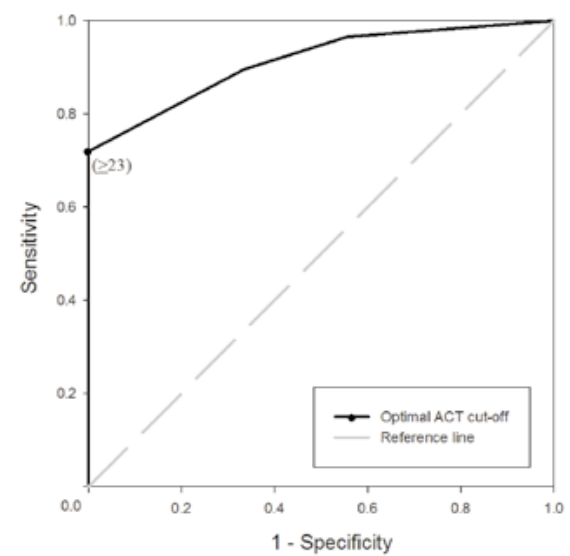

b.

Figure 3 Receiver operating characteristic (ROC) curves for a) C- ACT and b) ACT.

Area under the ROC curve (AUC) 0.81(C-ACT) and 0.91(ACT) respectively. The best C-ACT cut-off score for wellcontrolled asthma was $\geq 22$ (sensitivity $93.1 \%$; specificity $56.3 \%$ ). The best ACT cut-off score for well-controlled asthma was $\geq 23$ (sensitivity $100 \%$; specificity $71.9 \%$ ). 


\section{Asthma control and quality of life}

At baseline, children under the age of 12 years had a median asthma-related caregiver quality of life score (PACQLQ-score) of 6.5 (IQR 5.9-6.9, n=138). Adolescents with asthma reported lower asthma-related quality of life (PAQLQ), with median PAQLQ-scores of 6.2 (IQR 5.9-6.6, n=78). Children with well-controlled asthma had PACQLQ and PAQLQ scores that were significantly higher than those in children with partly controlled or uncontrolled asthma (both $p<0.001$ ) (Table 3). Quality of life scores and C-ACT or ACT were strongly correlated in children $\geq 12$ year $(r=0.81, p<0.001)$, whereas the correlation was moderate in children $<12$ years $(r=0.48, p<0.001)$. Also the changes in ACT or C-ACT scores correlated strongly with the change in PAQLQ score $(r=0.64, p<0.001)$ and PACQLQ score $(r=0.52, p<0.001)$.

\section{Minimal import differences}

The MID corresponding to a clinically relevant change of 0.5 in PAQLQ or PACQLQ score ${ }^{19}$, ${ }^{20}$ was 1.9 (95\% Cl 1.3-2.5) for the ACT and $1.6(95 \% \mathrm{Cl} 1.1-2.1)$ for the C-ACT. The MID for the web-based diary, also corresponding to a change of 0.5 PAQLQ or PACQLQ points, was -0.7 points $(95 \% \mathrm{Cl}-1.1--0.4)$.

\section{Adherence to web-based diary}

Of the baseline diary, $89.2 \%$ of the morning entries, were completed after a median of 16 hours (Interquartile range, IQR, 11-39). Similarly, the evening entries were filled in after a median of 18 hours (IQR 4-40), with a completion rate of $88.5 \%$. During the 4 -week baseline diary period, adherence to filling in diary cards remained stable $(88.4 \%$ in week 1 and $89.6 \%$ after 4 weeks). Fifty-four percent $(n=124)$ of the children filled in all diaries twice daily, and $85 \%(n=194)$ at least 21 days. Hundred ninety-nine patients $(87 \%)$ filled in the follow up diary after 1 year. In this 4 -week diary period, $88.3 \%$ of the morning entries were completed after a median of 28 hours (IQR 12-53), and $87.3 \%$ of the evening entries after a median of 24 hours (IQR 5-49). Here, 160 children (80\%) completed at least 21 diary days.

\section{Discussion}

In this study, we established the feasibility and validity of a web-based asthma diary to monitor asthma control in children. The correlation between diary scores and C-ACT and ACT was high, and the web-based diaries were able to detect changes in asthma control. We determined the optimal cut-off for defining well-controlled asthma and the clinically relevant changes in C-ACT score, ACT score and diary score. 
Evaluation of symptoms should be a core asthma outcome measure in clinical research, as was stated by the National Institutes of Health. In this report, the importance of validation studies and comparison of diaries versus retrospective questionnaires was recommended ${ }^{21}$. Indeed, in this study we show that a web-based diary was valid to assess symptoms and asthma control over a wide paediatric age range, and correlated well with the C-ACT or ACT, which are retrospective questionnaires, and determined the minimal important difference. The web-based diary was highly feasible in assessing asthma control in children aged 4-18 years. The completion rate was high, and did not decrease over 4 weeks. The high completion rates were in line with earlier studies that used web-based diaries. Moloney et al. used internet-based diaries to register headache symptoms in adults and they showed that in their population $75 \%$ diaries were completed within two days $^{22}$. Also $87 \%$ of the patients would have been willing to continue the diary for another 2 months. Sorbi et al. registered migraine symptoms using a web-based diary ${ }^{23}$. They reported a completion rate of $87 \%$. One earlier study used a web-based diary to record asthma symptoms in children and a completion rate of $80 \%$ was found, which is in line with our data ${ }^{11}$.

Paper-based diaries carry the risk of recall bias, errors, falsification and omissions ${ }^{5,24}$. These risks may be reduced if electronic diaries are used ${ }^{24-26}$. Recently, Ireland and colleagues have shown that an electronic diary is more reliable than a paper diary ${ }^{27}$. Although we did not compare web-based diaries with paper-based diaries, we confirm the high accuracy of web-based diaries in daily symptom recording. Also we found a good correlation between the diary data, C-ACT and ACT scores, and Paediatric Asthma Quality of Life scores. This is in line with earlier studies by Juniper et al., who showed strong correlations between diary data, the Asthma Control Questionnaire (ACQ), and Paediatric Asthma Quality of Life scores ${ }^{19,28}$.

Why did we use a 4-week diary to assess asthma control? In asthma studies symptom scores and symptom free days or asthma days are frequently used as a primary endpoint $^{29}$. Therefore, we wanted to assess the validity of diaries as we used in this study, in comparison with other measures of asthma control which are frequently used in daily practice like the C-ACT and ACT. We found that asthma diaries are valid for use in studies, although we realize that in daily practice simple questionnaires or GINA criteria are much more feasible and more easy to use.

In the same way, Okupa et al recently concluded that daily diaries might be more sensitive than the ACT for assessing differential treatment responses with respect to asthma control ${ }^{30}$.

For analyzing the diary data we only used data from patients who completed at least 21 diary days of the 28. It could be argued that the correlation between C-ACT or ACT and symptom scores might have been even better in children who filled in their diaries every 
day, as these may have been better aware of their symptoms. On the other hand, this might introduce a bias towards children with good symptom perception. However, there was no difference in corrected symptom scores, C-ACT and ACT scores, and PAQLQ scores between the children who did fill at least 21 out of 28 days and the children who filled in less days. Hence, there does not seem to be an important bias as a result of including those with only 21 days recording.

We determined C-ACT and ACT cut-off points for well-controlled asthma, and the MID of both tests based on the quality of life information of these children. The C-ACT and ACT were initially developed to detect uncontrolled asthma, and earlier studies showed that the cut-off points for uncontrolled asthma for both C-ACT and ACT were $\leq 19$ with $68 \%-71 \%$ sensitivity, and $71 \%-76 \%$ specificity 7,8 . However, a C-ACT or ACT score $\geq 20$ does not necessarily indicate well-controlled asthma ${ }^{30}$. The primary goal of clinical asthma management is to achieve control, but until now little attention has been paid to cut-off points for well-controlled asthma. Ito et al. recommend a higher C-ACT cut-off score of 23 for well-controlled asthma, taking lung function into account ${ }^{10}$. We found an optimal ACT cut-off point of $\geq 23$ and a C-ACT cut-off point of $\geq 22$ for well-controlled asthma. We propose to use these higher cut-off scores to accurately assess if a patient has wellcontrolled asthma.

For the Asthma Control Questionnaire (ACQ), Juniper et al. calculated a MID based on minimal important changes in asthma-related quality of life ${ }^{19}$. We followed a similar approach for ACT and C-ACT and the web-based diary score. To our knowledge, we are the first who determined minimal important differences in children. Schatz et al. recommend a MID of 3 points in ACT score in adults, which is based on distribution-based and anchorbased analyses instead of changes in quality of life ${ }^{31}$. These different analyses may be an explanation for the difference between the MID of 2 in our study and 3 in the study by Schatz et al. Second, we included adolescents rather than adults, and MID might differ for these 2 age groups.

A limitation of this study is the lack of a gold standard for asthma control. We used the C-ACT and ACT scores as reference tests to assess validity of the web-based diaries. The C-ACT and ACT are well-validated questionnaires to assess asthma control over a wide age range $\mathrm{e}^{7,8,14}$ and we and others found that they correlated well with GINA criteria of asthma control $^{11,30}$. In our opinion, the C-ACT and ACT were the best available standards of asthma control for our purpose. The same is true for establishing MIDs. In the absence of a gold standard for MIDs, we decided to use quality of life scores to define MIDs. Quality of life is an important and clinically relevant patient centered outcome. We did not choose to determine MID on objective parameters as FEV1 or FeNO. First, in the majority of children with asthma FEV1 is normal and clinically important differences of C-ACT or ACT based on changes in FEV1 may not be easy to establish. Second, FeNO was not considered an 
appropriate measure for determining MID as, despite the large amount of literature on FENO, the role of FENO in monitoring asthma control is not evident. Similar to earlier studies, we found no correlation between asthma control scores and FEV1 or FeNO ${ }^{32-34}$. Also, in our study FeNO could not predict well-controlled asthma and changes in FeNO were not correlated with the level of asthma control. Symptoms, lung function and airway inflammation represent different domains of the asthma phenotype, and show limited agreement. Presently, the role of FeNO in monitoring of children with asthma seems limited $^{29,35}$.

We believe that the widespread use of user-friendly electronic devices like tablets and smart phones will increasingly facilitate the use of web-based diaries in asthma research and clinical practise. Children and adolescents in particular are an attractive population for web-based studies as they are very active on the Internet with $75 \%$ of all European children of $6-17$ years using the Internet, and even $86 \%$ of the $15-17$ year olds, while in some countries like the Netherlands even $100 \%$ of all children of $15-17$ years use the internet ${ }^{36}$. Indeed, randomised controlled paediatric trials on internet-based asthma monitoring have already been published, with mostly promising results ${ }^{37,}{ }^{38}$. However, potential difficulties with web-based monitoring in less literate or technologically sophisticated populations warrant further research in these populations.

We conclude that our web-based diary was feasible and valid in recording symptoms in children with asthma; hence we recommend its use in clinical intervention studies. We established the C-ACT and ACT cut-offs for well-controlled asthma in children, and found a minimal important difference to be 2 C-ACT or ACT points. 


\section{References}

1. Bateman ED, Hurd SS, Barnes PJ, et al. Global strategy for asthma management and prevention: GINA executive summary. Eur Respir J 2008; 31(1): 143-78.

2. GINA. Global Strategy for Asthma Management and Prevention: Global Initiative for Asthma (GINA), 2011.

3. Pijnenburg MW, Bakker EM, Hop WC, De Jongste JC. Titrating steroids on exhaled nitric oxide in children with asthma: a randomized controlled trial. Am J Respir Crit Care Med 2005; 172(7): 831-6.

4. Vaessen-Verberne AA, van den Berg NJ, van Nierop JC, et al. Combination therapy salmeterol/fluticasone versus doubling dose of fluticasone in children with asthma. Am J Respir Crit Care Med 2010; 182(10): 12217.

5. Burton C, Weller D, Sharpe M. Are electronic diaries useful for symptoms research? A systematic review. $J$ Psychosom Res 2007; 62(5): 553-61.

6. Juniper EF, O’Byrne PM, Guyatt GH, Ferrie PJ, King DR. Development and validation of a questionnaire to measure asthma control. Eur Respir J 1999; 14(4): 902-7.

7. Liu AH, Zeiger R, Sorkness $\mathrm{C}$, et al. Development and cross-sectional validation of the Childhood Asthma Control Test. J Allergy Clin Immunol 2007; 119(4): 817-25.

8. Nathan RA, Sorkness CA, Kosinski M, et al. Development of the asthma control test: a survey for assessing asthma control. J Allergy Clin Immunol 2004; 113(1): 59-65.

9. Alvarez-Gutierrez FJ, Medina-Gallardo JF, Perez-Navarro P, et al. [Comparison of the Asthma Control Test (ACT) with lung function, levels of exhaled nitric oxide and control according to the Global Initiative for Asthma (GINA)] Relacion del test de control del asma (ACT) con la funcion pulmonar, niveles de oxido nitrico exhalado y grados de control segun la Iniciativa Global para el Asma (GINA). Arch Bronconeumol 2010; 46(7): 370-7.

10. Ito $\mathrm{Y}$, Adachi $\mathrm{Y}$, Itazawa $\mathrm{T}$, et al. Association between the results of the childhood asthma control test and objective parameters in asthmatic children. J Asthma 2011; 48(10): 1076-80.

11. Koolen BB, Pijnenburg MW, Brackel HJ, et al. Comparing Global Initiative for Asthma (GINA) criteria with the Childhood Asthma Control Test (C-ACT) and Asthma Control Test (ACT). Eur Respir J 2011; 38(3): 561-6.

12. Juniper EF, Guyatt GH, Feeny DH, Ferrie PJ, Griffith LE, Townsend M. Measuring quality of life in the parents of children with asthma. Qual Life Res 1996; 5(1): 27-34.

13. Raat H, Bueving HJ, de Jongste JC, Grol MH, Juniper EF, van der Wouden JC. Responsiveness, longitudinaland cross-sectional construct validity of the Pediatric Asthma Quality of Life Questionnaire (PAQLQ) in Dutch children with asthma. Qual Life Res 2005; 14(1): 265-72.

14. Schatz M, Mosen DM, Kosinski M, et al. Validity of the Asthma Control Test completed at home. Am J Manag Care 2007; 13(12): 661-7.

15. Schatz M, Sorkness CA, Li JT, et al. Asthma Control Test: reliability, validity, and responsiveness in patients not previously followed by asthma specialists. J Allergy Clin Immunol 2006; 117(3): 549-56.

16. American Thoracic S, European Respiratory S. ATS/ERS recommendations for standardized procedures for the online and offline measurement of exhaled lower respiratory nitric oxide and nasal nitric oxide, 2005 Am J Respir Crit Care Med 2005; 171(8): 912-30.

17. Juniper EF, Guyatt GH, Feeny DH, Ferrie PJ, Griffith LE, Townsend M. Measuring quality of life in children with asthma. Qual Life Res 1996; 5(1): 35-46.

18. Youden WJ. Index for rating diagnostic tests. Cancer 1950; 3(1): 32-5.

19. Juniper EF, Gruffydd-Jones K, Ward S, Svensson K. Asthma Control Questionnaire in children: validation, measurement properties, interpretation. Eur Respir J 2010; 36(6): 1410-6.

20. Juniper EF, Guyatt GH, Willan A, Griffith LE. Determining a minimal important change in a disease-specific Quality of Life Questionnaire. J Clin Epidemiol 1994; 47(1): 81-7.

21. Krishnan JA, Lemanske RF, Jr., Canino GJ, et al. Asthma outcomes: symptoms. J Allergy Clin Immunol 2012; 129(3 Suppl): S124-35.

22. Moloney MF, Aycock DM, Cotsonis GA, Myerburg S, Farino C, Lentz M. An Internet-based migraine headache diary: issues in Internet-based research. Headache 2009; 49(5): 673-86. 
23. Sorbi MJ, Mak SB, Houtveen JH, Kleiboer AM, van Doornen LJ. Mobile Web-based monitoring and coaching: feasibility in chronic migraine. J Med Internet Res 2007; 9(5): e38.

24. Hyland ME, Kenyon CA, Allen R, Howarth P. Diary keeping in asthma: comparison of written and electronic methods. BMJ 1993; 306(6876): 487-9.

25. Lam J, Barr RG, Catherine N, et al. Electronic and paper diary recording of infant and caregiver behaviors. $J$ Dev Behav Pediatr 2010; 31(9): 685-93.

26. Palermo TM, Valenzuela D, Stork PP. A randomized trial of electronic versus paper pain diaries in children: impact on compliance, accuracy, and acceptability. Pain 2004; 107(3): 213-9.

27. Ireland AM, Wiklund I, Hsieh R, Dale P, O'Rourke E. An electronic diary is shown to be more reliable than a paper diary: results from a randomized crossover study in patients with persistent asthma. J Asthma 2012; 49(9): 952-60.

28. Juniper EF, Svensson K, Mork AC, Stahl E. Measurement properties and interpretation of three shortened versions of the asthma control questionnaire. Respir Med 2005; 99(5): 553-8.

29. Reddel HK, Taylor DR, Bateman ED, et al. An official American Thoracic Society/European Respiratory Society statement: asthma control and exacerbations: standardizing endpoints for clinical asthma trials and clinical practice. Am J Respir Crit Care Med 2009; 180(1): 59-99.

30. Thomas M, Kay S, Pike J, et al. The Asthma Control Test (ACT) as a predictor of GINA guideline-defined asthma control: analysis of a multinational cross-sectional survey. Prim Care Respir J 2009; 18(1): $41-9$.

31. Schatz M, Kosinski M, Yarlas AS, Hanlon J, Watson ME, Jhingran P. The minimally important difference of the Asthma Control Test. J Allergy Clin Immunol 2009; 124(4): 719-23 e1.

32. Rosias PP, Dompeling E, Dentener MA, et al. Childhood asthma: exhaled markers of airway inflammation, asthma control score, and lung function tests. Pediatr Pulmonol 2004; 38(2): 107-14.

33. Senna G, Passalacqua G, Schiappoli M, Lombardi C, Wilcock L. Correlation among FEV, nitric oxide and asthma control test in newly diagnosed asthma. Allergy 2007; 62(2): 207-8.

34. Tibosch $\mathrm{M}$, de Ridder J, Landstra A, et al. Four of a kind: asthma control, FEV1, FeNO, and psychosocial problems in adolescents. Pediatr Pulmonol 2012; 47(10): 933-40.

35. Petsky HL, Cates CJ, Li A, Kynaston JA, Turner C, Chang AB. Tailored interventions based on exhaled nitric oxide versus clinical symptoms for asthma in children and adults. Cochrane Database Syst Rev 2009; (4): CD006340.

36. http://www.eukidsonline.net. Assessed June 19th 2013.

37. Chan DS, Callahan CW, Hatch-Pigott VB, et al. Internet-based home monitoring and education of children with asthma is comparable to ideal office-based care: results of a 1-year asthma in-home monitoring trial. Pediatrics 2007; 119(3): 569-78.

38. Jan RL, Wang JY, Huang MC, Tseng SM, Su HJ, Liu LF. An internet-based interactive telemonitoring system for improving childhood asthma outcomes in Taiwan. Telemed J E Health 2007; 13(3): 257-68. 



\section{Chapter}

\section{Novel monitoring strategies in children with asthma: a randomised controlled trial}

Sandra Voorend-van Bergen $\mathrm{MD}^{1}$, Anja A. Vaessen-Verberne MD PhD², Hein J. Brackel MD PhD ${ }^{3}$ Anneke M. Landstra MD PhD', Norbert J. van den Berg MD", Wim C. Hop ${ }^{6}$ Johan C. de Jongste MD PhD ${ }^{1}$, Peter J. Merkus MD PhD, Mariëlle W. Pijnenburg MD PhD ${ }^{1}$

${ }^{1}$ Dept of Paediatrics, division Pediatric Respiratory Medicine, Erasmus University Medical Center - Sophia Children's Hospital, Rotterdam, the Netherlands

${ }^{2}$ Dept of Pediatrics, Amphia Hospital, Breda, the Netherlands ${ }^{3}$ Dept of Pediatrics, Catharina Hospital, Eindhoven, the Netherlands ${ }^{4}$ Dept of Pediatrics, Rijnstate Hospital, Arnhem, the Netherlands ${ }^{5}$ Dept of Pediatrics, Flevo Hospital - De Kinderkliniek, Almere, the Netherlands ${ }^{6}$ Dept. of Biostatistics, Erasmus University Medical Center, the Netherlands ${ }^{7}$ Dept of Pediatric Pulmonology, Radboud University Medical Center, Nijmegen, the Netherlands 


\section{Abstract}

\section{Background}

Asthma guidelines recommend monitoring of asthma control. However, in a substantial proportion of children asthma is poorly controlled and the best monitoring strategy is not known.

\section{Objectives}

We studied 2 monitoring strategies for their ability to improve asthma outcomes in comparison with standard care: web-based monthly monitoring with the (Childhood) Asthma Control Test (ACT or C-ACT) and 4-monthly monitoring of fractional exhaled nitric oxide (FeNO).

\section{Methods}

In this randomized controlled multi-centre trial with a 1-year follow up, asthmatic children 4-18 years were randomized to 1 of 3 groups. In the web group, treatment was adapted according to ACT obtained via a website at 1 months intervals; in the FeNO group according to ACT and FeNO, and in the standard care group according to the ACT at 4-monthly visits. Primary endpoint was the proportion of symptom-free days (SFD).

\section{Results}

Two-hundred eighty children (mean age 10.4 years, $66 \%$ boys) were included, 268 completed the study. Mean changes from baseline in SFD were similar between the groups. Daily dose of inhaled corticosteroids (ICS) decreased more in the web-based group compared to both other groups $(-200 \mathrm{ug} /$ day, $p<0.004)$, while ACT and SFD remained similar. An increase in ACT scores of 1.7 points was seen in the FeNO group $(p=0.02)$.

\section{Conclusions}

The change from baseline in SFD did not differ between monitoring strategies. With web-based ACT monitoring ICS could be reduced substantially while control was maintained, while the FeNO strategy showed within-group improvement of ACT. 


\section{Introduction}

In a substantial proportion of children with asthma control is not achieved ${ }^{1-3}$. Guidelines pay little attention to monitoring strategies. The Asthma Control Test (ACT) and the Childhood ACT for children $<12$ yr are simple, validated tools to assess asthma control ${ }^{4,5}$. Web-based ACT monitoring of asthma control has the potential to standardize the assessment of asthma control, increase awareness of asthma and improve adherence. The fraction of nitric oxide in exhaled air (FeNO) is a non-invasive biomarker of eosinophilic airway inflammation ${ }^{6}$ but the benefits of FeNO for asthma monitoring are not yet clear? In the present study we evaluated the possible benefits of web-based monitoring with monthly ACT measurements and adapting the treatment based on 4-monthly FeNO measurements.

\section{Methods}

The 'Better Asthma Treatment: Monitoring with ACT and Nitric oxide' (BATMAN) study was a multi-centre, prospective, partly blinded, parallel-group, randomized controlled trial on monitoring strategies in asthmatic children with a follow up of 1 year (trial number NTR 1995).

\section{Patients}

Children aged 4 to 18 years, with atopic asthma based on clinical symptoms, a bronchodilator response of $>9 \%$ increase in forced expiratory volume in 1 sec of predicted (FEV1\%) and/ or airway hyperresponsiveness (AHR) were recruited from general hospitals $(n=5)$ and tertiary referral centres $(n=2)$ from February 2010 to November 2011. Atopy was defined as a radioallergosorbent test class 2 or higher for at least one airborne allergen. Patients had been using ICS for at least 3 months before the study. Exclusion criteria were active smoking, pulmonary diseases other than asthma, recent ( $<1$ year) or multiple admissions to an Intensive Care Unit for asthma, inability to perform FeNO measurements, and/or the use of omalizumab. The Medical Ethics Committee of the Erasmus University Medical Centre, Rotterdam, approved the study. All parents and children $\geq 12$ years gave written informed consent.

\section{Study design}

After a 4-week run-in period, children were randomly allocated to one of three groups, stratified for age ( $<12$ or $\geq 12$ years), centre and dose of ICS ( $<400$ ug or $\geq 400$ ug budesonide or equivalent daily dose) (Figure 1). Children who completed less than $50 \%$ of the diaries in the run-in period were withdrawn from the study. In the web group, treatment was 
adapted monthly according to the web-based ACT score, while in the FeNO group, treatment was adapted to FeNO and ACT score at clinic visits every 4 months (Figure 2). In the standard care (SC) group the ACT score during clinic visits directed treatment (Figure 2). The study duration was 12 months, with visits at 4-month intervals and one baseline visit 4 weeks prior to randomization. In addition, children randomized to the web group were asked to fill in an ACT every month on a web site that provided a treatment advice by email within 3 working days. In the FeNO and SC groups treatment changes were possible at the 4-monthly study visits, in the web group treatment could be changed monthly. Physicians were blinded for FeNO and ACT scores. The local investigators provided the physicians with treatment advice, based on the study algorithms and on the treatment plan (Figure 2, Table 1). Physicians could deviate from this advice for documented clinical reasons only. The primary endpoint was the proportion of symptom-free days (SFD); secondary endpoints were ACT, daily symptom score, daily bronchodilator doses, daily ICS dose, exacerbations, asthma-related quality of life, dose of methacholine causing a $20 \%$ fall in FEV1 (PD20), forced vital capacity (FVC), FEV1, and maximal expiratory flow at $25 \%$ of vital capacity (MEF25).

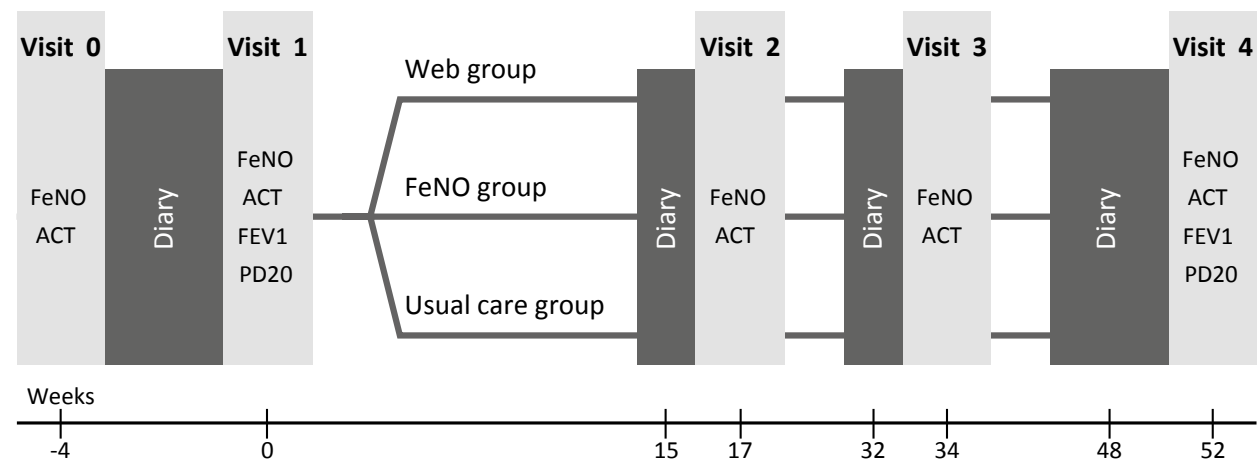

Figure 1 Study design. At visit 1 children were randomly allocated to one of three study groups.

Table 1 Treatment dose steps

\begin{tabular}{|l|l|}
\hline Step & Treatiment \\
\hline 1 & Short acting beta-agonists (SABA) as needed \\
\hline 2 & Budesonide 2 dd 100 ug or equivalent \\
\hline 3 & Budesonide 2 dd 200 ug or equivalent \\
\hline 4 & Budesonide 2 dd 200 ug or equivalent plus LABA \\
\hline 5 & Budesonide 2 dd 400 ug or equivalent plus LABA \\
\hline 6 & Budesonide 2 dd 400 ug or equivalent plus LABA plus LTRA \\
\hline 7 & Budesonide 2 dd 800 ug or equivalent plus LABA plus LTRA \\
\hline $\begin{array}{l}\text { LABA: Long-acting } \beta \text {-agonist. LTRA: Leukotriene receptor antagonist. At all steps short acting beta-agonists as } \\
\text { needed are prescribed. }\end{array}$
\end{tabular}




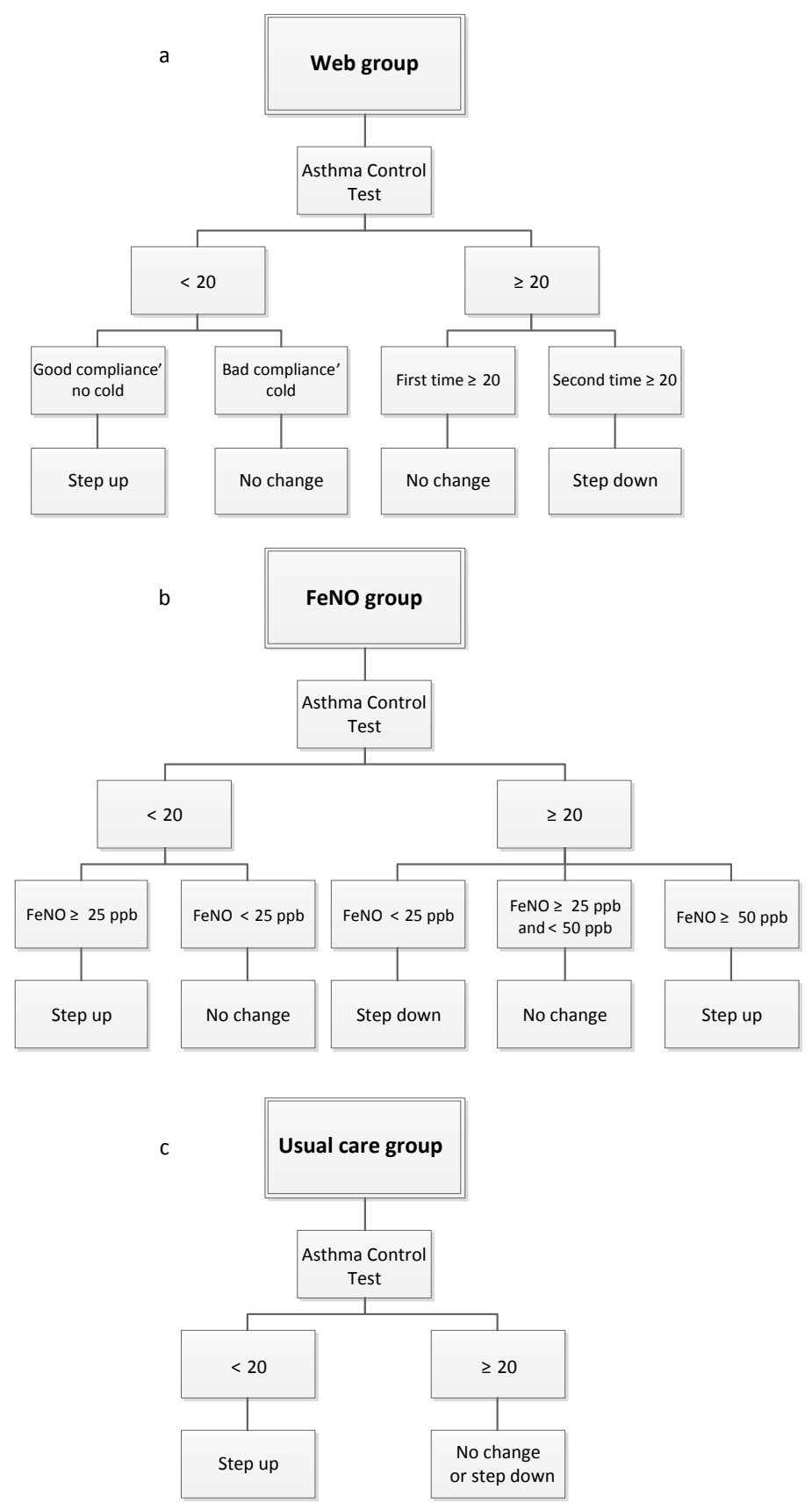

Figure 2 Study algorithm of (a) the web group, (b) the FeNO group, and (c) the standard care group. In the web group patients were asked about adherence to treatment and on signs of airways infection if they returned an ACT or C-ACT < 20. If adherence was poor, or patients had clinical signs of an airway infection (runny nose, fever, malaise), there was no step up in treatment. 


\section{Symptom-free days}

Symptom-free days (SFD) were defined as days without daytime or night-time symptoms and were obtained from a web-based diary which recorded daytime and night-time symptoms, limitation in activity and use of reliever medication ${ }^{8}$. Diary data were collected twice daily during the 4-week run-in period, during the 2 weeks preceding each visit and during 4 weeks preceding the final visit (Figure 1). Each symptom item had 4 response levels ( $0=$ asymptomatic to $3=$ highly symptomatic); the maximal daily diary score was 21 . Diaries were automatically date- and time-stamped and could be filled in until 5 days after the date. Participants received a reminder by email once daily.

\section{Asthma Control Test}

We used the Dutch, translated and linguistically validated version of the ACT (MAPIresearch institute, Lyon, France) in children from the age of 12 , and the C-ACT for children 4-11 years ${ }^{4,5}$.

\section{Lung function and FeNO}

FVC, FEV1 and MEF25 were assessed using an electronic spirometer (Masterscreen, Jaeger, Würzburg, Germany) and expressed as percentage predicted or z-score according to GLI2012 ${ }^{9}$. The provocative dose of methacholine that produced a $20 \%$ fall in FEV1 (PD20) was measured using the dosimeter method (details in supplement). FeNO was measured online on the NIOX chemiluminescence analyzer or NIOX MINO (Aerocrine, Stockholm, Sweden) according to guidelines ${ }^{10}$.

\section{Quality of Life}

In children 12 years and older, asthma-related quality of life was measured with the 23item self-reported Dutch validated version of the PAQLQ for children ${ }^{11,12}$ and expressed as overall asthma-related quality of life. In children below 12 years, we used the PACQLQ ${ }^{11}$. In both tests the maximal score of 7 indicates optimal quality of life.

\section{Statistical Analysis}

Because there were 2 major comparisons in this study (Web vs SC and FeNO vs SC) the alpha level was set at two-sided 0.025 . For all other comparisons the limit of significance was set at two-sided $p=0.05$.The power of the study was calculated to detect differences between the experimental arms and SC, based on $18 \%$ increase in the mean percentage of SFD (corresponding to 2.5 extra SFD in 2 weeks time) ${ }^{13}$. Baseline data were compared using the chi-square test for categorical data or the Kruskal-Wallis test for continuous 
data. Diary data were evaluated using Repeated measurements ANOVA (RmAnova) with baseline data during run-in used as covariates. The significance of differences of other continuous endpoints was determined using analysis of covariance (Ancova, adjusted for baseline). For within-group comparisons we used paired t-tests. The statistical analysis of PD20 is described in the supplement. Data were analysed with SPSS for Windows, version 21.0 .

\section{Results}

Of the 481 children who were eligible for participation 201 refused, mostly because they were too busy with school (Figure 3). Eight children could not be randomised because of non-adherence. Thus, 272 were included, 91 in the web group, 92 in the FeNO group, and 89 in the SC group. Baseline characteristics are given in Table 2. The drop-out rate during the trial was small in all groups (web: $n=1$, FeNO: $n=2 ; S C: n=2$ ), all related to noncompliance. Baseline ACT was significantly higher in the web group compared to the FeNO group, but in both groups ACT was not significantly different from the SC group.

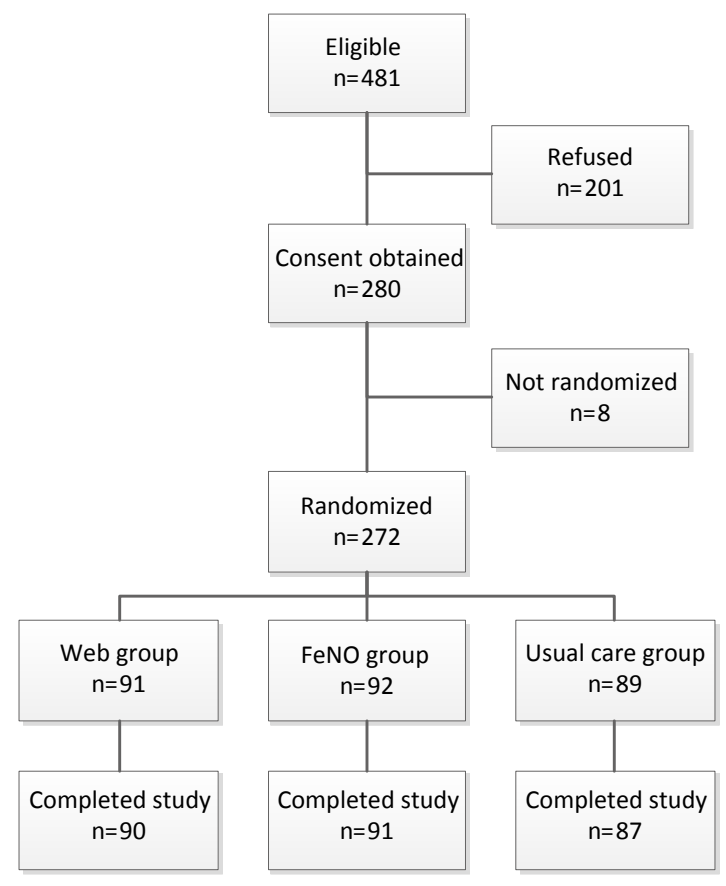

Figure 3 Patient flow. 481 children were approached to participate in the study, of whom 201 refused. Eight children could not be randomized. In the web group 1 dropped out; in the FeNO group 1 dropped out; in the standard care group 2 children dropped out. 


\section{Symptom-free days}

The change in the proportion of SFD between visit 1 and 4 did not differ significantly between the groups (SC vs. web group: 0.07 ( $p=0.2)$; SC vs. FeNO: $0.01(p=0.8)$ ). A small but significant within-group change was seen in both the FeNO group and in the SC group: 0.53 to $0.62(p=0.01)$ and 0.54 to $0.61(p=0.04)$, respectively (Table 3, Figure 4).

Table 2 Patient characteristics

\begin{tabular}{|c|c|c|c|c|}
\hline & $\begin{array}{l}\text { Web group } \\
(n=91)\end{array}$ & $\begin{array}{l}\text { FeNO group } \\
(n=92)\end{array}$ & $\begin{array}{l}\text { Standard care group } \\
(n=89)\end{array}$ & p-value \\
\hline Age, yr & $10.6(2.8)$ & $10.3(2.9)$ & $10.2(3.2)$ & 0.57 \\
\hline Male & $60(66)$ & $62(67)$ & $61(69)$ & 0.94 \\
\hline Initial ICS dose, ug & $400(400-800)$ & $400(400-800)$ & $400(400-800)$ & 0.97 \\
\hline LABA use & $42(46)$ & $44(48)$ & $40(45)$ & 0.93 \\
\hline LTRA use & $11(12)$ & $12(13)$ & $11(12)$ & 0.98 \\
\hline FeNO, ppb & $17.1(10.0-30.0)$ & $15.4(10.0-26.3)$ & $21.4(10.5-35.1)$ & 0.64 \\
\hline FEV1, \%pred & $98.1(12.6)$ & $95.2(12.6)$ & $93.9(14.0)$ & 0.11 \\
\hline FVC, \%pred & $103.3(12.2)$ & $100.3(12.8)$ & $101.0(13.0)$ & 0.29 \\
\hline MEF25, \%pred & $91.0(35.7)$ & $87.3(33.1)$ & $76.0(29.3)$ & 0.01 \\
\hline PD20, ug methacholine & $178.5(26.3-738.7)$ & $118.1(41.0-1084.4)$ & $158.2(36.6-379.9)$ & 0.46 \\
\hline ACT or C-ACT score & $22.1(3.5)$ & 20.7 (4.3) & 21.1 (3.3) & 0.03 \\
\hline Daily symptom score & $1.1(1.3)$ & $1.4(1.7)$ & $1.3(1.4)$ & 0.26 \\
\hline Daily SABA, puffs & $0.4(0.8)$ & $0.6(1.2)$ & $0.4(0.8)$ & 0.29 \\
\hline Symptom-Free days, \% & $54(35)$ & $53(34)$ & $61(33)$ & 0.26 \\
\hline PAQLQ score child & $6.3(5.9-6.6)$ & $6.0(5.6-6.6)$ & $6.2(5.9-6.6)$ & 0.65 \\
\hline PACQLQ score parent & $6.7(6.2-7.0)$ & $6.3(5.7-6.8)$ & $6.1(5.8-6.8)$ & 0.01 \\
\hline
\end{tabular}

Data shown are numbers of patients (\%), mean (SD) or median (interquartile range).

Definition of abbreviations: ICS: inhaled corticosteroids, LABA: long-acting beta-agonist, SABA: short acting betaagonist, LTRA: Leukotriene receptor antagonist, MEF25: maximal expiratory flow at $25 \%$ of vital capacity, PD20: doses of methacholine causing a $20 \%$ fall in FEV1, ACT: asthma control test, PAQLQ: pediatric asthma-related quality of life questionnaire, PACQL: pediatric asthma-related caregiver quality of life questionnaire.

\section{ACT scores}

The FeNO group showed an 1.7 points improvement in ACT that was higher than in the SC group (0.4 points) ( $p=0.02$ ). No significant change in ACT was seen in the web group.

\section{Symptom scores, limitation of activities, and use of $\beta-2$ agonists}

The change between visit 1 and 4 in mean daily symptom scores and the use of $\beta-2$ agonists did not differ between the SC and web group or between the SC and FeNO group (Table $3)$. The mean daily symptom score improved within the FeNO group only $(-0.40, p=0.01)$. 


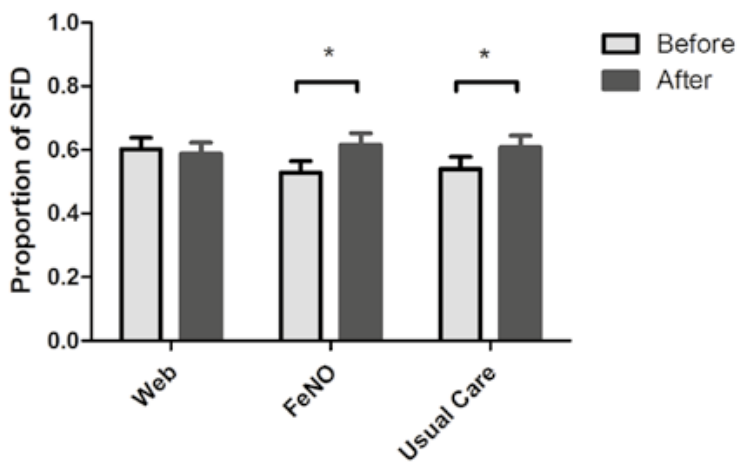

Figure 4 Proportion of symptom-free days (SFD) before and after (a) Web-based monitoring, (b) FeNO monitoring, compared to (c) standard care. ${ }^{*}$ ) significant at $p<0.05$.

Table 3 Changes from baseline of different outcome parameters

\begin{tabular}{|c|c|c|c|c|c|c|c|}
\hline & Web & FeNO & $\begin{array}{l}\text { Standard } \\
\text { care }\end{array}$ & $\begin{array}{l}\text { Difference Web vs } \\
\text { standard care } \\
(95 \% \mathrm{Cl})\end{array}$ & $p$ value & $\begin{array}{l}\text { Difference FeNO vs } \\
\text { standard care } \\
(95 \% \mathrm{Cl})\end{array}$ & $p$ value \\
\hline \multicolumn{8}{|c|}{ Asthma-related symptoms } \\
\hline SFD, \% & -2.1 & $8.9^{*}$ & $7.4^{*}$ & $-6.6(-15.5$ to 2.3$)$ & 0.15 & $1.2(-7.6$ to 10.0$)$ & 0.78 \\
\hline ACT or C-ACT & 0.12 & $1.73^{*}$ & 0.37 & $0.09(-0.92$ to 1.11$)$ & 0.86 & 1.2 (0.17 to 2.20$)$ & $0.02 *$ \\
\hline $\begin{array}{l}\text { Daily symptom } \\
\text { score }\end{array}$ & 0.08 & $-0.40^{*}$ & -0.11 & $0.06(-0.34$ to 0.46$)$ & 0.77 & $-0.27(-0.66$ to 0.13$)$ & 0.19 \\
\hline $\begin{array}{l}\text { Limitation of } \\
\text { activities }\end{array}$ & 0.04 & $-0.09 *$ & -0.02 & $0.05(-0.05$ to 0.15$)$ & 0.33 & $-0.05(-0.15$ to 0.05$)$ & 0.34 \\
\hline Exacerbations & 10 & 14 & 17 & 7 & 0.07 & 3 & $0.28^{\wedge}$ \\
\hline \multicolumn{8}{|l|}{ Medication } \\
\hline $\begin{array}{l}\text { SABA use } \\
\text { (puffs/day) }\end{array}$ & -0.15 & $-0.19 *$ & -0.18 & $-0.01(-0.19$ to 0.18$)$ & 0.93 & $-0.12(-0.30$ to 0.07$)$ & 0.21 \\
\hline ICS dose (ug) & $-201^{*}$ & $-107^{*}$ & -54 & $-150(-241$ to -60$)$ & $0.001 * *$ & $-53(-144$ to 36$)$ & 0.24 \\
\hline \multicolumn{8}{|c|}{ Lung function (z-score) } \\
\hline $\mathrm{FEV}_{1}$ & -0.1 & $0.2^{*}$ & $0.3^{*}$ & $-0.2(-0.5$ to 0.02$)$ & 0.07 & $-0.05(-0.29$ to 0.20$)$ & 0.71 \\
\hline FVC & -0.04 & $0.2^{*}$ & $0.2^{*}$ & $-0.18(-0.4$ to 0.03$)$ & 0.09 & $-0.21(-0.23$ to 0.19$)$ & 0.84 \\
\hline FEF75 & -0.2 & 0.09 & 0.16 & $-0.17(-0.4$ to 0.1$)$ & 0.21 & $0.06(-0.21$ to 0.34$)$ & 0.65 \\
\hline PD20,DD\# & -0.3 & 0.1 & -0.3 & $-0.1(-1.1$ to 1.0$)$ & 0.92 & $0.4(-0.7-1.6)$ & 0.46 \\
\hline FeNO'+ & $1.6^{*}$ & $1.4^{*}$ & $1.2^{*}$ & $1.33(1.09-1.62)$ & $0.01 * *$ & 1.12 (0.92 to 1.38$)$ & 0.24 \\
\hline \multicolumn{8}{|c|}{ Asthma-related quality of life } \\
\hline PAQLQ child & 0.17 & 0.25 & 0.24 & $-0.05(-0.34$ to 0.23$)$ & 0.7 & $-0.13(-0.42$ to 0.15$)$ & 0.4 \\
\hline $\begin{array}{l}\text { PACQLQ } \\
\text { parent }\end{array}$ & 0.02 & 0.22 & 0.05 & $0.10(-0.16$ to 0.35$)$ & 0.4 & $0.17(-0.08$ to 0.43$)$ & 0.2 \\
\hline
\end{tabular}

Data shown are mean values of changes as determined by RmAnova analyses for the diary data, ACT or C-ACT and ICS dose. Ancova was used for the lung function parameters in the comparison of groups, except for PD20 where the changes are calculated without adjustment for the baseline values.

\#) changes expressed as doubling doses (DD), +) changes expressed as ratio of geometric means, ^) mannwhitney test, ${ }^{*}$ ) significant at $\mathrm{p}<0.05{ }^{* *}$ ) significant at $\mathrm{p}<0.025$. 


\section{Exacerbations}

There were 42 exacerbations during the study: 7 hospital admissions and 35 systemic steroid courses. The distribution over the groups was similar: 10, 14 and 17 exacerbations in the web, FeNO and SC groups, respectively.

\section{Lung function and FeNO}

Mean changes from baseline in lung function and PD20 did not differ between groups (Table 3). FEV1 and FVC increased significantly in both the FeNO and the SC group. Data on PD20 are presented in the supplement. Within all groups, a significant increase in FeNO was found. Geometric means of FeNO increased with a factor of 1.6 in the web group, 1.4 in the FeNO group (both $p<0.001)$, and 1.2 in the SC group $(p=0.04)$. Changes in FeNO during the study were significantly different between the $\mathrm{SC}$ and the web group, but not between the SC and the FeNO group. The ratios of geometric means, adjusted for baseline, were $1.3(p=0.006)$ for the web group and 1.1 for the FeNO group $(p=0.24)$ as compared to the SC group.

\section{Treatment levels and ICS doses}

At visit 1 , median ICS doses, long-acting $\beta$-agonist (LABA) use and leukotriene receptor antagonist (LRTA) use did not differ between the study groups (Table 2). In all groups, medication could be reduced (supplement Table 1). Medication could been reduced in $74 \%$ of the children in the web group, in $52 \%$ in the FeNO group and in $45 \%$ in the SC group. The reduction was significantly larger in the web group compared to SC group $(p<0.001)$, but not in the FeNO group. The mean daily ICS dose was reduced by 201 ug in the web group, by 107 ug in the FeNO group and by 54 ug in the SC group (both $p=0.001$, Table 3).

\section{Quality of Life}

In all groups, there were no significant changes in PAQLQ or PACQLQ scores and mean changes from baseline did not differ between the groups (Table 3).

\section{Decision making}

For the FeNO group and the SC group, we determined if the treatment advice would have been different if patients had been allocated to the other study group, which was the case in $62 \%$ of all decisions. 


\section{Adherence of Patients and Physicians}

The completion rates of the web-based diary cards, web-based ACTs, medication adherence and physicians adherence to the protocol were excellent (see supplement).

\section{Discussion}

We compared web-based ACT monitoring and FeNO monitoring with standard care in children with asthma. After 1 year, both strategies had not improved the number of SFD more than SC. However, monthly web-based ACTs resulted in a clinically relevant decrease of ICS dose, while maintaining asthma control. Moreover, children in the FeNO group showed an increase in ACT score as compared to SC, with similar average medication levels.

The ACT is increasingly used in asthma management and GINA guidelines state that 'the value of ACT and C-ACT in clinical use has yet to be demonstrated but will likely become evident in coming years ${ }^{2}$. Indeed, this study shows benefit from monitoring of asthma control with the ACT in clinical practice. By administering the ACT once monthly a fast response to changes in asthma control is possible. We were able to decrease the dose of ICS significantly only in the web group, and this suggests that ACT-guided step-down of treatment is feasible and safe, and reduces overtreatment. The higher frequency of health care contacts may explain part of the success of this approach. Web-based monitoring is a promising new strategy in the care for patients with a chronic illness, including asthma. It enables for remote delivery of care, facilitating timely access to healthcare, supporting selfmonitoring, medication adherence and education ${ }^{14-18}$. Earlier studies showed improved lung function, increased adherence, improved asthma control, increased knowledge, and improved quality of life after web-based monitoring of asthma compared to standard care $^{19-21}$. We did not find improved asthma control with web-based ACT monitoring. Although not significantly different, the web group at baseline had slightly higher ACT, PAQLQ, lung function and SFD compared to the usual care group, leaving less room for improvement. However, our simple strategy reduced the dose of ICS substantially, which is potentially cost-saving, and may prevent overtreatment and limit side effects. A meta-analysis on 21 randomized controlled trials on telemonitoring interventions in both children and adults with asthma concluded that telemonitoring was comparable to standard care regarding quality of life, emergency room visits and hospitalizations for asthma ${ }^{22}$. A recent review on digital asthma self-management interventions concluded that these interventions are promising, with evidence of beneficial effects ${ }^{23}$. Differences in populations, web-based interventions or frequency of Internet contact may account for these discrepancies. The relatively low monitoring frequency in our study might have 
contributed to the high compliance rates and positive effect. The application of webbased monitoring in childhood asthma management has previously been shown feasible and was well accepted ${ }^{24-26}$. In our study, compliance with web-based ACT monitoring was high and patients were generally satisfied with the web-based strategy, in line with earlier studies $^{26,27}$. Future research should focus on determining which patients will benefit most from web-based interventions, to achieve personalised management. One might argue that baseline ACT was higher in the web group than in the control group, suggesting that the children in the web group had better controlled asthma and ICS reduction could have been assumed to be more successful. However, the difference between ACT at baseline and the change in ACT from baseline was not significantly different for both groups.

Several studies addressed titration of ICS treatment on FeNO as a marker of eosinophilic inflammation ${ }^{13,28-30}$. Although our primary endpoint of SFD did not improve more with FeNO monitoring than with standard care, we observed that FeNO monitoring improved asthma control with similar doses of ICS as compared to SC. The ACT increase of 1.7 points is clinically relevant ${ }^{8}$. Our result is in contrast with the conclusions of a recent systematic review of 4 paediatric studies showing no differences in exacerbations, symptoms or lung function between FeNO- and symptom based monitoring, 7, 28-30. In a recent study, FeNOguided asthma management did not improve the proportion of SFD, which is in line with our study, but did result in fewer exacerbations ${ }^{31}$. How does the current study differ from earlier studies? First, we used 2 FeNO cut-off points to define treatment adjustments, in contrast to other FeNO dose titration studies, but similar to the study of Szefler et al. ${ }^{28}$. The use of 2 cut-offs to decrease $(<25 \mathrm{ppb})$ or increase ( $>50 \mathrm{ppb})$ the dose of ICS is more in accordance with clinical practice. While FeNO $>25$ ppb may be abnormal in healthy subjects, in patients with well-controlled asthma such a value is common, and a growing body of evidence suggests that cut-offs should be based on FeNO levels characteristic of the population of interest ${ }^{32}$. In our study population, children with well controlled asthma had a median FeNO level of 25 ppb (IQR 16-47). Therefore a cut-off of 25 ppb might not be valid to increase the dose of ICS in asthmatic children. Several studies have shown that 50 ppb seems a more appropriate cut-off ${ }^{33}$. Second, in our study we could decrease ICS when FeNO values were low, while most earlier studies did not allow for this. Third and probably most important, the treatment algorithms based on FeNO and SC differed substantially: taking FeNO into account led to a different treatment decision at 5 of 8 possible treatment changes (discordance-concordance ratio 1.7$)^{34}$. In our study, including FeNO in the treatment algorithm had actually influenced $62 \%$ of all treatment decisions. Are our findings generalizable to general paediatric asthma care? Almost half of all eligible children refused participation to the study, which may limit the conclusions due to selection bias. However these children did not differ from included children regarding baseline characteristics. A limitation might be bias due to the required internet access. 
However, more than $95 \%$ of Dutch households have internet access at home, and only one eligible child was excluded for this reason.

In conclusion, we have shown that web-based monitoring with monthly ACT or 4-monthly FeNO in children with asthma was feasible but did not improve SFD, our primary outcome. Web-based monitoring led to a significant and clinically relevant reduction in ICS dose with similar asthma control, suggesting better, personalized asthma management. FeNO monitoring improved asthma control without the need for higher ICS doses. Hence, both monitoring strategies might be considered to improve childhood asthma management. 


\section{References}

1. Gustafsson PM, Watson L, Davis KJ, Rabe KF. Poor asthma control in children: evidence from epidemiological surveys and implications for clinical practice. Int J Clin Pract 2006; 60(3): 321-34.

2. GINA. Global Strategy for Asthma Management and Prevention: Global Initiative for Asthma (GINA), 2011.

3. National Asthma E, Prevention P. Expert Panel Report 3 (EPR-3): Guidelines for the Diagnosis and Management of Asthma-Summary Report 2007. J Allergy Clin Immunol 2007; 120(5 Suppl): S94-138.

4. Liu AH, Zeiger R, Sorkness $\mathrm{C}$, et al. Development and cross-sectional validation of the Childhood Asthma Control Test. J Allergy Clin Immunol 2007; 119(4): 817-25.

5. Nathan RA, Sorkness CA, Kosinski M, et al. Development of the asthma control test: a survey for assessing asthma control. J Allergy Clin Immunol 2004; 113(1): 59-65.

6. Pijnenburg MW, De Jongste JC. Exhaled nitric oxide in childhood asthma: a review. Clinical and experimental allergy : journal of the British Society for Allergy and Clinical Immunology 2008; 38(2): 246-59.

7. Petsky HL, Cates CJ, Li A, Kynaston JA, Turner C, Chang AB. Tailored interventions based on exhaled nitric oxide versus clinical symptoms for asthma in children and adults. Cochrane Database Syst Rev 2009; (4): CD006340.

8. Voorend-van Bergen S, Vaessen-Verberne AA, Landstra AM, et al. Monitoring childhood asthma: Web-based diaries and the asthma control test. The Journal of allergy and clinical immunology 2013.

9. Quanjer PH, Stanojevic S, Cole TJ, et al. Multi-ethnic reference values for spirometry for the 3-95-yr age range: the global lung function 2012 equations. The European respiratory journal 2012; 40(6): 1324-43.

10. American Thoracic S, European Respiratory S. ATS/ERS recommendations for standardized procedures for the online and offline measurement of exhaled lower respiratory nitric oxide and nasal nitric oxide, 2005. American journal of respiratory and critical care medicine 2005; 171(8): 912-30.

11. Juniper EF, Guyatt GH, Feeny DH, Ferrie PJ, Griffith LE, Townsend M. Measuring quality of life in children with asthma. Qual Life Res 1996; 5(1): 35-46.

12. Raat H, Bueving HJ, de Jongste JC, Grol MH, Juniper EF, van der Wouden JC. Responsiveness, longitudinaland cross-sectional construct validity of the Pediatric Asthma Quality of Life Questionnaire (PAQLQ) in Dutch children with asthma. Qual Life Res 2005; 14(1): 265-72.

13. Pijnenburg MW, Bakker EM, Hop WC, De Jongste JC. Titrating steroids on exhaled nitric oxide in children with asthma: a randomized controlled trial. American journal of respiratory and critical care medicine 2005; 172(7): 831-6.

14. Van Gaalen JL, Hashimoto S, Sont JK. Telemanagement in asthma: an innovative and effective approach. Current opinion in allergy and clinical immunology 2012; 12(3): 235-40.

15. Meystre $S$. The current state of telemonitoring: a comment on the literature. Telemedicine journal and e-health : the official journal of the American Telemedicine Association 2005; 11(1): 63-9.

16. Ekeland AG, Bowes A, Flottorp S. Methodologies for assessing telemedicine: a systematic review of reviews. International journal of medical informatics 2012; 81(1): 1-11.

17. Ekeland AG, Bowes A, Flottorp S. Effectiveness of telemedicine: a systematic review of reviews. International journal of medical informatics 2010; 79(11): 736-71.

18. Jaana $M$, Pare $G$, Sicotte $C$. Home telemonitoring for respiratory conditions: a systematic review. The American journal of managed care 2009; 15(5): 313-20.

19. Rasmussen LM, Phanareth K, Nolte H, Backer V. Internet-based monitoring of asthma: a long-term, randomized clinical study of 300 asthmatic subjects. The Journal of allergy and clinical immunology 2005; 115(6): 1137-42.

20. Jan RL, Wang JY, Huang MC, Tseng SM, Su HJ, Liu LF. An internet-based interactive telemonitoring system for improving childhood asthma outcomes in Taiwan. Telemed J E Health 2007; 13(3): 257-68.

21. Chan DS, Callahan CW, Hatch-Pigott VB, et al. Internet-based home monitoring and education of children with asthma is comparable to ideal office-based care: results of a 1-year asthma in-home monitoring trial. Pediatrics 2007; 119(3): 569-78.

22. McLean S, Chandler D, Nurmatov U, et al. Telehealthcare for asthma: a Cochrane review. CMAJ : Canadian Medical Association journal = journal de l'Association medicale canadienne 2011; 183(11): E733-42. 
23. Morrison D, Wyke S, Agur K, et al. Digital asthma self-management interventions: a systematic review. Journal of medical Internet research 2014; 16(2): e51.

24. Finkelstein J, Cabrera MR, Hripcsak G. Internet-based home asthma telemonitoring: can patients handle the technology? Chest 2000; 117(1): 148-55.

25. Finkelstein J, Hripcsak G, Cabrera MR. Patients' acceptance of Internet-based home asthma telemonitoring. Proceedings / AMIA Annual Symposium AMIA Symposium 1998: 336-40.

26. Deschildre A, Beghin L, Salleron J, et al. Home telemonitoring (forced expiratory volume in $1 \mathrm{~s}$ ) in children with severe asthma does not reduce exacerbations. The European respiratory journal 2012; 39(2): 290-6.

27. Koolen BB, Pijnenburg MW, Brackel HJ, et al. Validation of a web-based version of the asthma control test and childhood asthma control test. Pediatric pulmonology 2011; 46(10): 941-8.

28. Szefler SJ, Mitchell H, Sorkness CA, et al. Management of asthma based on exhaled nitric oxide in addition to guideline-based treatment for inner-city adolescents and young adults: a randomised controlled trial. Lancet 2008; 372(9643): 1065-72.

29. Fritsch $M, U x a S$, Horak F, Jr., et al. Exhaled nitric oxide in the management of childhood asthma: a prospective 6-months study. Pediatric pulmonology 2006; 41(9): 855-62.

30. de Jongste JC, Carraro S, Hop WC, Group CS, Baraldi E. Daily telemonitoring of exhaled nitric oxide and symptoms in the treatment of childhood asthma. American journal of respiratory and critical care medicine 2009; 179(2): 93-7.

31. Peirsman EJ, Carvelli TJ, Hage PY, et al. Exhaled nitric oxide in childhood allergic asthma management a randomised controlled trial. Pediatric pulmonology 2013.

32. Barnes PJ, Dweik RA, Gelb AF, et al. Exhaled nitric oxide in pulmonary diseases: a comprehensive review. Chest 2010; 138(3): 682-92.

33. Dweik RA, Boggs PB, Erzurum SC, et al. An official ATS clinical practice guideline: interpretation of exhaled nitric oxide levels (FENO) for clinical applications. American journal of respiratory and critical care medicine 2011; 184(5): 602-15.

34. Gibson PG. Using fractional exhaled nitric oxide to guide asthma therapy: design and methodological issues for ASthma TReatment ALgorithm studies. Clinical and experimental allergy : journal of the British Society for Allergy and Clinical Immunology 2009; 39(4): 478-90. 


\section{Supplement}

\section{Method of airway hyperresponsiveness measurement}

Bronchial provocation tests with methacholine were performed according to the dosimeter method with calibrated nebulizers (DeVilbiss 646, DeVilbiss Co, Somerset, USA) and dosimeters (KoKo, PSD instrumentation, Louisville, USA). ICS, bronchodilators, leukotriene receptor antagonists and antihistamines were stopped for at least 36 hours prior to the bronchial provocation test. Nebulized methacholine bromide was given in doubling concentrations $(0.038$ to $39.2 \mathrm{mg} / \mathrm{ml})$ with mouth doses of 0.76 up to $786 \mathrm{ug}$. Doses causing a 20\% fall in FEV1 from baseline (PD20) were calculated by means of linear interpolation of the logdose-response curve. For safety reasons PD20 methacholine was only measured in patients with FEV1/ FVC ratio $>0.7$ or FEV1 $>75 \%$ predicted. One center did not perform bronchial provocation tests because of different equipment $(n=22)$.

\section{Statistical analyses of PD20}

For PD20 and FeNO a logtransformation was applied in all analyses and changes in PD20 were reported as doubling doses. For analysis of PD20 outcomes the program 'cnreg' from the STATA package was used to allow for patients who did not reach the FEV1 threshold of a $20 \%$ decrease ("censored" data).

\section{Results on airway hyperresponsiveness}

At visit 1, bronchoprovocation tests could not be performed in 70 children (28\%) due to FEV1 $<75 \%$ predicted and/or FEV1/ FVC $<70 \%(n=16)$, because they were too young to perform reproducible spirometry $(n=32)$, or for other reasons, including equipment failure $(n=22)$. At visit 4 , bronchoprovocation could not be performed in 88 children (too obstructive $n=25$, bad technique $n=15$, no bronchoprovocation test at visit $1 n=29$, other $\mathrm{n}=19$ ). In 12 children, no PD20 was reached after the maximal dose of methacholine at both visit 1 and 4 . Because no conclusion could be drawn on changes in PD20 in these children, they were excluded from the analyses of changes in PD20. In the remaining 132 children, the mean change in PD20 was 0.8 doubling doses in the web group $(p=0.4), 1.1$ in the FeNO group $(p=0.5)$, and 0.8 in the standard care group $(p=0.8)$. The difference of these changes between the groups was not significant ( $p=0.5$ and $p=0.9$, respectively).

\section{Adherence}

During the run-in period, $92 \%$ of the web-based diaries were completed. One hundred and forty-seven (54\%) children completed all diaries twice daily, and 244 (90\%) completed 
at least 21 days. After 1 year follow-up, adherence to filling in diary cards did not decrease $(88 \%)$ and 141 (54\%) of the children completed all. Children randomized to the web group completed $88 \%$ (median) of the web-based ACTs. Forty-three \% completed all and $85 \%$ completed $>75 \%$ of diaries. Overall self-reported medication adherence during the study was $94.1 \%$ in the web group, $91.5 \%$ in the FeNO group, and $91.4 \%$ in the standard care group $(p=0.3)$.

\section{Deviation form study protocol}

The study design allowed the physician to deviate from the recommended treatment step. This happened mean 0.36 times per patient in the web group, 0.57 times in the FeNO group, and 0.36 in the standard care group. The distribution over the groups and over time was similar. The main reasons for deviations were suspected airways infections, or reaching the minimal or maximal treatment step. 



\section{Chapter

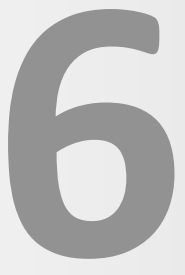

\section{Cost-effectiveness of FeNO- and web-based monitoring in pediatric asthma management: a randomized controlled trial}

Thijs Beerthuizen $\mathrm{MD}^{1}$, Sandra Voorend-van Bergen MD², Wilbert B. van den Hout PhD Anja A. Vaessen-Verberne MD PhD ${ }^{3}$, Hein J. Brackel MD PhD ${ }^{4}$, Anneke M. Landstra MD $\mathrm{PhD}^{5}$, Norbert J. van den Berg $\mathrm{MD}^{6}$, Johan C. de Jongste MD PhD², Peter J. Merkus MD $\mathrm{PhD}^{7}$, Mariëlle W. Pijnenburg MD PhD², Jacob K. Sont $\mathrm{PhD}^{1}$

${ }^{1}$ Dept of Medical Decision Making, Leiden University Medical Center, Leiden, The Netherlands

${ }^{2}$ Dept of Pediatrics, division Pediatric Respiratory Medicine, Erasmus University Medical Center - Sophia Children's Hospital, Rotterdam, The Netherlands

${ }^{3}$ Dept of Pediatrics, Amphia Hospital, Breda, The Netherlands

${ }^{4}$ Dept of Pediatrics, Catharina Hospital, Eindhoven, The Netherlands

${ }^{5}$ Dept of Pediatrics, Rijnstate Hospital, Arnhem, The Netherlands ${ }^{6}$ Dept of Pediatrics, Flevo Hospital - De Kinderkliniek, Almere, The Netherlands

${ }^{7}$ Dept of Pediatric Pulmonology, Radboud University Medical Center, Nijmegen,

The Netherlands 


\section{Abstract}

\section{Background}

In children with asthma, web-based monitoring and inflammation-driven therapy might lead to improved asthma control and reduction in medications. However, the cost-effectiveness of these novel monitoring strategies is yet unknown.

\section{Objective}

We assessed the cost-effectiveness of web-based monthly monitoring with the (Childhood-) Asthma Control Test (ACT or C-ACT) and of 4-monthly Fractional exhaled Nitric Oxide (FeNO), as compared to standard care.

\section{Methods}

An economic evaluation was performed alongside a randomized controlled multicenter trial with a 1-year follow up. Two hundred seventy-two asthmatic children, age range 4-18 years, were randomized to 1 of 3 strategies. In standard care treatment was adapted according to ACT at 4-monthly visits, in the web-based strategy also according to web-ACT at 1 months intervals, and in the FeNO-based strategy according to ACT and FeNO at 4-monthly visits. Outcome measures were patient utilities, healthcare costs, societal costs and incremental cost per quality adjusted life year (QALY) gained.

\section{Results}

No significant differences were found in QALY's and costs between the 3 strategies. The web-based strategy had $80 \%$ chance of being most cost-effective from a health care perspective at a willingness to pay of a generally accepted $€ 40,000 / Q A L Y$. The FeNObased strategy had $68 \%$ chance of being most cost-effective at $€ 40,000 / Q A L Y$ from a societal perspective.

\section{Conclusion}

Economically, web-based monitoring strategy was preferred from a health care perspective, whilst the FeNO-based strategy was preferred from a societal perspective, although no significant changes were found in QALY's and costs. As clinical outcomes also favoured the web-based and FeNO-based strategies, they may be useful additions to standard care. 


\section{Introduction}

Asthma is a disease characterized by chronic inflammation and airway hyperresponsiveness that leads to recurrent episodes of wheezing, breathlessness, chest tightness and coughing ${ }^{1}$. Treatment is aimed at achieving and maintaining asthma control and therefore adjusting therapy is based on regular assessment of the level of asthma control ${ }^{2}$. Effective disease management therefore requires simple, reliable and affordable tools to assess asthma control. However, guidelines offer little practical guidance for monitoring asthma in children and in clinical practice asthma control is not achieved in a substantial proportion of children which leads to increased healthcare costs and productivity loss of parents ${ }^{3-6}$. Web-based self-monitoring may improve asthma control in children ${ }^{7}$. A simple and affordable tool that can be offered via Internet is the Asthma Control Test (ACT, for children > 11 years) or Childhood Asthma Control Test (C-ACT, for children 4-11 years) $)^{8-11}$. In addition, since chronic airway inflammation is the target for treatment with inhaled corticosteroids (ICS) monitoring of airway inflammation is another opportunity to tailor therapy and improve asthma outcomes ${ }^{12}$. Measuring the Fraction of exhaled Nitric Oxide (FeNO) is a non-invasive and simple method to quantify eosinophilic airway inflammation. In a recent study in children with asthma between 4 and 18 years of age, we evaluated the effectiveness of 1 year tailoring treatment based on two different asthma monitoring strategies as compared to standard care: 1 ) web-based monitoring with monthly ACT and; 2) a 4-monthly FeNO monitoring strategy ${ }^{13}$. Web-based monitoring led to a significant and clinically relevant reduction in ICS dose with similar asthma control, suggesting better, personalized asthma management. The FeNO-based strategy improved asthma control as assessed with the ACT without the need for higher ICS doses, and therefore both monitoring strategies might be considered to improve childhood asthma from a clinical and patient perspective ${ }^{13}$. However, to date it is unknown to what extent the clinical benefits outweigh the costs and whether the strategies can be recommended from a health economic perspective.

To that end, we performed an economic evaluation alongside the randomized trial ${ }^{13}$. We hypothesized that web-based monitoring of asthma control and monitoring of airways inflammation by FeNO, in addition to standard care, are cost-effective.

\section{Methods}

This economic evaluation was conducted alongside the 'Better Asthma Treatment: Monitoring with ACT and Nitric oxide' (BATMAN) study. This three-arm multi-center randomized trial with 12 months follow-up was conducted from February 2010 through 
November, 2012 in The Netherlands. The Medical Ethics Committee of the Erasmus University Medical Center, Rotterdam, approved the study. All parents and all children above twelve years of age gave written informed consent before entering the study. Procedures were in accordance with the Helsinki Declaration, and this trial is registered in the Netherlands Trial Register (NTR1995). The methodological details of the trial are reported elsewhere and briefly summarized here ${ }^{13}$.

\section{Patients}

Children with asthma (age range 4 - 18 years) were recruited from five general hospitals and two tertiary referral centers as described previously ${ }^{13}$. Patients used ICS during at least 3 months before the study. Exclusion criteria were active smoking, lung disease other than asthma, recent ( $<1$ year) or multiple admissions to an Intensive Care Unit for asthma, and/or the use of omalizumab.

\section{Design}

Children were randomly allocated to one of three strategies: 1) standard care; 2) webbased monitoring and 3) FeNO-based monitoring, stratified for age ( $<12$ or $\geq 12$ years), center and dosage of ICS. Patients visited the outpatient clinic at a baseline visit 4 weeks prior to randomization and every four months over the course of one year. At these visits asthma control status was assessed using the ACT score. In standard care the ACT score during clinic visits directed treatment. In the web-based strategy, treatment was additionally adapted monthly and communicated by e-mail, following a dedicated algorithm according to the ACT score, which was filled out on the Internet. In the FeNObased strategy, treatment was adjusted following a dedicated algorithm, taking into account the FeNO measurement prior to their physician visit, in addition to standard care. Patients in all three strategies filled out questionnaires as described below at baseline and after 4, 8 and 12 months. This article addresses the cost-effectiveness of the randomized controlled trial, whereas the article of Voorend-Van Bergen addressed the clinical outcomes of the study.

\section{Utilities and QALY's}

The health economic outcome of this study was the costs per quality-adjusted life year (QALY) gained from the health care and the societal perspective. Utilities reflect the individual preferences for different health states. Health-related quality of life was reported using the EuroQoL classification system (EQ-5D) ${ }^{14}$. In patients under 12 years of age, their parents filled out the questionnaire. In children 12 years and older, the patients filled out the questionnaires aided by their parents ${ }^{14}$. The domain scores were obtained 
by calculating the mean of the EQ-5D-scores of 4, 8 and 12 months of follow-up. Statistical significance was assessed using Student's t-test. QALY's were obtained by calculating the area under the health state utility curve based on the Dutch tariff of the EuroQol classification system (EQ-5D) $)^{15}$.

\section{Costs}

We assessed the costs from both health care and societal perspective. Health care costs consisted of both asthma and non-asthma contacts with healthcare providers (clinical consultations, telephonic consultations and home visits), emergency room visits, hospital admissions and medication. We requested the participant's permission to collect pharmacist data about medications. Total medication costs were assessed by obtaining all medication prescriptions from local pharmacy records, using standard Dutch pricing [20]. In the FeNO-based and web-based strategies, additional costs of the intervention were added to these costs. Patients reported each type of consultation for each type of healthcare provider (general practitioner, pediatrician, other type of specialist, paramedic or complementary care) separately. We used standard Dutch prices for consultations per type of healthcare provider ${ }^{16}$, and standard prices for medication determined by the Dutch authority of insurance companies. The intervention costs for the FeNO-based strategy consisted of the purchase and exploitation costs of the FeNO-analyzer, and for the web-based strategy we estimated the ICT costs and the costs of a nurse-practitioner who communicated with the children when they filled out the ACT questionnaire.

Societal costs consisted of the above mentioned healthcare costs and the loss of productivity in both paid and unpaid self-reported labor. Paid labor absenteeism due to the child's health for the parents (for children $<12$ years of age) or for the child (for children $\geq 12$ years of age) was valued using age specific wages ${ }^{17}$. Hours spent on unpaid volunteer work (housekeeping, grocery shopping, etc.) were valued using a standard voluntary work compensation and relative to the average hours in the study populations (so negative costs reflect above-average hours of unpaid work). Total costs were obtained by adding the costs of three relevant categories: all healthcare costs, productivity loss, and intervention costs, consisting of additional costs for the measurement of FeNO or web-based support. Because the follow-up was one year costs were not discounted.

\section{Statistical analysis}

Patients were analysed according to intention-to-treat. To correct for possibly selective non-response, we imputed missing data using linear regression modelling. We constructed 10 sets of imputations, with study group, age, gender, center and available utilities as regression variables. We used Rubin's rules to congregate the imputation sets to single values $^{18}$. To compare the differences between the different strategies we performed 
unpaired Student's T-tests with the following contrasts: standard care vs. web-based, standard care vs. FeNO-based, and FeNO vs. web-based for each category of costs. Statistical uncertainty of cost-effectiveness was analysed using the net benefit approach ${ }^{19}$. The net benefit (NB) is defined as $\lambda \times \triangle Q A L Y-\Delta$ costs, where $\lambda$ is the willingness to pay for a gain of one quality-adjusted life year. This way, the observed QALY difference is reformulated into a monetary difference. To assess the likelihood of cost-effectiveness of the intervention strategies, we used two different perspectives: a healthcare and a societal perspective, as described above. The probability of each strategy to be the most cost-effectiveness of the three strategies was assessed in acceptability curves, from the healthcare and societal perspective at different $\lambda$ levels. All analyses were performed with Stata/IC 11.0.

\section{Results}

\section{Recruitment and baseline characteristics}

In total, 481 children satisfied the inclusion criteria and were approached for the study, of whom 201 refused to participate. Prior to randomization, 8 children were excluded for non-adherence to the study protocol during the pre-randomization measurements. The remaining 272 participants were randomized over the different study arms: 89 in the standard care group, 91 in the web-based group and 92 in the FENO group. Baseline characteristics are shown in Table 1 . There were no significant differences between the strategies for age, sex, FeNO, lung function and ICS dose. ${ }^{13}$ Although asthma control at baseline was better in the web-based group compared to the FeNO group, asthma control was not statistically significantly different from the standard care group for both novel monitoring strategies. ${ }^{13}$ In addition, there were no statistically significant differences in patient utilities at baseline between the strategies.

\section{Costs}

The health care costs of the different strategies are shown in Table 2. Total health care costs varied between $€ 795$ and $€ 888$ per patient per year across the different strategies, which was not significantly different. The amount of nurse practitioners consultations was the only category of health care costs that differed significantly between the strategies: the web-based strategy accounted for an average of $€ 129$ annual expenditure ( 1.79 consultations per year per patient * $€ 72$ per consultation), whereas standard care accounts for $€ 86$ ( 1.20 consultations per patients per year, $p=0.001$ ) and FeNO-based care accounts for $€ 96$ ( 1.33 consultations per year per patient, $p=0.01$ ). 
Table 1 Baseline characteristics

\begin{tabular}{|c|c|c|c|c|}
\hline & $\begin{array}{l}\text { Standard } \\
(n=89)\end{array}$ & $\begin{array}{l}\text { Web-based } \\
(n=91)\end{array}$ & $\begin{array}{l}\text { FeNO-based } \\
(n=92)\end{array}$ & p-value \\
\hline Age, yr (SD) & $10.2(3.2)$ & $10.6(2.8)$ & $10.3(2.9)$ & 0.57 \\
\hline Male (\%) & $61(69 \%)$ & $60(66 \%)$ & $62(67 \%)$ & 0.94 \\
\hline Initial ICS dose (IQR) ( $\mu \mathrm{g})$ & $400(400-800)$ & $400(400-800)$ & $400(400-800)$ & 0.97 \\
\hline LABA use (\%) & $40(45 \%)$ & $42(46 \%)$ & $44(48 \%)$ & 0.93 \\
\hline LTRA use (\%) & $11(12 \%)$ & $11(12 \%)$ & $12(13 \%)$ & 0.98 \\
\hline FeNO, ppb (IQR) & $21.4(10.5-35.1)$ & $17.1(10.0-30.0)$ & $15.4(10.0-26.3)$ & 0.64 \\
\hline FEV1, \%pred (SD) & $93.9(14.0)$ & $98.1(12.6)$ & $95.2(12.6)$ & 0.11 \\
\hline FVC, \%pred (SD) & $101.0(13.0)$ & $103.3(12.2)$ & $100.3(12.8)$ & 0.29 \\
\hline ACT or C-ACT score (SD) & $21.1(3.3)$ & $22.1(3.5)$ & $20.7(4.3)$ & 0.03 \\
\hline Daily SABA, puffs (SD) & $0.4(0.8)$ & $0.4(0.8)$ & $0.6(1.2)$ & 0.29 \\
\hline Symptom-Free days, (SD) & $61 \%(33)$ & $54 \%(35)$ & $53 \%(34)$ & 0.26 \\
\hline PAQLQ score child (IQR) & $6.2(5.9-6.6)$ & $6.3(5.9-6.6)$ & $6.0(5.6-6.6)$ & 0.65 \\
\hline PACQLQ score parent (IQR) & $6.1(5.8-6.8)$ & $6.7(6.2-7.0)$ & $6.3(5.7-6.8)$ & 0.01 \\
\hline EQ5D score (SD) & $0.913(0.095)$ & $0.915(0.092)$ & $0.922(0.102)$ & 0.81 \\
\hline
\end{tabular}

Data shown are numbers of patients (\%), mean (SD) or median (interquartile range).

Definition of abbreviations: ICS: inhaled corticosteroids, LABA: long-acting beta-agonist, SABA: short acting beta-agonist, LTRA: Leukotriene receptor antagonist, ACT: asthma control test, PAQLQ: pediatric asthma-related quality of life questionnaire, PACQLQ: pediatric asthma-related caregiver quality of life questionnaire.

\section{Patient utilities}

The scores of the EQ-5D domains are shown in Table 3. These domains range from 1-3, where 1 represents the most favourable score. Overall the average scores were close to 1 , indicating high quality of life within this population. Two significant differences were found across the strategies: self-care scores between the standard care and FeNO-based strategy were significantly different, favouring the FeNO-based strategy, and Mood scores were significantly better in the web-based strategy as compared to standard care.

The changes in patient utilities during follow-up are shown in Figure 1. The best outcomes were seen in the web-based strategy at 4 months follow-up ( $p=0.26$ compared with standard care, $p=0.15$ compared with FeNO). Although these outcomes were statistically non-significant, they account for the higher overall QALY in the web-based strategy. The standard care group and the web-based group show a similar pattern over time, with a peak after 4 months follow-up, with a subsequent decrease in quality of life. The FeNO strategy offers a more constant pattern, with a slight non-significant peak after 8 months follow-up. Quality-adjusted life years are shown in Table 2. These results, although statistically non-significant, slightly favour the web-based strategy. The mean utility scores across the strategies vary between 0.928 and 0.939 , indicating relatively high utilities in this population. 


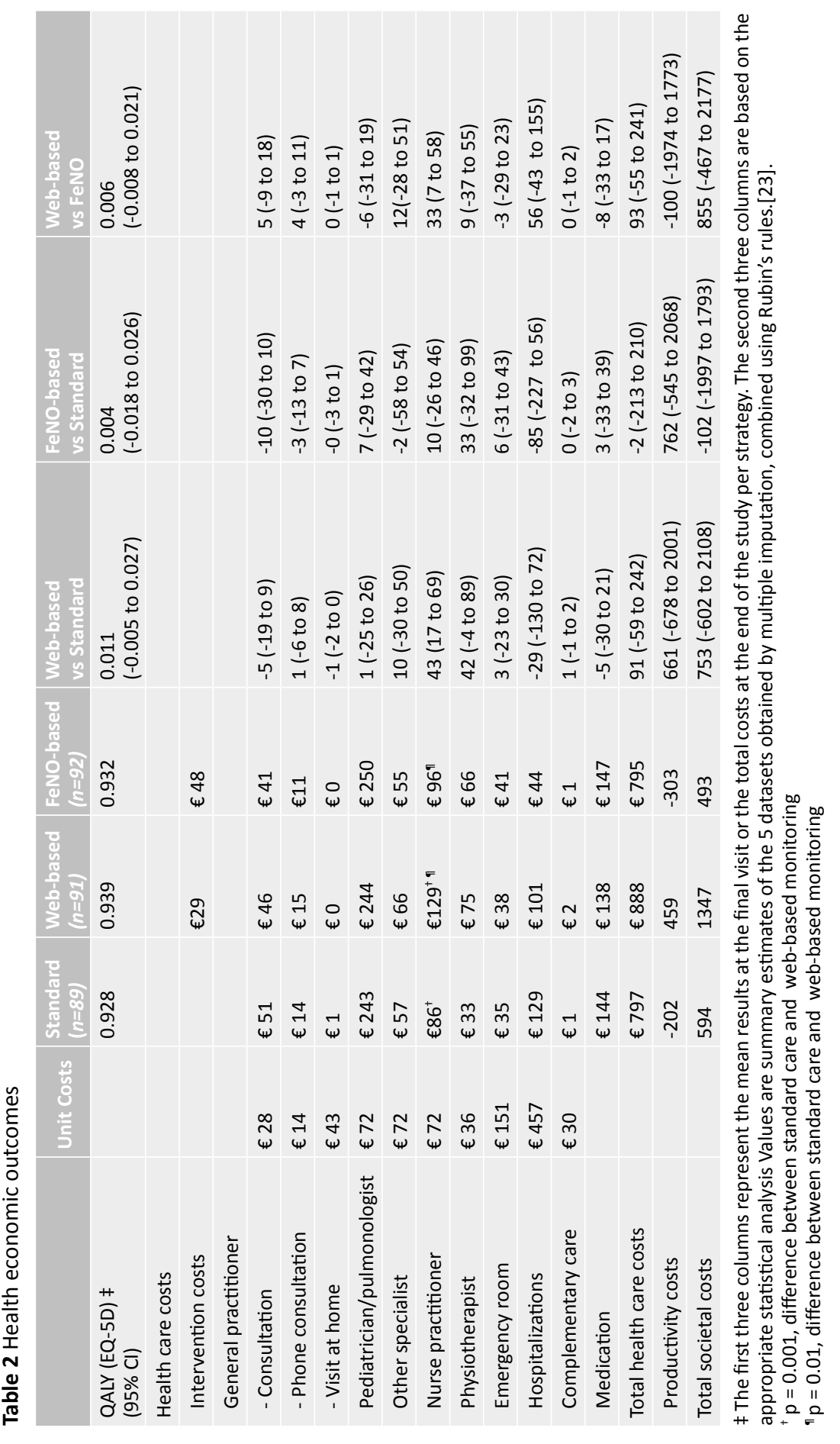


Table 3 Average scores of EQ-5 sub-domains over 1 year follow-up

\begin{tabular}{|l|l|l|l|}
\hline & $\begin{array}{l}\text { Standard } \\
(n=89)\end{array}$ & $\begin{array}{l}\text { Web-based } \\
(n=91)\end{array}$ & $\begin{array}{l}\text { FeNO-based } \\
(n=92)\end{array}$ \\
\hline Mobility & $1.04(1.01-1.06)$ & $1.04(1.02-1.07)$ & $1.05(1.02-1.07$ \\
\hline Self-care & $1.01(1.00-1.02)^{\dagger}$ & $1.02(1.01-1.04)$ & $1.00(1.00-1.01)^{\dagger}$ \\
\hline Usual activities & $1.11(1.07-1.15)$ & $1.11(1.07-1.15)$ & $1.15(1.11-1.16)$ \\
\hline Pain / Discomfort & $1.21(1.16-1.26)$ & $1.24(1.19-1.30)$ & $1.21(1.16-1.26)$ \\
\hline Anxiety / Depression & $1.12(1.08-1.16)$ & $1.08(1.04-1.12)^{\ddagger}$ & $1.14(1.10-1.18)^{\ddagger}$
\end{tabular}

Data shown are means of sub-domain scores ( $95 \%$ confidence intervals). Higher scores indicate more severe problems.

${ }^{+} \mathrm{p}=0.049$; difference between standard and FeNO-based care. ${ }^{\ddagger} \mathrm{p}=0.029$; difference between web-based and FeNO-based care

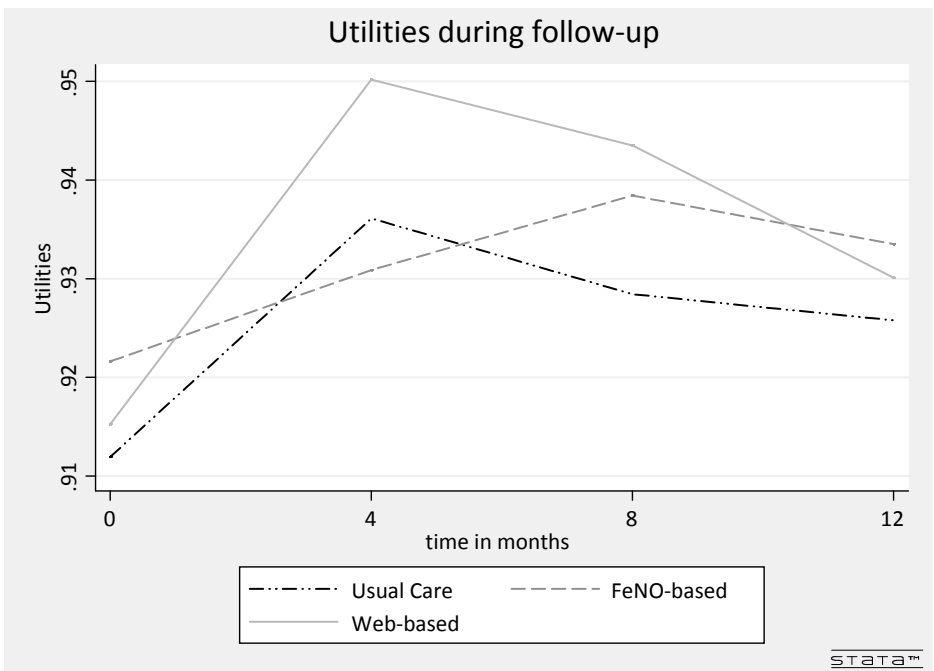

Figure 1 Average patient utilities over time.

\section{Cost-effectiveness}

The probability that any strategy is more cost-effective compared to the two other strategies was assessed by cost-effectiveness acceptability curves from a healthcare perspective (which includes only healthcare costs) and a societal perspective (including both healthcare costs and costs due to loss of productivity) (Figure 2). From the health care perspective, the web-based strategy showed the highest probability of costeffectiveness over a wide range of willingness-to-pay values (€10,000 - €100,000/QALY). Specifically, at a generally acceptable willingness to pay threshold of $€ 40,000 /$ ALY $^{20,21}$, the web-based strategy was $79 \%$ likely to be the most cost-effective, whilst this was $2 \%$ for 
the standard care and $19 \%$ for the FeNO-based strategy. At a threshold of $€ 80,000 / Q A L Y$, which is mentioned in the Netherlands as the maximum costs considered acceptable $\mathrm{e}^{20,21}$, the web-based strategy has a $85 \%$ likelihood of being most cost-effective. From a societal perspective, uncertainty was substantially higher, favouring the FeNO-based strategy over a wide range of willingness-to-pay values, which has the highest $74 \%$ chance of being most cost-effective at a willingness-to-pay of about €40,000/QALY (Figure 2).
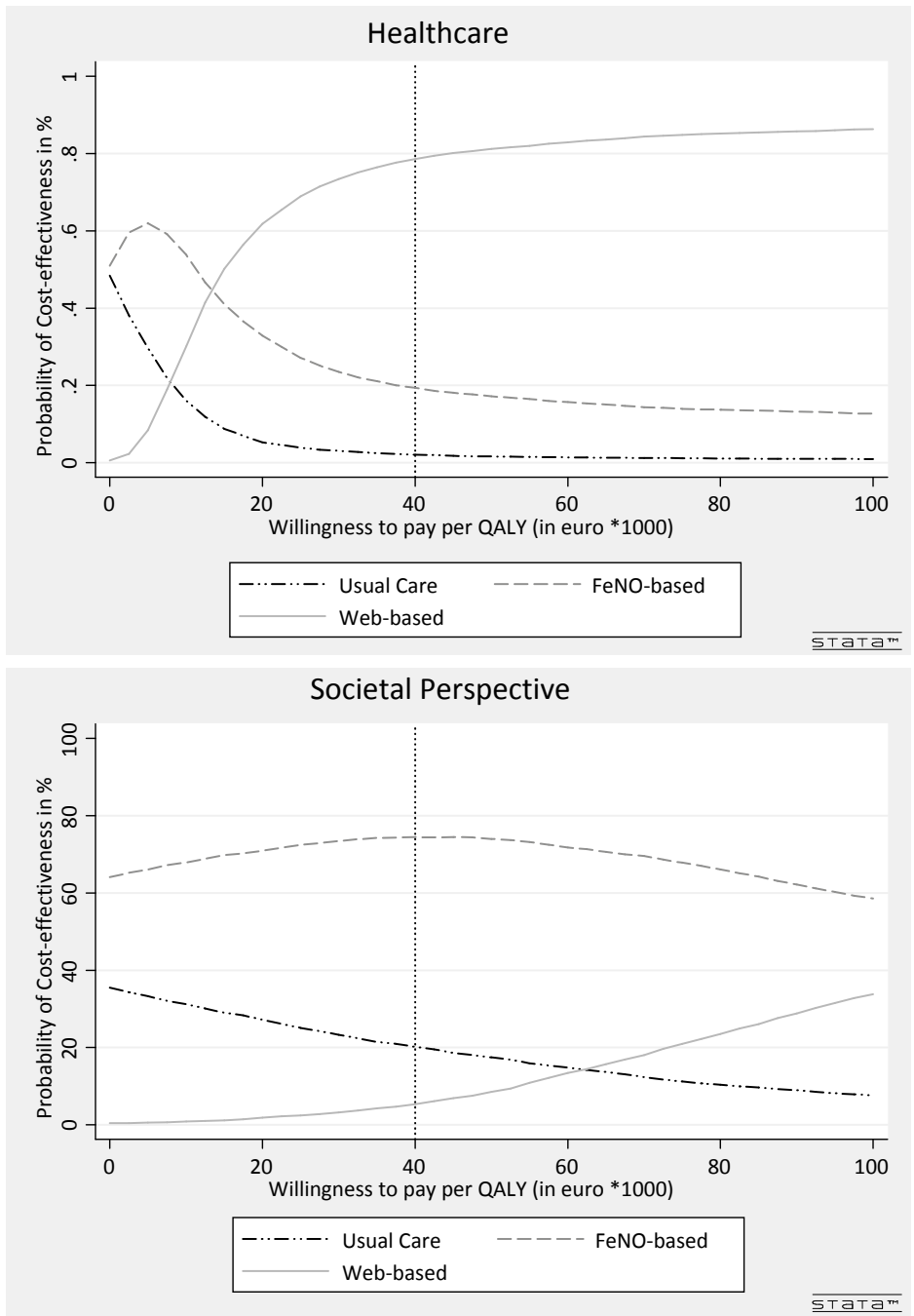

Figure 2 Cost-effectiveness acceptability curve.

This figure shows the probability that a strategy is the most cost-effective compared to the other two strategies at different willingness-to-pay per QALY. The perspective is either the healthcare perspective, which includes only healthcare costs (upper panel) or the societal perspective, which includes all healthcare costs and costs due to loss of productivity (lower panel). 


\section{Discussion}

In this study we assessed the cost-effectiveness of a web-based monitoring strategy and a FeNO driven strategy compared to standard care in children with asthma in secondary and tertiary care. Both monitoring strategies were in addition to standard care. Although we found no significant differences in costs and QALY's between the strategies, the web-based strategy was most likely to be cost-effective over a wide range of acceptable willingnessto-pay values for a gain in quality adjusted life and was the preferred strategy from the health care perspective. From a societal perspective the FeNO-based strategy was the preferred strategy with an overall higher probability of cost-effectiveness as compared to the web-based strategy and standard care.

To our knowledge this is the first study regarding the cost-effectiveness of a web-based and a FeNO-based monitoring strategy in children with asthma. This study was performed alongside a clinical study which showed that both the web-based monitoring strategy and a FeNO-driven strategy did not improve the number of symptom free days more than the standard care strategy ${ }^{13}$. However, monthly web-based symptom monitoring did result in a clinically relevant decrease of inhaled corticosteroids, while maintaining asthma control. Remarkably, the FeNO-based strategy improved asthma control as assessed with the ACT and as compared to standard care, without increasing medications. Our results fit in with this study, since it is likely that improved asthma control in the FeNO-based strategy positively impacts productivity costs and therefore the cost-effectiveness from a societal perspective ${ }^{4}$. We observed relatively high patient utilities of around 0.93 in this population. Hence it would be interesting to compare the different strategies in a population with worse disease, and more room for improvement.

The results of this study might be influenced by differences at baseline, missing data, or selection bias. We think that this was unlikely for the following reasons. First, with respect to patient utilities there were no statistical or clinical important differences between the strategies at baseline. However, asthma control was somewhat better, although not significantly different, in the web-based strategy at baseline and therefore left less room for improvement. Therefore, it is unlikely that the statistically non-significant improvement in utilities in the web-based strategy can be explained by baseline differences. Second, there was a low frequency of missing values, which was not associated with a particular strategy and sensitivity analyses using different imputation methods all showed similar results. Third, a potential limitation of this study might be selection bias at enrolment. About $50 \%$ of eligible children refused participation. However, non-participating children did not differ from participants regarding age, lung function and ICS dose ${ }^{13}$. We feel that this study population seems representative for Dutch second and third line pulmonary pediatric clinics. 
One of the strengths of this study was the comprehensive coverage of costs by questionnaires and medication prescriptions from local pharmacy records. Besides the more clearly defined health care costs, we assessed productivity costs by a number of relevant variables. There is increasing evidence that children with uncontrolled asthma experience asthma-related night-time awakenings, and it is not unlikely that their caregivers too are awakened more often at night ${ }^{4}$. This could be a driving factor in impaired work performance the next day ${ }^{4}$. However, the valuation of productivity losses of children and their parents is still a methodological challenge. No consensus exists about the calculation of costs of unpaid labor, parent's absence of work due to their children's health status, and the long-term economic impact of absence of school. Therefore the outcome from the societal perspective might be more sensitive to subjective choices of valuation than outcomes from the health care perspective.

How can we interpret the current findings? Although the cost-effectiveness analysis showed no significant gain in quality of life or reduction in costs, the finding of about $85 \%$ probability for the web-based strategy of being most cost-effective at a generally accepted willingness-to-pay of $€ 40,000$ and at $€ 80,000$, respectively, is arguably an interesting trend. Even at a willingness to pay of $€ 20,000$, the web-based strategy had clearly the highest chance of being cost-effective. One could argue that the cost-effectiveness of web-based care might be further improved if some of the 4-monthly clinic visits are substituted by an e-consult. In addition, the FeNO-based strategy was overall the preferred strategy from the societal perspective irrespective of the uncertainty in the valuation of productivity costs. We conclude that both web-based and FeNO-based monitoring on top of standard care have additional value and are likely to be more cost-effective than standard care alone. This is in line with the earlier findings of additive value in clinical outcomes ${ }^{13}$. The present analysis supports the case for a web-based and/or FeNO monitoring strategy in addition to standard care in children with asthma from a health economic perspective. 


\section{References}

1. Global Initiative of A. Report: Global strategy for asthma management and prevention, updated May 2014, accessed July 2014, http://www.ginasthma.org. 2014.

2. National Heart L, Blood I. Guideline: Managing asthma long term, updated august 2007, accessed July 2014, http://www.nhlbi.nih.gov/guidelines. 2014.

3. Bahadori K, Doyle-Waters MM, Marra C, et al. Economic burden of asthma: a systematic review. BMCPulmMed 2009; 9: 24-9.

4. Dean BB, Calimlim BC, Sacco P, Aguilar D, Maykut R, Tinkelman D. Uncontrolled asthma: assessing quality of life and productivity of children and their caregivers using a cross-sectional Internet-based survey. Health QualLife Outcomes 2010; 8: 96-8.

5. Gustafsson PM, Watson L, Davis KJ, Rabe KF. Poor asthma control in children: evidence from epidemiological surveys and implications for clinical practice. IntJClinPract 2006; 60: 321-34.

6. Rabe KF, Adachi M, Lai CK, et al. Worldwide severity and control of asthma in children and adults: the global asthma insights and reality surveys. JAllergy Clinlmmunol 2004; 114: 40-7.

7. Rikkers-Mutsaerts ER, Winters AE, Bakker MJ, et al. Internet-based self-management compared with usual care in adolescents with asthma: a randomized controlled trial. PediatrPulmonol 2012; 47: 1170-9.

8. Liu AH, Zeiger R, Sorkness $\mathrm{C}$, et al. Development and cross-sectional validation of the Childhood Asthma Control Test. JAllergy ClinImmunol 2007; 119: 817-25.

9. Nathan RA, Sorkness CA, Kosinski M, et al. Development of the asthma control test: a survey for assessing asthma control. JAllergy Clinlmmunol 2004; 113: 59-65.

10. Schatz M, Mosen DM, Kosinski M, et al. Validity of the Asthma Control Test completed at home. AmJManagCare 2007; 13: 661-7.

11. Schatz M, Sorkness CA, Li JT, et al. Asthma Control Test: reliability, validity, and responsiveness in patients not previously followed by asthma specialists. JAllergy ClinImmunol 2006; 117: 549-56.

12. Green $\mathrm{RH}$, Brightling $\mathrm{CE}$, McKenna $\mathrm{S}$, et al. Asthma exacerbations and sputum eosinophil counts: a randomised controlled trial. Lancet 2002; 360: 1715-21.

13. Voorend-van B, S, Vaessen $\mathrm{V}$, et al. Novel monitoring strategies in children with asthma: a randomised controlled trial, 2014.

14. EuroQol G. EuroQol--a new facility for the measurement of health-related quality of life. Health Policy 1990; 16: 199-208.

15. Lamers LM, McDonnell J, Stalmeier PF, Krabbe PF, Busschbach JJ. The Dutch tariff: results and arguments for an effective design for national EQ-5D valuation studies. Health Econ 2006; 15: 1121-32.

16. Institute for Health Insurance The N. Manual of cost research, updated 2010. 2014.

17. Centraal Bureau voor S. Werkgelegenheid; banen, lonen, arbeidsduur, SBI2008; kerncijfers. 2014.

18. Rubin DB. Multiple imputation for non response in surveys. New York: Wiley; 1987.

19. Stinnett AA, Mullahy J. Net health benefits: a new framework for the analysis of uncertainty in costeffectiveness analysis. MedDecisMaking 1998; 18: S68-S80.

20. Council for Public H, Health C. Sensible and sustainable care [In Dutch]. The Hague: Council for Public Health and Health Care.

21. Paris VBA. Value in Pharmaceutical Pricing. OECD Health Working Papers No. 63. OECD Publishing. 2013. 



\section{Chapter}

\section{FeNO monitoring in concordant and discordant asthma phenotypes in children}

Sandra Voorend-van Bergen MD ${ }^{1}$, Anja A. Vaessen-Verberne MD PhD², Anneke M. Landstra MD PhD ${ }^{3}$, Hein J. Brackel ${ }^{4}$, Norbert J. van den Berg MD', Johan C. de Jongste MD PhD ${ }^{1}$, Peter J Merkus MD PhD ${ }^{6}$, Mariëlle W Pijnenburg MD PhD ${ }^{1}$

${ }^{1}$ Dept of Pediatric Pulmonology, Erasmus University Medical Center Sophia Children's Hospital, Rotterdam, the Netherlands

${ }^{2}$ Dept of Pediatrics, Amphia Hospital, Breda, the Netherlands

${ }^{3}$ Dept of Pediatrics, Rijnstate Hospital, Arnhem, the Netherlands

${ }^{4}$ Dept of Pediatrics, Catharina Hospital, Eindhoven, the Netherlands

${ }^{5}$ Dept of Pediatrics, Flevo Hospital - De Kinderkliniek, Almere, the Netherlands

${ }^{6}$ Dept of Pediatric Pulmonology, Radboud University Nijmegen Medical Center, Nijmegen, the Netherlands

Based on 'FeNO monitoring in concordant and discordant asthma phenotypes in children

(letter to the editor)'

Submitted 


\section{Abstract}

\section{Background}

Regular monitoring of Fractional exhaled Nitric Oxide (FeNO), a biomarker of eosinophilic airway inflammation, could improve asthma outcomes. Patients with discordance of FeNO and symptoms may benefit most from FeNO-guided treatment.

\section{Objectives}

To assess the stability of concordant and discordant asthma phenotypes in children and to assess if children with a discordant phenotype would benefit more from FeNOguided treatment.

\section{Methods}

In this randomized controlled multi-center trial with a 1-year follow up, asthmatic children 4-18 years were randomized to treatment with FeNO monitoring or standard care. At baseline and after 4 weeks, children were classified as having a concordant or discordant asthma phenotype, based on FeNO and Asthma Control Test (ACT) scores. After 1-year follow up, the phenotypes were re-assessed and treatment effects compared. Primary endpoint was the proportion of symptom-free days (SFD).

\section{Results}

175 children were included; $65 \%$ had a concordant and $35 \%$ a discordant phenotype, which was unstable in $32 \%$ of children. In both stable discordant and concordant phenotypes, the change in SFD, ACT, dose of inhaled corticosteroids, and number of exacerbations did not differ between the FeNO group and the standard care group. Similarly, the change in SFD did not differ between the FeNO group and the standard care group in children with an unstable phenotype.

\section{Conclusions}

Discordant phenotypes were common and often unstable in asthmatic children. FeNOguided treatment was not more effective in children with discordant phenotypes. 


\section{Introduction}

Guidelines place a strong emphasis on monitoring of asthma control ${ }^{1}$. However, the most effective way to monitor childhood asthma has not been established yet. Several randomized controlled trials addressed the question if adjustment of therapy on repeated measurements of Fractional exhaled Nitric Oxide (FeNO) as a biomarker of eosinophilic airway inflammation could improve asthma outcomes ${ }^{2}$. A meta-analysis concluded that the benefits of FeNO monitoring were not yet clear ${ }^{3}$, however, two recent studies in children showed better asthma control and less exacerbations in children in whom treatment had been adjusted to $\mathrm{FeNO}^{4,5}$. The concept of concordant and discordant phenotypes has been put forward by Haldar et al, who defined concordant (concordant symptoms and inflammation) and a discordant phenotypes (high inflammation, low symptoms or high symptoms, low inflammation). The authors showed that management based on eosinophils in induced sputum reduced exacerbations, or the dose of inhaled corticosteroids (ICS) particularly in discordant phenotypes ${ }^{6}$. The aim of our study was first, to assess the presence and stability of concordant and discordant phenotypes in children, and if children with a discordant phenotype would benefit more from adjusting treatment to FeNO.

\section{Methods}

We performed a preplanned subgroup analysis of the 'Better Asthma Treatment: Monitoring with ACT and Nitric oxide' ('BATMAN') study, a prospective RCT on monitoring strategies in asthmatic children. Participants were between 4 and 18 years of age, had a doctor's diagnosis of atopic asthma and used ICS for at least 3 months. At baseline, an asthma control test $(\mathrm{ACT})^{7,8}$ or Childhood ACT (if $<12$ years) ${ }^{9}$ was completed and FeNO was measured. Subsequently, a diary was filled in during a 4 weeks run-in phase, while treatment was not changed. After run-in ACT and FeNO measurements were repeated and children were randomly allocated to a FeNO group, where treatment was adapted every 4 months to FeNO and ACT score, or a standard care group with ACT measurement every 4 months. After one year the 4-week diary, ACT and FeNO measurements were repeated. Primary endpoint was the proportion of symptom-free days (SFD), defined as days without daytime or night-time symptoms, obtained from diaries. Secondary endpoints included ACT score and dose of ICS.

Based on the ACT and FeNO, patients were classified as having a concordant or discordant phenotype. Concordant was defined as controlled asthma (ACT $\geq 20$ ) and normal FeNO $(<25 \mathrm{ppb})$ or uncontrolled asthma $(\mathrm{ACT}<20)$ and elevated FeNO $(\geq 25 \mathrm{ppb})$. Discordant 
was defined as uncontrolled asthma $(\mathrm{ACT}<20)$ with normal FeNO $(<25 \mathrm{ppb})$ or controlled asthma (ACT $\geq 20$ ) with high FeNO ( $\geq 25 \mathrm{ppb}$ ). Significance of differences was compared by analysis of covariance. Data were analyzed with SPSS 21.0. The limit of significance was set on $\mathrm{p}=0.5$ (two-sided).

\section{Results}

Ninety-two children were allocated to the FeNO group and 89 to the standard care group. Six patients dropped out. At the start, 113 children (65\%) had a concordant- and 62 (35\%) a discordant phenotype. After 4 weeks the phenotype had remained stable in 119 children (68\%). Nineteen percent $(n=34)$ switched from concordant to discordant and $13 \%(n=22)$ from discordant to concordant (Figure 1).

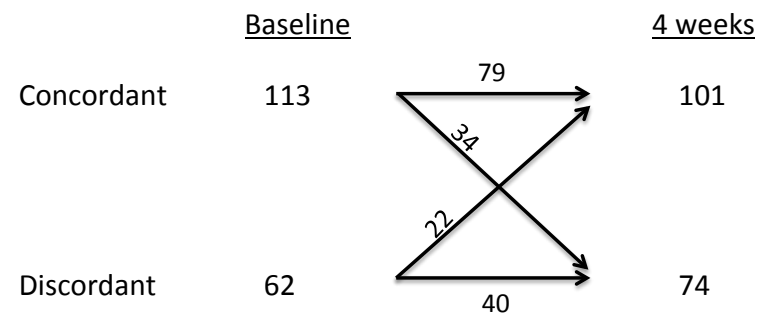

Figure 1 Number of children with a concordant or discordant phenotype at baseline and after 4 weeks.

Forty out of the 119 children (34\%) had a stable discordant phenotype (19 in FeNO and 21 in standard care group). In these discordant children, the change in SFD did not differ between the FeNO and the standard care group after 1 year $(p=0.9)$. The same was true for the ACT score $(p=0.3)$, the dose of ICS $(p=0.3)$ and the number of exacerbations ( 5 in the FeNO group and 4 in the standard care group).

Seventy-nine children (66\%) had a stable concordant phenotype (42 in the FeNO group and 37 in the standard care group). Also in these children, the change in SFD, ACT score and dose of ICS did not differ between the groups after 1 year $(p=0.7,0.1$ and 0.2 , respectively).

Similarly, the change in SFD did not differ between the FeNO group and the standard care group in both unstable phenotypes (concordant to discordant $(n=34): p=0.5$; discordant to concordant $(n=22): p=0.4)$.

Children with stable phenotypes showed no change in SFD during the study, whereas children with unstable phenotypes showed a significant and substantial improvement in SFD, with or without FeNO monitoring (Table 1). 
Within the FeNO group 55 children (60\%) had a concordant and 37 (40\%) a discordant phenotype before randomization. Changes from baseline in SFD did not differ significantly between discordant and concordant children.

Table 1 Baseline values and changes from baseline

\begin{tabular}{|c|c|c|c|c|c|c|}
\hline \multirow{2}{*}{$\begin{array}{l}\text { Baseline } \\
\text { (t=4 wks) }\end{array}$} & \multicolumn{3}{|c|}{ FeNO } & \multicolumn{3}{|c|}{ Standard Care } \\
\hline & $\begin{array}{l}\text { Stable } \\
\text { Discordant } \\
(n=19)\end{array}$ & $\begin{array}{l}\text { Stable } \\
\text { Concordant } \\
(n=42)\end{array}$ & $\begin{array}{l}\text { Unstable } \\
\text { phenotype } \\
(n=26)\end{array}$ & $\begin{array}{l}\text { Stable } \\
\text { Discordant } \\
(n=21)\end{array}$ & $\begin{array}{l}\text { Stable } \\
\text { Concordant } \\
(n=37)\end{array}$ & $\begin{array}{l}\text { Unstable } \\
\text { phenotype } \\
(n=30)\end{array}$ \\
\hline Age, yrs & $9.7(3.7)$ & $10.5(2.8)$ & $10.6(3.1)$ & $11.1(3.7)$ & $9.9(2.7)$ & $9.9(3.2)$ \\
\hline Gender, male & $13(68)$ & $29(69)$ & $16(62)$ & $16(76)$ & $26(70)$ & $18(60)$ \\
\hline ICS, ug & $\begin{array}{l}400 \\
(400-800)\end{array}$ & $\begin{array}{l}400 \\
(400-800)\end{array}$ & $\begin{array}{l}400 \\
(400-800)\end{array}$ & $\begin{array}{l}400 \\
(400-800)\end{array}$ & $\begin{array}{l}400 \\
(400-800)\end{array}$ & $\begin{array}{l}400 \\
(400-500)\end{array}$ \\
\hline FeNO, $\mathrm{ppb}^{\#}$ & $\begin{array}{l}26.2 \\
(16.0-45.1)\end{array}$ & $\begin{array}{l}14.8 \\
(10.2-22.3)\end{array}$ & $\begin{array}{l}14.7 \\
(9.8-28.2)\end{array}$ & $\begin{array}{l}35.2 \\
(19.6-55.5)\end{array}$ & $\begin{array}{l}15.7 \\
(10.0-23.7)\end{array}$ & $\begin{array}{l}21.7 \\
(8.5-33.2)\end{array}$ \\
\hline FEV1,\% pred & $97.3(10.4)$ & $98.3(11.3)$ & $89.6(13.8)$ & $93.8(15.9)$ & $91.9(14.6)$ & 95.7 (11.9) \\
\hline ACT or C-ACT score & $20.1(5.4)$ & $22.0(4.1)$ & $19.5(3.0)$ & $21.1(3.4)$ & $21.6(3.4)$ & $20.4(3.1)$ \\
\hline SFD, \% & $53(33)$ & $62(32)$ & $39(35)$ & $57(34)$ & $62(33)$ & $42(35)$ \\
\hline \multicolumn{7}{|c|}{ Changes from baseline } \\
\hline SFD, \% & 6 & 2 & $20 *$ & 8 & -1 & $18^{*}$ \\
\hline ACT or C-ACT score & $1.9 *$ & 1.0 & $2.6^{*}$ & 0.2 & -0.2 & 1.2 \\
\hline ICS, ug & 0 & -200 & 0 & 0 & -200 & 0 \\
\hline
\end{tabular}

Data shown are mean (SD) or median (interquartile range). *) Significant at $p<0.05$. \#) Geometric mean.

\section{Discussion}

Earlier we demonstrated that FeNO monitoring improved asthma control as measured with the ACT but did not improve the primary endpoint of SFD ${ }^{5}$. We hypothesized that the effect of FeNO monitoring would be stronger in patients with a discordant phenotype, but our present findings indicate that this was not the case.

Our results seem to disagree with findings by Haldar et al. who found that management aimed at reduction of sputum eosinophils reduced exacerbations in the inflammationpredominant discordant cluster, and a dose reduction of ICS in the symptom-predominant discordant cluster ${ }^{6}$. Although patient numbers were similar, different populations (refractory asthma vs mild-moderate asthma), different ages (adults vs children), the use of sputum eosinophils versus FeNO and different endpoints (exacerbations vs SFD) may all account for these discrepancies. Also, it could be argued that our cut-off value of FeNO to define the phenotype may have been too low. However, when we repeated our analysis using a higher cut-off of $50 \mathrm{ppb}$ the results were similar (data not shown). Similary, our 
cut-off for the ACT to define controlled asthma may have been too low ${ }^{10}$, but also here results were similar with cut-offs $A C T \geq 23$ and C-ACT $\geq 22$ (data not shown). Thirty-five percent of the children in our study had a stable discordant phenotype, which is in line with an earlier study showing discrepancies between symptoms and inflammation in $32 \%$ of subjects ${ }^{11}$.

We showed for the first time that discordant phenotypes are common, but often unstable in children. How could this be explained? It has been shown that airway inflammation in a highly selected population of children with severe asthma is variable and does not necessarily correlate with symptom changes $^{12}$. It is unknown if this may also be the case in subpopulations of children with less severe disease. Indeed several studies have indicated that correlations between inflammation and symptoms are weak or absent in asthmatics $^{13-16}$, suggesting that these reflect different aspects of asthma. We speculate that common exposures, specifically viral airway infections, may transiently alter the relation between inflammation and symptoms in asthmatic children.

A striking observation in our study was the better SFD treatment response in children with unstable phenotypes, irrespective of group allocation. The reason for this is unclear; one possible explanation might be that the unstable phenotype reflected the presence of viral infections at the onset of the study, with subsequently more opportunity for improvement. Indeed, the findings at baseline tended to be slightly worse for FEV1 and ACT scores in children with an unstable phenotype.

We conclude that discordant phenotypes were common and often unstable in asthmatic children. FeNO-guided treatment was not more effective in children with discordant phenotypes. 


\section{References}

1. GINA. Global Strategy for Asthma Management and Prevention: Global Initiative for Asthma (GINA), 2011.

2. Pijnenburg MW, De Jongste JC. Exhaled nitric oxide in childhood asthma: a review. Clinical and experimental allergy : journal of the British Society for Allergy and Clinical Immunology 2008; 38(2): 246-59.

3. Petsky HL, Cates CJ, Li A, Kynaston JA, Turner C, Chang AB. Tailored interventions based on exhaled nitric oxide versus clinical symptoms for asthma in children and adults. Cochrane Database Syst Rev 2009; (4): CD006340.

4. Peirsman EJ, Carvelli TJ, Hage PY, et al. Exhaled nitric oxide in childhood allergic asthma management a randomised controlled trial. Pediatric pulmonology 2013.

5. Voorend-van Bergen S, Vaessen-Verberne A, Landstra A, et al. FeNO and web-based monitoring in paediatric asthma management; the BATMAN study. European Respiratory Society Annual Congress. Barcelona; 2013.

6. Haldar P, Pavord ID, Shaw DE, et al. Cluster analysis and clinical asthma phenotypes. Am J Respir Crit Care Med 2008; 178(3): 218-24.

7. Nathan RA, Sorkness CA, Kosinski M, et al. Development of the asthma control test: a survey for assessing asthma control. The Journal of allergy and clinical immunology 2004; 113(1): 59-65.

8. Schatz M, Sorkness CA, Li JT, et al. Asthma Control Test: reliability, validity, and responsiveness in patients not previously followed by asthma specialists. The Journal of allergy and clinical immunology 2006; 117(3): 549-56.

9. Liu AH, Zeiger R, Sorkness C, et al. Development and cross-sectional validation of the Childhood Asthma Control Test. The Journal of allergy and clinical immunology 2007; 119(4): 817-25.

10. Voorend-van Bergen S, Vaessen-Verberne AA, Landstra AM, et al. Monitoring childhood asthma: Web-based diaries and the asthma control test. The Journal of allergy and clinical immunology 2013.

11. Boulay ME, Boulet LP. Discordance between asthma control clinical, physiological and inflammatory parameters in mild asthma. Respir Med 2013; 107(4): 511-8.

12. Fleming L, Tsartsali L, Wilson N, Regamey N, Bush A. Sputum inflammatory phenotypes are not stable in children with asthma. Thorax 2012; 67(8): 675-81.

13. Khalili B, Boggs PB, Shi R, Bahna SL. Discrepancy between clinical asthma control assessment tools and fractional exhaled nitric oxide. Ann Allergy Asthma Immunol 2008; 101(2): 124-9.

14. Shirai T, Furuhashi K, Suda T, Chida K. Relationship of the asthma control test with pulmonary function and exhaled nitric oxide. Ann Allergy Asthma Immunol 2008; 101(6): 608-13.

15. Tibosch $M$, de Ridder J, Landstra A, et al. Four of a kind: asthma control, FEV1, FeNO, and psychosocial problems in adolescents. Pediatr Pulmonol 2012; 47(10): 933-40.

16. Waibel V, Ulmer H, Horak E. Assessing asthma control: symptom scores, GINA levels of asthma control, lung function, and exhaled nitric oxide. Pediatr Pulmonol 2012; 47(2): 113-8. 



\section{Chapter}

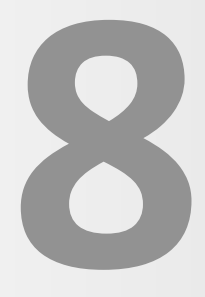

General Discussion 



\section{General Discussion}

Asthma is a common chronic disease in children in the developed world and affects approximately 150.000 children in the Netherlands. We showed that in up to $80 \%$ of children the goals of asthma management are not fully reached ${ }^{1}$, which means that despite current treatment guidelines numerous children still suffer from symptoms, sleep disturbances and/or reduced exercise tolerance. These data are in line with earlier data in different populations ${ }^{2,3}$ and suggest that there is considerable room for improvement. Guidelines for the treatment of children with asthma emphasize monitoring of asthma control $^{4,5}$, but the best way to monitor childhood asthma has not been established yet. Therefore we aimed to address if specific monitoring strategies may improve asthma control in children. First, we focused on the validity and usefulness of the Asthma Control Test (ACT) and the Childhood Asthma Control Test (C-ACT), including their use as a webbased monitoring tool. Second, we focused on the Fraction of exhaled Nitric Oxide (FeNO) as 'inflammometer' to monitor airway inflammation in childhood asthma in general, and in specific asthma phenotypes in particular. In the present chapter we will discuss the main findings of our studies and their scientific and clinical implications, and make suggestions for future research.

\section{The assessment of asthma control}

Asthma guidelines advise a stepwise approach for pharmacological asthma treatment, with a pivotal role for the level of asthma control ${ }^{4,5}$. For this purpose, reliable, simple and affordable methods to assess asthma control are essential to manage asthma effectively and to initiate or adapt pharmacotherapy. A simple, cheap and validated tool to assess asthma control is the Asthma Control Test (ACT, for children > 11 years) or the Childhood Asthma Control Test (C-ACT, for children 4-11 years) ${ }^{6-8}$. The use of questionnaires for the assessment of asthma control in daily practice contributes to the standardized evaluation of children with asthma and helps to track asthma symptoms. However, validation studies in a wide range of settings and randomized controlled trials addressing the added value of these questionnaires are lacking. In this thesis we determined the optimal ACT and C-ACT cut-off points for defining well-controlled asthma and calculated the minimal important difference in ACT and C-ACT based on quality-of-life scores. We found an optimal ACT cut-off of $\geq 23$ points, and a C-ACT cut-off of $\geq 22$ points for well-controlled asthma. This is considerably higher than the cut-offs used in many studies which defined good control by using the much lower cut-offs for uncontrolled asthma. In our study, for the first time the minimal important difference in ACT or C-ACT score in children was established, which makes the score clinically useful over time and allows for the use of C-ACT or ACT as reliable endpoints in clinical studies. Future research should focus on external validation 
and reproducibility of these cut-off points in different populations, and comparison of scores with the patient's perception and doctor's assessment of asthma control, and such studies may include lung function and assessment of airway inflammation.

\section{Asthma monitoring: the basics}

In many children with asthma inadequately controlled disease leads to reduced quality of life and increased healthcare costs. A major reason for poor asthma control is poor adherence to treatment ${ }^{5}$. Several studies have shown that adherence to ICS is far from optimal and a recent review of the studies using electronic adherence monitoring shows that half of them report mean adherence rates of $50 \%$ or below, and the majority report rates below $75 \%$, 9, 10 . However, reliable assessment of adherence is a challenge in clinical practice, as well as in research. Krishnan et al showed that adherence of $<80 \%$ of the prescribed doses was seen in $75 \%$ of the children by objective measures (number of doses left), while this lack of adherence was only reported in $6 \%$ of the children by self-reported diaries $^{9}$. Bush and Saglani showed that in patients with severe asthma, less than half the patients had picked up more than $80 \%$ of the required prescriptions, an nearly a third had picked up less than $50 \%{ }^{11}$. Also, even young children $(20 \%$ of 7 -year-olds and $50 \%$ of 11-year-olds) were left to take asthma treatments unsupervised ${ }^{11}$. Also, the parents' perception of the child's asthma is crucial for adherence to recommended therapy ${ }^{12}$, even as their concerns and beliefs about effects and side-effects ${ }^{13}$. Another factor of treatment failure is poor inhaler technique. In a review of 21 studies looking at misuse of metered dose inhalers, a mean of $50 \%$ of all children had poor inhaler technique ${ }^{14}$. Therefore, although sophisticated monitoring strategies may improve asthma outcomes, adherence to treatment and correct inhaler technique should first be secured.

\section{Web-based diaries and web-based monitoring}

Patient-reported diaries provide the opportunity to collect real-time information about respiratory symptoms, SABA use, and other information. Compared with interval questionnaires at study visits (which are based on retrospective assessments over the previous 1 to 4 weeks or more), diaries are less susceptible to problems related to incomplete recall and/or recall bias ${ }^{15}$. However, diary data are often incomplete, and results of studies indicate that diaries are often not completed in real time and are susceptible to data fabrication ${ }^{16-18}$. These risks may be reduced if electronic diaries are used to record asthma symptoms. Our web-based diary was highly feasible in assessing asthma control, the completion rate was high, and did not decrease over 4 weeks. Automatic e-mail reminders and the restricted data-entry were powerful tools that reduced recall bias. We feel that in clinical research web-based diaries are superior to paper-based diaries and their use should be recommended. For clinical use, it is mandatory to use validated diaries 
and minimal clinically important differences should be known. The disadvantages of webbased diaries include high costs, the need to develop user-friendly interfaces for data entry and download, possible equipment malfunction, and availability and adequacy of technical support.

The added value of using diaries in clinical practice has not been established. A recent study showed that keeping a symptom diary on a regular basis in asthmatic children did not have a beneficial effect on asthma control ${ }^{19}$. The completion of daily web-based diaries may be too time-consuming on the long term, and reminds the patient of his or her disease every day, which may reduce their quality of life. For the web-based assessment of asthma control, questionnaires like the ACT and C-ACT may be more appropriate as these can be completed easily and quickly and ask for symptoms over intervals that range from 1 (ACQ) to 4 (ACT) weeks ${ }^{20}$. However, such questionnaires may miss important information as open questions are lacking and there is no room for additional information. However, the same can be true for diaries. Also the patient and/or parents may misinterpret questions or the final result of the test. The assessment of asthma control by patients will partly depend on their perception of airway obstruction, as well as their personal interpretation of optimal control. Contrary to a face-to-face contact at the outpatient clinic, the context and history of the patient and a physical examination are missing, and additional questions or signaling of misunderstandings are not possible. Future research should focus on optimizing web-based diaries, and their way of administration.

In a recent Cochrane review the authors focused on the use of smartphones and tablet apps for the self-management of asthma ${ }^{21}$. Only two randomized controlled trials were included, the results were inconclusive and there were concerns in both studies in relation to attrition bias and other sources of bias. The authors concluded that the current evidence base is not sufficient to advise the use of apps for the delivery of asthma selfmanagement programs, which underlines the need for proper validation studies.

We showed that web-based monitoring with a monthly ACT or C-ACT in children with asthma led to a significant and clinically relevant reduction in ICS dose with similar asthma control and similar lung function. This strongly suggests that through systematic, regular monitoring, improved personalized asthma management is feasible with the benefit of a considerably lower dose of ICS as a result. By monthly assessing asthma control we were able to respond more quickly to changes in asthma control compared to the 3-6 monthly clinic visits in the usual care, thus avoiding overtreatment. Frequent contact between physician and patient offers the possibility to alter therapy frequently, which might result in a quick response to fluctuations in disease activity. Also, it is well known from clinical trials that frequent contacts with health care providers as such may improve asthma symptoms ${ }^{22}, 23$. Will it be possible to improve our results more with web-based monitoring and obtain even better asthma control and dose reduction of ICS? We propose that monitoring with different or advanced asthma control questionnaires, perhaps extended 
with lung function parameters, might further improve asthma control, and should be further explored. The optimal frequency of web-based monitoring is unknown, and we decided for monthly administration of the ACT and C-ACT as the recall window for these questionnaires is 4 weeks. As it seemed, 4 weekly contacts were sufficient to improve therapy, and not too frequent to decrease adherence to web monitoring. One might also argue that more frequent adjustment of treatment is not desirable from a patient's point of view and because ICS require several months to reach their optimal effect.

Specific patient groups may benefit more from web-based monitoring than others. For instance adolescents or patients who live far away from the outpatient clinic may be appropriate target groups for web-based interventions. Adolescents have a positive attitude towards web-based medicine, and appreciate the possibility of electronic monitoring and feedback ${ }^{24}$. In general, children from the age of 13 spend approximately 15 hours a week on the Internet. They use the Internet mainly for information, movies, email, chats, games, and social media ${ }^{25}$. With the increasing use of Internet on smartphones, tablets, notebooks etc., we expect that the Internet-based strategies will fit in with the needs of patients to independently assess their asthma control, to communicate more easily with their health care providers, and that this will improve adherence to treatment, although it is unclear if this effect still remains over time. Rikkers-Musaerts et al. showed a short-term improvement of asthma control and quality of life by a web-based intervention in a selected group of adolescents, but after one year the effect disappeared ${ }^{26}$. However, more research is needed to substantiate these expectations, and optimize care. Future research should focus on determining which monitoring strategy will be optimal in terms of costs and benefits, to come to a more personalized management. We speculate that web based monitoring may be particularly useful in children with difficult-to-treat asthma and/or uncontrolled asthma and in adolescents. In children with well-controlled asthma on step 2 or 3 treatment the added value of web monitoring may be limited, although in the future web consultations might partly replace clinic visits in this group, thus reducing the burden for child and parents and the costs of care.

\section{Telemonitoring in chronic diseases}

Telemonitoring seems also be a valuable tool in the management of other chronic diseases. Much research has been down in the field of chronic heart failure and hypertension. It has been shown that structured telephone support and telemonitoring can provide specialized heart failure care to a large number of patients with limited access to healthcare services. A Cochrane review demonstrates that chronic heart failure interventions utilizing information technology can reduce the rates of death and hospitalization and improve the quality of life ${ }^{27}$. Striking was the fact that the majority of elderly patients learned to use the technology easily and were satisfied with receiving healthcare in this way ${ }^{27}$. 
Also in the management of hypertension, telemonitoring has been shown very effective. Several reviews and meta-analyses showed that telehealthcare interventions led to a greater decrease in systolic and diastolic bloodpressure compared with usual care ${ }^{28}$ ${ }^{30}$. In addition, close management of diabetic patients through telemonitoring showed significant reduction in $\mathrm{HbA1c}$ and complications with a good acceptance by patients ${ }^{31}$. The telemonitoring effects on clinical effectiveness outcomes (e.g., decrease in the emergency visits, hospital admissions, average hospital length of stay) seems to be more consistent in pulmonary and cardiac studies than diabetes and hypertension ${ }^{32}$.

\section{FeNO monitoring}

As a second aim of this thesis FeNO monitoring was evaluated, and we found an improvement of ACT or C-ACT in the FENO managed group, without higher doses of ICS. Based on previous research ${ }^{33}$, we hypothesized that patients with discordant asthma phenotypes, in whom symptoms and inflammation did not point in the same direction, would benefit most from FeNO monitoring, but showed that this was not the case. This might however be explained by relatively low numbers in our subgroup analysis and by the fact that discordant and concordant phenotypes were unstable in children during time. As measuring FeNO improved asthma control and the measurement is cheap, noninvasive and easy to interpret, we recommend measuring FeNO on a regular basis in daily practice. A recent meta-analysis showed a $50 \%$ reduction in exacerbations when a FeNO monitoring strategy was used, which strongly supports this recommendation ${ }^{34}$. The most recent Cochrane review concluded that the benefits of FeNO monitoring were not yet clear, partly due to large variations in study design ${ }^{35}$. We suggest that it is now time to perform a new meta-analysis, using all original data of FENO monitoring studies, and whenever possible to stratify the analysis for phenotypes, as specific phenotypes or populations (age, atopic status, level of asthma control, etc) might benefit more from FeNO monitoring. The effect of FeNO monitoring depends highly on cut-off values: lower cut-off FeNO values for increasing ICS doses leads to less reduction of ICS and higher cutoff values to more reduction. In children with well-controlled asthma, lowering the dose of ICS without losing control is important, but in children whose asthma is not completely controlled a higher level of asthma control will be more important. Therefore, different cut-offs for FeNO (e.g. for well controlled asthma, partly controlled and uncontrolled asthma) are necessary to choose the best strategy in individual children. Also, it may be needed to define reference values that take patient characteristics as age, obesity, atopic status and level of asthma control into account. Further research should focus on defining specific populations that benefit most from FeNO measurements. Also, reference values should be further evaluated in different populations, and cut-offs adjusted accordingly. 


\section{Strengths and limitations}

Our BATMAN study had several strengths like the large sample size of 288 children, and including asthmatic children of all ages with different levels of severity. Because the BATMAN study was a multi-center study, children from different parts of the Netherlands were included, with different ethnicities, and cultural and social backgrounds, which increases the generalizability of our findings. Also the adherence to the study protocol was very high. Only four children dropped out and completion rates of the web-based diaries varied from 87 to $89 \%$. Even more important is the wide range of outcomes that we studied, including patient-centered outcomes, which are most relevant from the patient's perspective. In the BATMAN study we measured changes in SFDs, exacerbations, dose of ICS, number of reliever medication taken. These outcomes are directly related to the patient and the impact on daily life.

It could be argued that there is no gold standard for the assessment of asthma control. Levels of asthma control according to GINA guidelines are frequently used, but the proposed definition by GINA of controlled, partly controlled and uncontrolled asthma is not validated for children, was developed primarily for adults and used as an essentially arbitrary working scheme ${ }^{36}$. In the BATMAN study, we used the ACT and C-ACT to assess asthma control and used the scores as reference to assess validity of the web-based diary scores. Although data supporting the use of these tests in asthma management are limited, we considered these as suitable for our purpose. Several studies have evaluated the diagnostic performances of the ACT and C-ACT in assessing levels of asthma control based on GINA criteria, and in general they showed a high level of agreement ${ }^{37-41}$.

\section{Recommendations for future monitoring strategies}

What would be the best strategy for improving asthma control in children? We speculate that optimal assessment should include a weighted score of multiple asthma outcomes. Symptoms should be evaluated with monthly web-based scores, in selected cases complemented by a web-based diary 2 weeks prior the doctor's appointment. Pulmonary function and inflammation should be evaluated during the visit at the outpatient clinic and compared to the patient's personal best. Disease-specific quality of life questionnaires should be assessed, perhaps with larger intervals. Every item should be scored and weighted to estimate overall asthma control. Depending on the percentage change, treatment should be adapted individually, instead of using group-based cut-off values. Current guidelines and assessments of asthma control do not show the complete picture of a patient's asthma status. Future research should focus on the benefits of using compound measures of asthma outcome. 
In current research, health economics is often neglected, although cost-effectiveness is more and more important when resources are limited. From a societal perspective, costs of medication, health care visits, hospitalizations, and technical equipment have to be taken into account when implementing new strategies and cost-effectiveness analyses should be part of every randomized controlled trial. We showed that the assessment of asthma control by means of web-based monitoring, and the regular measurement of FeNO were indeed likely to be cost-effective from different points of view, and this sort of analysis may help to implement these monitoring strategies in clinical practice.

\section{Conclusions}

Monitoring of asthma is an essential part of asthma management as adequate asthma monitoring may lead to better asthma control and more effective use of medication. Webbased monitoring with a monthly ACT or C-ACT produced a significant and clinically relevant reduction in ICS dose while maintaining good asthma control, and therefore we propose web-based monitoring as a cost-effective tool for the near future. FeNO monitoring improved asthma control as assessed with the ACT or C-ACT, without increasing the dose of ICS, and was cost-effective from a societal perspective. Hence, we propose that FeNO monitoring should be reconsidered when updating asthma guidelines.

\section{Further Research}

Further research should focus on optimizing web-applications for the assessment of asthma control, in particular on which patients will benefit most from Internet strategies. It should be evaluated if more advanced questionnaires will better fit the needs of a web-based monitoring program. As web-based monitoring and FeNO monitoring each have a positive effect of asthma control separately, we hypothesize that a combination of web-based monitoring and repeated FeNO measurements at the outpatient clinic might be even more effective. In future research a combination of both strategies should be evaluated.

A critical issue is the definition of asthma control. There is at present no gold standard, and future studies should aim at defining optimal asthma control for specific populations, taking the various aspects of asthma in consideration, including personal perception. To assess asthma control in a standardized way, asthma control questionnaires are helpful, but more validation in a wider range of settings is needed, including confirmation of cutoff values and minimal important differences for specific populations and purposes.

Finally, as asthma is a heterogeneous disease, future studies should focus on asthma 
phenotypes and examine if stratification of monitoring strategies per phenotype may lead to a better, personalized approach of children with asthma. 


\section{References}

1. Voorend-van Bergen S, Vaessen-Verberne AA, Landstra AM, et al. Monitoring childhood asthma: web-based diaries and the asthma control test. J Allergy Clin Immunol 2014; 133(6): 1599-605 e2.

2. Gustafsson PM, Watson L, Davis KJ, Rabe KF. Poor asthma control in children: evidence from epidemiological surveys and implications for clinical practice. Int J Clin Pract 2006; 60(3): 321-34.

3. Rabe KF, Vermeire PA, Soriano JB, Maier WC. Clinical management of asthma in 1999: the Asthma Insights and Reality in Europe (AIRE) study. Eur Respir J 2000; 16(5): 802-7.

4. BTS. BTS/SIGN Guideline on the management of asthma: British Thoracic Society, 2012.

5. GINA. Global Strategy for Asthma Management and Prevention: Global Initiative for Asthma (GINA), 2011.

6. Liu AH, Zeiger R, Sorkness $C$, et al. Development and cross-sectional validation of the Childhood Asthma Control Test. J Allergy Clin Immunol 2007; 119(4): 817-25.

7. Nathan RA, Sorkness CA, Kosinski M, et al. Development of the asthma control test: a survey for assessing asthma control. J Allergy Clin Immunol 2004; 113(1): 59-65.

8. Schatz M, Sorkness CA, Li JT, et al. Asthma Control Test: reliability, validity, and responsiveness in patients not previously followed by asthma specialists. J Allergy Clin Immunol 2006; 117(3): 549-56.

9. Krishnan JA, Bender BG, Wamboldt FS, et al. Adherence to inhaled corticosteroids: an ancillary study of the Childhood Asthma Management Program clinical trial. J Allergy Clin Immunol 2012; 129(1): 112-8.

10. Morton RW, Everard ML, Elphick HE. Adherence in childhood asthma: the elephant in the room. Archives of disease in childhood 2014.

11. Bush A, Saglani S. Management of severe asthma in children. Lancet 2010; 376(9743): 814-25.

12. Klok T, Brand PL, Bomhof-Roordink H, Duiverman EJ, Kaptein AA. Parental illness perceptions and medication perceptions in childhood asthma, a focus group study. Acta paediatrica 2011; 100(2): 248-52.

13. Koster ES, Wijga AH, Koppelman GH, et al. Uncontrolled asthma at age 8: the importance of parental perception towards medication. Pediatric allergy and immunology : official publication of the European Society of Pediatric Allergy and Immunology 2011; 22(5): 462-8.

14. Giraud V, Roche N. Misuse of corticosteroid metered-dose inhaler is associated with decreased asthma stability. Eur Respir J 2002; 19(2): 246-51.

15. Reznik M, Sharif I, Ozuah PO. Classifying asthma severity: prospective symptom diary or retrospective symptom recall? The Journal of adolescent health : official publication of the Society for Adolescent Medicine 2005; 36(6): 537-8.

16. Cote J, Cartier A, Malo JL, Rouleau M, Boulet LP. Compliance with peak expiratory flow monitoring in home management of asthma. Chest 1998; 113(4): 968-72.

17. Kamps AW, Roorda RJ, Brand PL. Peak flow diaries in childhood asthma are unreliable. Thorax 2001; 56(3): 180-2.

18. Krishnan JA, Lemanske RF, Jr., Canino GJ, et al. Asthma outcomes: symptoms. J Allergy Clin Immunol 2012; 129(3 Suppl): S124-35.

19. Arga M, Sahbaz H, Bakirtas A, Turktas I, Demirsoy MS. Does self-monitoring by means of symptom diaries improve asthma control in children? The Journal of asthma : official journal of the Association for the Care of Asthma 2014; 51(3): 299-305.

20. Schatz M, Mosen DM, Kosinski M, et al. Validity of the Asthma Control Test completed at home. Am J Manag Care 2007; 13(12): 661-7.

21. McLean S, Chandler D, Nurmatov U, et al. Telehealthcare for asthma: a Cochrane review. CMAJ : Canadian Medical Association journal = journal de l'Association medicale canadienne 2011; 183(11): E733-42.

22. de Jongste JC, Carraro S, Hop WC, Group CS, Baraldi E. Daily telemonitoring of exhaled nitric oxide and symptoms in the treatment of childhood asthma. Am J Respir Crit Care Med 2009; 179(2): 93-7.

23. Szefler SJ, Mitchell $H$, Sorkness CA, et al. Management of asthma based on exhaled nitric oxide in addition to guideline-based treatment for inner-city adolescents and young adults: a randomised controlled trial. Lancet 2008; 372(9643): 1065-72.

24. van der Meer V, van Stel HF, Detmar SB, Otten W, Sterk PJ, Sont JK. Internet-based self-management offers an opportunity to achieve better asthma control in adolescents. Chest 2007; 132(1): 112-9. 
25. Addiction NloMHa. Adolescents and Internet, 2010.

26. Rikkers-Mutsaerts ER, Winters AE, Bakker MJ, et al. Internet-based self-management compared with usual care in adolescents with asthma: a randomized controlled trial. Pediatric pulmonology 2012; 47(12): 1170-9.

27. Inglis SC, Clark RA, McAlister FA, et al. Structured telephone support or telemonitoring programmes for patients with chronic heart failure. Cochrane Database Syst Rev 2010; (8): CD007228.

28. AbuDagga A, Resnick HE, Alwan M. Impact of blood pressure telemonitoring on hypertension outcomes: a literature review. Telemedicine journal and e-health : the official journal of the American Telemedicine Association 2010; 16(7): 830-8.

29. Omboni S, Guarda A. Impact of home blood pressure telemonitoring and blood pressure control: a metaanalysis of randomized controlled studies. American journal of hypertension 2011; 24(9): 989-98.

30. Verberk WJ, Kessels AG, Thien T. Telecare is a valuable tool for hypertension management, a systematic review and meta-analysis. Blood pressure monitoring 2011; 16(3): 149-55.

31. Jaana M, Pare G. Home telemonitoring of patients with diabetes: a systematic assessment of observed effects. Journal of evaluation in clinical practice 2007; 13(2): 242-53.

32. Pare G, Jaana M, Sicotte C. Systematic review of home telemonitoring for chronic diseases: the evidence base. Journal of the American Medical Informatics Association : JAMIA 2007; 14(3): 269-77.

33. Haldar P, Pavord ID, Shaw DE, et al. Cluster analysis and clinical asthma phenotypes. Am J Respir Crit Care Med 2008; 178(3): 218-24.

34. Peirsman EJ, Carvelli TJ, Hage PY, et al. Exhaled nitric oxide in childhood allergic asthma management a randomised controlled trial. Pediatric pulmonology 2013.

35. Petsky HL, Cates CJ, Li A, Kynaston JA, Turner C, Chang AB. Tailored interventions based on exhaled nitric oxide versus clinical symptoms for asthma in children and adults. Cochrane Database Syst Rev 2009; (4): CD006340.

36. Reddel HK, Taylor DR, Bateman ED, et al. An official American Thoracic Society/European Respiratory Society statement: asthma control and exacerbations: standardizing endpoints for clinical asthma trials and clinical practice. Am J Respir Crit Care Med 2009; 180(1): 59-99.

37. Koolen BB, Pijnenburg MW, Brackel HJ, et al. Comparing Global Initiative for Asthma (GINA) criteria with the Childhood Asthma Control Test (C-ACT) and Asthma Control Test (ACT). Eur Respir J 2011; 38(3): 561-6.

38. Korn S, Both J, Jung M, Hubner M, Taube C, Buhl R. Prospective evaluation of current asthma control using ACQ and ACT compared with GINA criteria. Annals of allergy, asthma \& immunology : official publication of the American College of Allergy, Asthma, \& Immunology 2011; 107(6): 474-9.

39. Nguyen VN, Chavannes N, Le LT, Price D. The Asthma Control Test (ACT) as an alternative tool to Global Initiative for Asthma (GINA) guideline criteria for assessing asthma control in Vietnamese outpatients. Primary care respiratory journal : journal of the General Practice Airways Group 2012; 21(1): 85-9.

40. Thomas M, Kay S, Pike J, et al. The Asthma Control Test (ACT) as a predictor of GINA guideline-defined asthma control: analysis of a multinational cross-sectional survey. Primary care respiratory journal : journal of the General Practice Airways Group 2009; 18(1): 41-9.

41. Yu HR, Niu CK, Kuo HC, et al. Comparison of the Global Initiative for Asthma guideline-based Asthma Control Measure and the Childhood Asthma Control Test in evaluating asthma control in children. Pediatrics and neonatology 2010; 51(5): 273-8. 


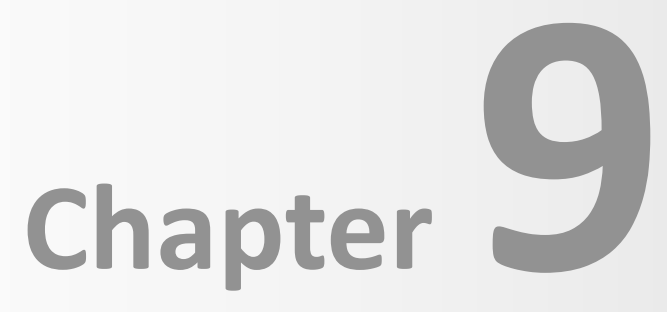

Summary

Nederlandse samenvatting 



\section{Summary}

Asthma affects approximately 150,000 children in the Netherlands. The goal of asthma treatment is to achieve and maintain clinical control and reduce future risks to the patient. However, despite the availability of effective treatment, in many asthmatic children asthma control is poor. Better monitoring of childhood asthma and adjusting treatment accordingly may lead to an improvement of asthma control. This thesis focuses on monitoring of childhood asthma, the definition of asthma control, the assessment of asthma control and achieving better asthma control. We describe two new monitoring strategies and compare them with standard care.

Chapter $\mathbf{1}$ is a general introduction to the different aspects of monitoring childhood asthma. In this chapter the aims of this thesis are described and an outline of this thesis given.

Chapter 2 provides an overview of commonly used asthma control questionnaires and explores their usefulness in asthma management in children. The use of asthma control questionnaires in daily practice and in research contributes to the standardized evaluation of children with asthma and helps to track asthma symptoms, but validation studies in a wider range of settings are needed. Also studies on their usefulness to improve asthma outcomes are lacking.

In Chapter $\mathbf{3}$ we compared the assessment of asthma control by children and parents using the Childhood Asthma Control Test (C-ACT). The C-ACT consists of 2 parts: the child fills in the first part of the C-ACT, and the parent completes the second part. Subscores of 283 children and their parents were compared. On average, children scored $8.3 \%$ lower than parents, irrespective of the child's age. This suggests that parents underestimate the asthmatic symptoms of their children.

Chapter 4 describes the validity of a web-based diary in assessing asthma control in children, the cut-off levels for 'well-controlled' asthma and the minimal important differences of the Asthma Control Test (ACT) and the Childhood Asthma Control Test (C-ACT). Web-based diaries were feasible with a completion rate of $89 \%$. Diary scores correlated strongly with C-ACT and ACT scores and changes in diary scores correlated well with changes in C-ACT and ACT scores, which made our web-based diary valid for recording asthma symptoms. The best cut-off points for well-controlled asthma were C-ACT $\geq 22$ and ACT $\geq 23$. We have shown that 2 C-ACT or ACT points difference is the minimal clinically important difference. 
Chapter 5 reports the results of the BATMAN study, a randomized controlled multicenter trial in asthmatic children with a 1-year follow up. In this study we compared two novel monitoring strategies with standard care: monthly web-based assessment of asthma control by means of the ACT, and 4-monthly measurements of FeNO, a noninvasive biomarker of airway inflammation in asthma. Two hundred eighty children were randomized to one of three study groups, and 268 children completed the study. We compared the mean changes from baseline of the proportion of symptom-free days between each of the intervention groups and the standard care group. We concluded that the changes from baseline did not differ between the monitoring strategies. However, the FeNO strategy showed a within-group improvement of asthma control assessed with the Asthma Control Test, while in children with web-based consultations ICS could be reduced substantially while control was maintained.

Chapter 6 describes an economic evaluation of the BATMAN study; the cost-effectiveness of web-based monitoring and FeNO monitoring in comparison with standard care. The web-based strategy had $80 \%$ chance of being most cost-effective from a health care perspective at a willingness to pay of a generally accepted $€ 40,000$ per Quality Adjusted Life Year (QALY). The FeNO-based strategy had $68 \%$ chance of being most cost-effective at $€ 40,000$ per QALY from a societal perspective. Economically, this means that the webbased monitoring strategy would be preferable from a health care perspective, and the FeNO-based strategy from a societal perspective, although this was not significant in QALY's and costs. As the clinical outcomes also favoured the web-based and FeNO-based strategies, we concluded that they may be useful additions to standard care.

Chapter 7 reports the results of a study in which we evaluated the effect of web-based monitoring and FeNO monitoring in different pediatric asthma phenotypes. Children were defined as having a concordant (concordant symptoms and inflammation) or a discordant (high inflammation, low symptoms or low inflammation, high symptoms) phenotype. Of the 175 asthmatic children, $65 \%$ had a concordant and $35 \%$ a discordant phenotype, which was unstable during 4 weeks in $32 \%$ of the children. Second, we evaluated if children with a discordant phenotype would benefit more from adjusting treatment to FeNO according to previous results. We found no differences between FeNO monitoring and standard care in terms of symptom-free days, Asthma Control Test scores, dose of inhaled corticosteroids, and number of exacerbations in both stable discordant and concordant phenotypes or in children with an unstable phenotype. Hence, FeNO-guided treatment was not more effective in children with discordant phenotypes.

Chapter $\mathbf{8}$ is the general discussion in which the main findings and implications described in this thesis are discussed. 


\section{Samenvatting}

Astma is de meest voorkomende chronische ziekte bij schoolkinderen: in Nederland hebben ongeveer 150.000 kinderen astma. Het doel van astmabehandeling is om de klachten zo goed mogelijk onder controle te krijgen en te houden en om complicaties zoals astma-aanvallen te voorkomen. Hoewel er effectieve astmamedicatie beschikbaar is, zijn desondanks bij de meerderheid van de kinderen de astmaklachten niet goed onder controle. Het beter monitoren van kinderen met astma en het bijstellen van de behandeling op grond van de verkregen gegevens is daarom belangrijk om astma beter onder controle te krijgen. Dit proefschrift richt zich op het vaststellen van de mate van astmacontrole met behulp van de Astma Controle Test, en op de doelmatigheid van twee nieuwe monitoringstrategieën bij de behandeling van kinderen met astma.

Hoofdstuk 1 is een algemene introductie over het monitoren van astma op de kinderleeftijd. Dit hoofdstuk geeft een overzicht over de opbouw van dit proefschrift en beschrijft de doelen.

Hoofdstuk 2 geeft een uiteenzetting van de beschikbare vragenlijsten voor het vaststellen van de mate van astmacontrole bij kinderen. De voor- en nadelen van het gebruik van deze vragenlijsten worden besproken, evenals hun toepasbaarheid in de praktijk en in klinisch onderzoek. De conclusie van dit hoofdstuk is dat het gebruik van vragenlijsten zinvol is voor het op een gestandaardiseerde manier vaststellen van de klachten en de mate van astma controle. Echter er zijn meer validatiestudies nodig in verschillende populaties. Ook gegevens over het verbeteren van astma uitkomsten door astma controle vragenlijsten ontbreken nog.

Hoofdstuk 3 vergelijkt hoe kinderen en ouders de astmacontrole bij het kind inschatten, gebruikmakend van de Astma Controle Test voor kinderen (C-ACT). De C-ACT bestaat uit 2 gedeelten: het eerste deel wordt ingevuld door het kind, het tweede door de ouder. Van 283 kinderen en hun ouders werden de subscores vergeleken. Gemiddeld scoorden de kinderen $8,5 \%$ lager dan hun ouders, onafhankelijk van de leeftijd van het kind. Dit suggereert dat ouders de astmaklachten van hun kinderen onderschatten.

Hoofdstuk 4 beschrijft de validatie van een internetdagboek om de mate van astmacontrole bij kinderen vast te stellen. Tevens geeft het afkapwaarden voor 'gecontroleerd' astma en het 'minimal important difference' voor de Astma Controle Test (ACT) en de Astma Controle Test voor kinderen (C-ACT). In totaal werden $89 \%$ van de internet dagboeken ingevuld, hetgeen betekent dat het internet dagboek goed bruikbaar was in de praktijk. 
De dagboekgegevens kwamen sterk overeen met de scores van de (C-)ACT. Ook de veranderingen in de (C-)ACT scores en de dagboekdata kwamen overeen. Dit maakt het internetdagboek valide voor het registreren van astmasymptomen. De afkapwaarden voor 'gecontroleerd' astma waren $\geq 22$ voor de C-ACT en $\geq 23$ voor de ACT. Een verschil van 2 C-ACT of ACT punten is klinisch van belang.

Hoofdstuk 5 geeft de resultaten van de BATMAN studie, een gerandomiseerde multicentrische studie van 1 jaar bij kinderen met astma. In deze studie werden twee nieuwe monitoringstrategieën vergeleken met de gebruikelijke zorg: maandelijkse internetconsulten door vaststelling van de astmacontrole middels een ACT vragenlijst op het internet, en 4-maandelijkse bepalingen van FeNO. In totaal werden 280 kinderen gerandomiseerd naar een van de drie studiegroepen. Hiervan volbrachten 268 kinderen de studie. De verandering in het aantal symptoomvrije dagen voor en na de interventie bleek niet verschillend tussen de interventiegroepen en de gebruikelijke zorg groep. Echter in de groep kinderen bij wie FeNO bepalingen de behandeling mede bepaalde, was wel de astmacontrole verbeterd, en de kinderen met de maandelijkse internetconsulten hadden een lagere dosering inhalatiecorticosteroïden nodig bij gelijkblijvende astma controle.

Hoofdstuk 6 beschrijft een economische evaluatie van de BATMAN studie: de kosteneffectiviteit van internetmonitoren en FeNO bepalingen bij de behandeling van astma, in vergelijking met de gebruikelijke zorg. Vanuit zorgperspectief had Internetmonitoren een kans van $80 \%$ om kosteneffectief te zijn bij een algemeen geaccepteerd bedrag van $€ 40,000$ per 'Quality Adjusted Life Year' (QALY). Vanuit een sociaal perspectief had de FeNO strategie 68\% kans om kosteneffectief te zijn bij een bedrag van $€ 40,000$ per QALY. Economisch gezien betekent dit dat, vanuit de zorg gezien, de internetstrategie de voorkeur heeft, en vanuit de maatschappij gezien de FeNO strategie, hoewel dit statistisch niet significant was in QALY's en kosten.

Hoofdstuk 7 beschrijft de resultaten van een onderzoek waarin we het effect van internetmonitoren en FeNO monitoren hebben vergeleken bij verschillende astma fenotypen. Kinderen werden gedefinieerd met een concordant (symptomen en ontsteking wijzen in dezelfde richting, dus veel symptomen en hoog FeNO of weinig symptomen en laag FeNO) of een discordant fenotype (hoog FeNO en weinig klachten of laag FeNO en veel klachten). Van de 175 astmatische kinderen had 65\% een concordant en $35 \%$ een discordant fenotype. Het fenotype was onstabiel bij $32 \%$ van de kinderen in een periode van 4 weken. Kinderen met een discordant fenotype bleken niet te verbeteren als FeNO mee genomen werd in de behandelbeslissingen. Er waren geen verschillen in het aantal symptoomvrije dagen, Astma Control Test scores, dosering inhalatiecorticosteroïden en 
het aantal exacerbaties tussen de groep met FeNO metingen en de gebruikelijke zorg zowel bij kinderen met een stabiel concordant en discordant fenotype als bij kinderen met een onstabiel fenotype. Een behandeling gestuurd door FeNO metingen was dus niet effectiever bij kinderen met een discordant fenotype.

Hoofdstuk 8 is een algemene discussie waarin de belangrijkste resultaten van dit proefschrift en hun toepasbaarheid worden bediscussieerd. 



\section{Chapter}

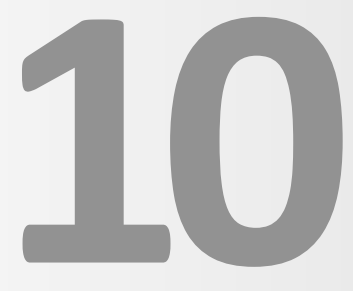

List of abbreviations

List of publications

PhD portfolio

About the author

Dankwoord 



\section{List of abbreviations}

\begin{tabular}{|c|c|}
\hline ACT & Asthma control test \\
\hline ACQ & Asthma control questionnaire \\
\hline AHR & Airway hyperresponsiveness \\
\hline ANCOVA & Analyses of covariance \\
\hline ATAQ & Asthma treatment assessment questionnaire \\
\hline AUC & Area under the curve \\
\hline BTS & British Thoracic Society \\
\hline C-ACT & Childhood asthma control test \\
\hline EQ5D & EuroQol classification system \\
\hline FeNO & Fraction of exhaled nitric oxide \\
\hline $\mathrm{FEV}_{1}$ & Forced expiratory volume in 1 second \\
\hline FVC & Force vital capacity \\
\hline GINA & Global initiative for asthma \\
\hline GLI & Global lungs initiative \\
\hline ICS & Inhaled corticosteroids \\
\hline ICC & Intraclass correlation coefficient \\
\hline IQR & Interquartile range \\
\hline LABA & Long-acting $\beta$-agonist \\
\hline LTRA & Leukotriene receptor antagonist \\
\hline MEF25 & Maximal expiratory flow at $25 \%$ of vital capacity \\
\hline MID & Minimal important difference \\
\hline PEF & Peak expiratory flow \\
\hline PD20 & Provocative dose causing a $20 \%$ fall in $\mathrm{FEV}_{1}$ \\
\hline PACQLQ & Pediatric asthma-related caregiver quality of life questionnaire \\
\hline PAQLQ & Pediatric asthma-related quality of life questionnaire \\
\hline QALY & Quality-adjusted life year \\
\hline $\mathrm{RCT}$ & Randomized controlled trial \\
\hline ROC curve & 'Receiver Operator Characteristic'-curve \\
\hline SABA & Short-acting beta agonist \\
\hline SFD & Symptom-free days \\
\hline TRACK & Test for respiratory and asthma control in kids \\
\hline
\end{tabular}





\section{List of publications}

S Voorend-van Bergen, AA Vaessen-Verberne, JC de Jongste, MW Pijnenburg Asthma control questionnaires in the management of asthma in children: a review.

Pediatr Pulmonol. 2014. Epub 2014/09/3, doi: 10.1002/ppul.23098

S Voorend-van Bergen, HJ Brackel, D Caudri, JC de Jongste, MW Pijnenburg. Assessment of asthma control by children and parents. Eur Respir J 2013; 41: 233-247

S Voorend-van Bergen, AA Vaessen-Verberne, AM Landstra, HJ Brackel, NJ van den Berg, D Caudri, JC de Jongste, PJ Merkus, MW Pijnenburg. Monitoring childhood asthma: webbased diaries and the asthma control test. J Allergy Clin Immunol 2014;133:1599-605

S Voorend-van Bergen, AA Vaessen-Verberne, HJ Brackel, AM Landstra, NJ van den Berg, WC Hop, JC de Jongste, PJ Merkus, MW Pijnenburg. Novel monitoring strategies in children with asthma: a randomised controlled trial. Thorax 2014; revision

T. Beerthuizen, S Voorend-van Bergen, WB van den Hout, AA Vaessen-Verberne, HJ Brackel, AM Landstra, NJ van den Berg, JC de Jongste, PJ Merkus, MW Pijnenburg, JK Sont. Cost-effectiveness of FeNO- and web-based monitoring in pediatric asthma management: a randomized controlled trial. Submitted

S Voorend-van Bergen, AA Vaessen-Verberne, HJ Brackel, AM Landstra, NJ van den Berg, JC de Jongste, PJ Merkus, MW Pijnenburg. FeNO monitoring in concordant and discordant asthma phenotypes in children. Submitted 



\section{PhD Portfolio}

Name PhD student:

Erasmus MC Department:

PhD Period:

Promotor:

Supervisor:
Sandra Voorend-van Bergen

Pediatric Pulmonology

September 2009-January 2014

Prof. Dr. J.C. de Jongste

Dr. M.W.H. Pijnenburg

\section{PhD Training}

\begin{tabular}{lcc} 
General courses & Year & $\begin{array}{c}\text { Workload } \\
\text { (ECTS) }\end{array}$ \\
\hline Biomedical English Writing and Communication & 2012 & 4.0 \\
Statistics & 2011 & 5.7 \\
Introduction to Clinical Research - Nihes & 2010 & 0.9 \\
BROK ('Basiscursus Regelgeving Klinisch Onderzoek') & 2010 & 0.9 \\
EndNote course & 2010 & 0.2 \\
English Course - advanced & 2010 & 2.1
\end{tabular}

\section{Specific courses}

ERS School course 'Monitoring of Airway Diseases', Veruno

\section{Seminars and workshops}

Netherlands Respiratory Society Young Investigator Symposium, 2009

Utrecht

Pediatric Research day, Rotterdam

Epidemiology of Childhood Asthma, Rotterdam

Asthma Symposium, Amersfoort

Methodology of human research, Rotterdam

PhD Career Event Erasmus MC, Rotterdam

Asthma Self Management Symposium, Leiden

2010

0.1

PhD Career Event EUR, Rotterdam

Dutch lung conference, Utrecht [Oral and Poster presentation]

DoHAD satellite Meeting, Rotterdam [Oral presentation] 


\section{International conferences}

American Thoracic Society (ATS) conference, San Francisco, USA $2012 \quad 1$ [Poster presentation]

European Respiratory Society (ERS) conference, Vienna, Austria $\quad 2012 \quad 1.2$ [2 Poster presentations]

European Respiratory Society (ERS) conference, Barcelona, 2013 Spain [Oral presentation, best abstract in pediatric allergy and asthma]

\section{Other}

Research Meetings 2009-2013 1

Outpatient clinic pediatric pulmonology

2009-2013 1

\section{Teaching}

Clinical course to physician assistants $2011 \quad 0.1$

Lecture 'Lung function' to medical students

0.3

Lecture 'Nutrition' to medical students

2012

0.2 


\section{About the author}

Sandra Voorend-van Bergen was born in Oostflakkee, the Netherlands on March $18^{\text {th }} 1984$. She graduated in $\mathbf{2 0 0 2}$ from secondary school at the "Regionale Scholengemeenschap Goeree-Overflakkee" in Middelharnis. In the same year she started her medical training at the Medical Faculty of the Erasmus University of Rotterdam.

During her study, she has worked in the medical student team at the Department of Pediatrics at the Sint Franciscus Gasthuis in Rotterdam. In 2008 she performed a research project 'Liquid Chromatography Mass Spectrometry of exhaled breath condensate in asthmatic children', supervised by dr. M.W.H. Pijnenburg at the department of Pediatric Pulmonology, Erasmus MC-Sophia Children's Hospital, which greatly increased her enthusiasm for clinical research.

Her final rotation of 3 months was spent at the pediatric department of the Sint Francisus Gasthuis in Rotterdam. She obtained her medical degree in 2008 and continued working at the Sint Fransicus Gasthuis as a pediatric intern. In September 2009, she started as a PhD student at the department of Pediatric Pulmonology of Erasmus MC- Sophia Children's Hospital working on the project 'Better asthma treatment: monitoring with ACT and nitric oxide', supervised by dr. M.W.H. Pijnenburg and Prof. dr. J.C. de Jongste. The results of this study are described in this thesis. In 2013 she received a grant for the best abstract in 'Pediatric Allergy and Asthma' during the European Respiratory Society congress in Barcelona, Spain.

In February 2014 she started to work as a medical doctor at the Child Health Care Rijnmond. She lives together with her husband Jasper and their sons Ruben (2013) and Thomas (2014). 



\section{Dankwoord}

Vier jaar werk nu samengebonden in een boekje: mijn proefschrift. En wat ben ik trots! Maar alleen was mij dit natuurlijk nooit gelukt en graag wil ik daarom een aantal mensen enorm bedanken.

Allereerst wil ik alle deelnemers van de BATMAN studie bedanken. Zonder jullie was dit onderzoek er niet geweest! Jullie zijn het onderzoek ontzettend trouw gebleven en daarvoor ben ik jullie heel dankbaar. Hierdoor zijn we nu een stap verder in de behandeling van astma bij kinderen.

Mijn supervisor, Dr. M.W.H. Pijnenburg. Beste Mariëlle, een paar jaar geleden ben ik als student voor mijn afstudeeronderzoek bij jou gekomen en nu sta ik hier. Door jou werd ik zowaar enthousiast over wetenschappelijk onderzoek en samen gingen we een promotietraject aan. I $\mathrm{k}$ had de eer je eerste promovendus te zijn en als volleerde supervisor heb jij deze klus geklaard. Een betere copromotor had ik mij niet kunnen wensen! Je vertrouwen en support heb ik enorm gewaardeerd; ik kon altijd op je bouwen. Ik bewonder je talent, je kennis en je passie voor het vak. Maar vooral bewonder ik je als mens; je bent een warm, hartelijk en begripvol persoon met een groot hart voor je patiënten en je promovendi. Ik heb in alle opzichten veel van jou geleerd. Dankzij jou kan ik terug kijken op een fantastisch promotietraject en ik ben je daar enorm dankbaar voor! Mijn promotor, Prof. Dr. J.C. de Jongste. Beste Johan, bedankt voor de begeleiden van dit traject. Je eeuwige enthousiasme, je supersnelle correcties en je oog voor detail heb ik altijd bijzonder gewaardeerd en mede door jou kan ik nu ontzettend trots zijn op dit boekje. Dank je wel!

Prof. Dr. Raat, Prof. Dr. Rutten en Prof. Dr. Koppelman. Bedankt voor uw bereidheid plaats te nemen in de kleine commissie en voor de beoordeling van mijn proefschrift. Prof. Dr. Rings, Prof. Dr. Bel, Dr. Turner, Dr. Vaessen-Verberne, hartelijk dank voor uw deelname aan de grote commissie en uw aanwezigheid bij de verdediging.

Alle leden van het BATMAN studieteam. Alle kinderartsen: Anja, Peter, Hein, Anneke, Norbert, Wim, bedankt voor het participeren in de BATMAN studie en het perfectioneren van de artikelen. We kunnen denk ik met recht spreken van een zeer succesvolle samenwerking! Alle overige co-auteurs: Wim, Daan, Thijs en Wilbert, bedankt voor jullie imput en samenwerking! Alle uitvoerenden van de BATMAN studie: Simone, Hannie, Bas, Christel, Linda, Gracé, Renata, Coosje en Saeeda. Jullie zijn toppers! Elk bezoek was een feest door jullie warme onthaal en ik ben er van overtuigt dat door jullie inzet en enthousiasme onze studie een succes is geworden. Ook Dorien ( $2 x)$, Cindy, Annejet, Mark, Martin, Jessie, Petra, Ghislaine en Else heel erg bedankt voor jullie inzet. 
Alle medewerkers van KinderHaven: Magda, Jantine, Nicolette A, Trix, Kirsten, Lonneke, Maria, Yvonne, Nicolette de J, Natascha, en de rest. Jullie hebben me vanaf dag 1 omarmt, waardoor ik me ontzettend thuis heb gevoeld op de KinderHaven. Bedankt daarvoor! Jullie enthousiasme en liefde voor de kinderen maken KinderHaven tot een fantastische plek en daar heb ik tijdens mijn onderzoek heel veel profijt van gehad. Ik zal jullie gezelligheid heel erg missen. Mag, ik zie je bij Guus!

Alle (ex-)collega's van de Z-flat: Marianne, Gerthe, Marjolein v W, Nienke, Sjoerd, Suzanne, Esther, Nynke, Charlotte, Yvonne, Laura, Daan, Alexandra, Yuen, Karlijn, Dwight, Maarten, Noortje, Lennart, Salome, en Jeroen. Een bijzondere dank aan mijn eerste kamergenootjes Gerthe en Marjolein en mijn laatste roomie Marianne. Wat hebben we veel lief, leed en gezelligheid gedeeld! Jullie zijn de echte reden van dit promotiesucces; ik heb een heerlijke tijd met jullie gehad!

Alle collega's van het pulmo-researchteam. Bedankt voor jullie input tijdens de wekelijkse researchmeeting; een bron van goede ideeën. Irma, bedankt voor je eeuwig helpende hand. In het bijzonder wil ik mijn lieve pulmo-collegaatjes Esther, Agnes en Marjolein bedanken voor de mentale support, maar vooral de gezelligheid tijdens onze congrestripjes naar Veruno, San Francisco, Wenen en Barcelona. Maar natuurlijk ook tijdens de bakkies de rest van het jaar!

Mijn paranimfen, Esther en Marjolein. Mijn lieve pulmo-promotiemaatjes. We hebben met elkaar gelachen, gehuild, stoom afgeblazen en successen gevierd. Altijd geïnteresseerd en altijd stonden jullie klaar met een luisterend oor. Wat fijn en vertrouwd dat jullie ook dit laatste stukje aan mijn zijde staan.

Beste luitjes, lieve vrienden. Het leven is als een muziekinstrument, waarvan je de snaren moet spannen en ontspannen om het aangenaam te maken. En jullie waren de bron van ontspanning; bedankt daarvoor!

Lieve opa's en oma's. Bedankt voor jullie interesse. Wat fijn dat jullie dit nog mee mogen maken.

Lieve Theo, Marianne en Robin, lieve schoonfamilie. Al ruim 15 jaar ben ik kind aan huis bij jullie en bij alle belangrijke momenten stonden jullie ook aan mijn zij; zo ook nu. Jullie zijn altijd geïnteresseerd en altijd bereid de helpende hand te bieden. Het is heel fijn te weten dat jullie altijd voor ons klaar staan. Bedankt daarvoor!

Lieve Johan en Linda, lieve broer en schoonzus. Een betere broer en schoonzus kan ik me niet wensen. Ik ben trots op jullie en super trotse tante van Sophie en Esmee. Bedankt voor jullie interesse, support en liefde. Lieve Jo, bedankt dat je mijn maatje bent, en altijd bent geweest. Ik ga wel onze lunch-loopjes rond het Haringvliet missen! 
Lieve pap en mam, zonder jullie had ik hier absoluut niet gestaan. Jullie hebben me altijd door dik en dun gesteund, gemotiveerd en geholpen. Jullie warme huis staat altijd open en jullie staan altijd voor ons klaar. Kenmerkend is jullie uitspraak: 'Ons geluk is jullie geluk', en dat vind ik heel bijzonder. Jullie zijn de liefste ouders die ik me maar kan wensen. Mijn dank is eigenlijk niet in woorden uit te drukken.

Lieve Jasper, lieve man. Jij bent mijn grote liefde, mijn steun en toeverlaat, maar vooral mijn maatje. Samen kunnen we alles aan. Het leven is zo mooi met jou aan mijn zijde. Bedankt voor alles, gewoon door er altijd voor mij en ons gezin te zijn. Ik hou ontzettend veel van je.

Lieve Ruben en Thomas, jullie zijn mijn kanjers en mijn grote trots! Mama houdt van jullie!

$$
\text { - Sandra }
$$


